Portland State University

PDXScholar

1990

\title{
Employment Decline in the Douglas-fir Region's Lumber and Plywood Industries: An Analysis of Structural and Cyclical Factors
}

Majid Rasoolzadeh

Portland State University

Follow this and additional works at: https://pdxscholar.library.pdx.edu/open_access_etds

Part of the Agribusiness Commons, and the Urban Studies and Planning Commons Let us know how access to this document benefits you.

Recommended Citation

Rasoolzadeh, Majid, "Employment Decline in the Douglas-fir Region's Lumber and Plywood Industries: An Analysis of Structural and Cyclical Factors" (1990). Dissertations and Theses. Paper 1294.

https://doi.org/10.15760/etd.1293

This Dissertation is brought to you for free and open access. It has been accepted for inclusion in Dissertations and Theses by an authorized administrator of PDXScholar. Please contact us if we can make this document more accessible: pdxscholar@pdx.edu. 


\title{
EMPLOYMENT DECLINE IN THE DOUGLAS-FIR REGION'S LUMBER AND PLYWOOD INDUSTRIES: AN ANALYSIS OF STRUCTURAL AND CYCLICAL FACTORS
}

\author{
by \\ MAJID RASOOLZADEH
}

\begin{abstract}
A dissertation submitted in partial fulfilment of the requirements for the degree of
\end{abstract}

\section{DOCTOR OF PHILOSOPHY \\ in \\ URBAN STUDIES}

Portland State University

(C) 1990 
TO THE OFFICE OF GRADUATE STUDIES:

The members of the Committee approve the dissertation of Majid Rasoolzadeh presented on July 12, 1988.

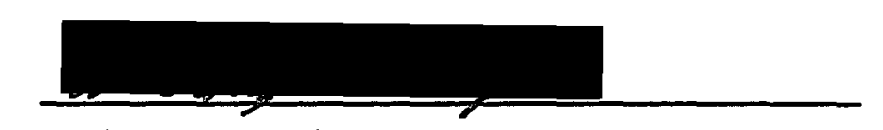

Anthony M. Rufolo, Chairman
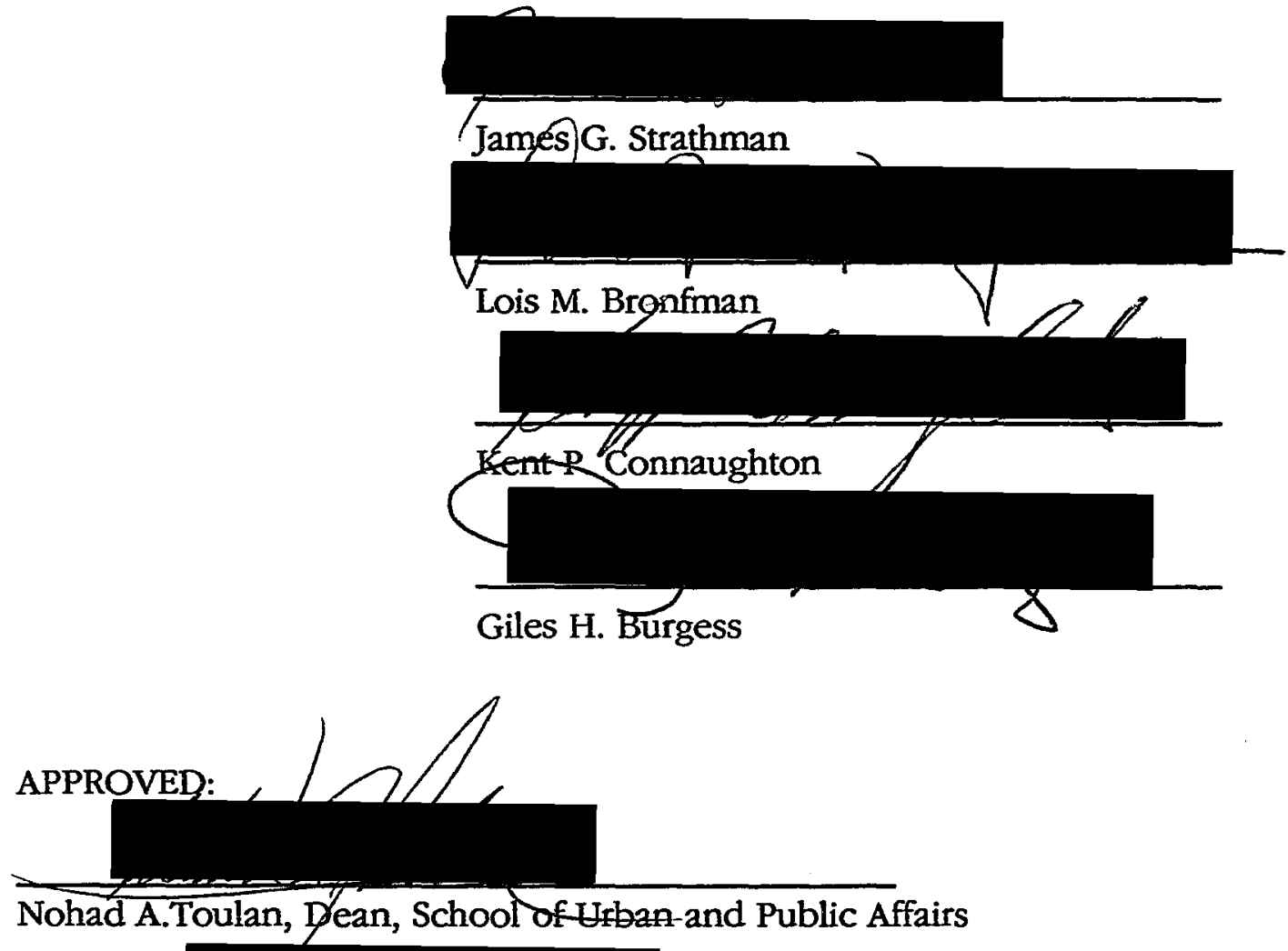

C. William Savery, Interim Vice Provost for Graduate Studies and Research 
AN ABSTRACT OF THE DISSERTATION OF MAJID RASOOLZADEH for the Doctor of Philosophy in Urban Studies presented July 12, 1988.

Title: Employment Decline in the Douglas-fir Region's Lumber and Plywood Industries: An Analysis of Structural and Cyclical Factors

APPROVED BY MEMBERS OF THE DISSERTATION COMMITTEE:

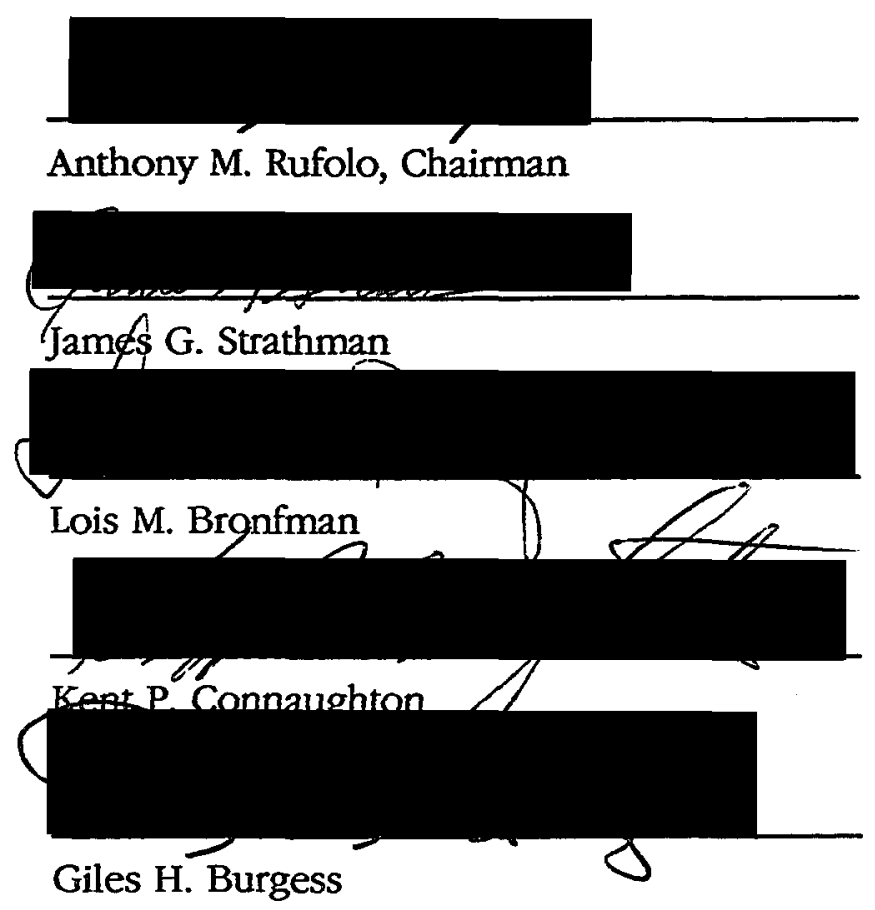

Over the years a significant decline in employment has occurred in the Douglas-fir region's lumber and wood products industry. High levels of unemployment can lead to undesirable economic and social effects. An understanding of the nature of unemployment can facilitate future planning as well as mitigating current problems. This study has attempted to examine the underlying causes of employment decline in the region's softwood lumber and 
plywood industries, specifically over the period 1979-86. This time span is of particular importance since there was a rapid decline in employment levels after 1979. There has been much controversy over the causes of this reduction but no comprehensive empirical analysis was ever undertaken to determine its cause. Meanwhile levels of output, which also declined in the early part of this span, have again reached pre-recession levels.

A cost function approach was employed as the basis of the empirical analysis. The results suggest that most of the employment decline in these industries has been caused by changes in the structure of production and by increasing labour productivity. Although there are indications of cyclical unemployment, much of the reduction in the industries' labour force seems to be attributable to greater substitution of capital and logs for labour. Simulation analyses tend to suggest that changes in factor prices would not have had any dramatic effect on employment levels. It was found that of the recent employment decline in the two industries, around one-quarter of the loss in the lumber industry and one-third in the plywood industry are caused by cyclical forces. Structural factors were assumed to be the cause of the remaining loss in levels of labour input. 
TO MY PARENTS

$=\ldots$ 


\section{ACKNOWLEDGMENTS}

First and foremost I would like to thank Dr. Anthony Rufolo for his excellent guidance and direction throughout this research. I would also like to express my appreciation to other members of my dissertation committee: Dr. James Strathman for his invaluable comments and guidance, not only through the research process but during my time in the programme; Dr Lois Bronfman for her constructive comments as well as editorial suggestions that immensley improved the presentation of this document; Dr. Kent Connaughton, for teaching me so much and for contributing immeasurably to the completion of this study; and Dr. Giles Burgess, for making constructive criticisms and most helpful comments.

I would like to extend my gratitude to the following: Dr. Kuan Lin, Department of Economics, Portland State University, to whom I am immensely indebted for all his suggestions and comments. Mr. Brian Wall, economist, U.S. Forest Service, Experiment Station, Portland, who spent many hours sharing with me so much of his invaluable knowledge; and Dr. David Merrifield, Western Washington University, Bellingham, for his generosity in providing most valuable advice and suggestions when all seemed lost. 


\section{TABLE OF CONTENTS}

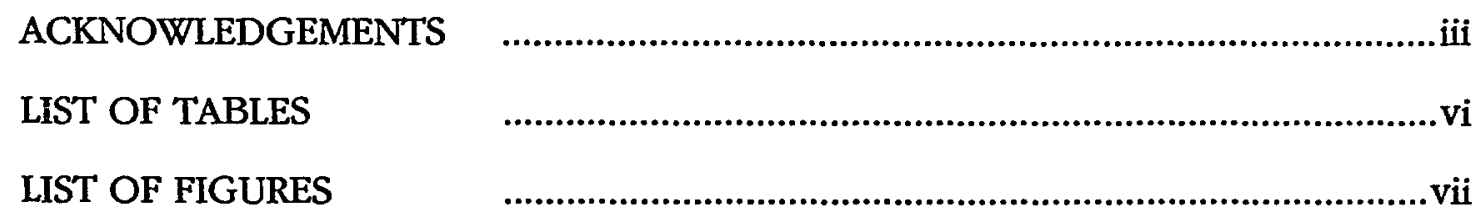

\section{CHAPTER}

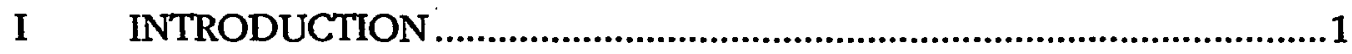

II STRUCTURE OF THE WOOD PRODUCTS INDUSTRY .....................7

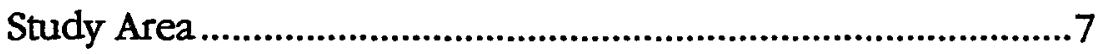

Employment Trends .........................................................11

Manufacturing process

Plywood Industry .......................................................13

Lumber Industry .........................................................15

Demand for The Final Product .........................................16

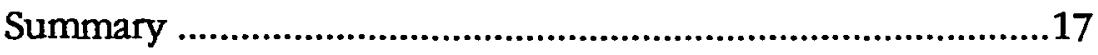

III REVIEW OF THE LITERATURE ..............................................20

Theoretical Review ..........................................................20

The Issue of Structural and Cyclical Unemployment in the Lumber and Plywood Industries ............................................................23

Methodological Review ....................................................227

Estimation procedures in the Pacific Northwest Wood Products Industry .....................................................33

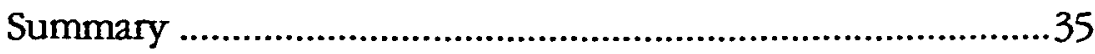


IV EMPIRICAL IMPLEMENTATION .................................................36

Theoretical Framework ..................................................36

Estimation Procedure ........................................................39

Production Functions ................................................39

Data Construction and Sources ...........................................50

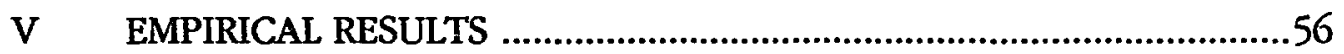

Simulation Experiments .........................................................77

Implications and Conclusion .............................................83

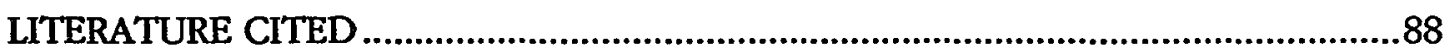

APPENDICES

A PLOTS OF OBSERVED AND PREDICTED VALUES ........................98

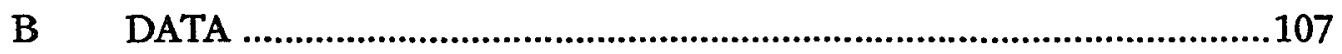




\section{LIST OF TABLES}

TABLE

PAGE

I Demand by End Use Market (\%) - Lumber ...................................18

II Demand by End Use Market (\%) - Plywood ........................................19

III Lumber Industry Cost Funtion ......................................................5

IV Plywood Industry Cost Function ...................................................59

V Share of Factor Inputs (Observed Values)

- Lumber Industry ...................................................................60

VI Share of Factor Inputs (Observed Values)

- Plywood Industry ..................................................................61

VII Share of Factor Inputs (Predicted Values)

- Lumber Industry ....................................................................62

VIII Share of Factor Inputs (Predicted Values)

- Plywood Industry .........................................................................63

IX Allen Partial Elasticities of Substitutions .........................................63

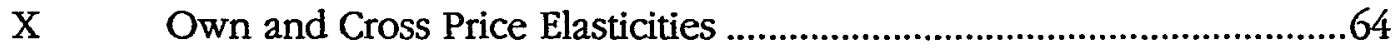

XI Returns to Scale - Plywood and Lumber Industry .............................68

XII Percentage Change in Factors of Inputs and Outputs

in the Lumber Industry ..............................................................69

XIII Percentage Change in Factors of Inputs and Outputs in the Plywood Industry ................................................................ 70

XIV Estimates of Productivity Growth of Labour ................................... 77 


\section{LIST OF FIGURES}

FIGURE $\quad$ PAGE

1 Sub-region Boundaries of the Pacific Northwest .......................................8

2 Employment Dependency of the Pacific Northwest's

Planning Districts on Lumber and Wood Products Industry.......................10

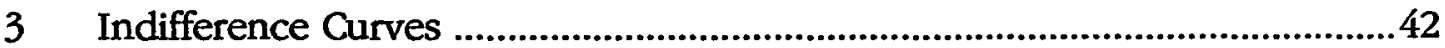

4 Percentage change in Factors of Input and .

Output in the Lumber Industry................................................................75

5 Percentage change in Factors of Input and

Output in the Plywood Industry..........................................................76 


\section{CHAPTER I}

\section{INTRODUCTION}

There has been a continuing debate over the causes of employment decline in the Pacific Northwest region's timber industry. It is generally perceived that labour saving technology and improved productivity are the major causes of this decline. Productivity is basically defined as the rate at which inputs are turned into final products. In other words, productivity is measured as the ratio of output to inputs; any increase in productivity is expressed as a reduction of levels of input or an increase in the level of output with inputs constant.

Labour saving technology may simply involve increasing automation leading to a decline in labour requirements and a simultaneous increase in utilization of other factors of production. There are, however, other market-related variables that may have contributed even more strongly to changes in employment. The employment decline could have been a consequence of a decline in aggregate demand or a fall in demand for the end product. The introduction of new technology does not necessarily lead to lower levels of employment. Other manufacturing industries in this region have also enjoyed the benefit of innovations, but none has suffered such heavy loss of employment. In fact, despite new technology, some have actually increased their total workforce.

The importance of the lumber and wood products industry to the Pacific Northwest can be seen in terms of employment and earning ratios. Over 5 
percent of the labour force in Oregon and more than 2 percent in Washington are employed in this sector and more than 7 percent of total earnings in Oregon and 3 percent in Washington are paid by the wood products industry. The degree of dependency, however, is far greater for the western side of the states, i.e., a larger percentage of the workforce are, directly and indirectly, employed by this industry. In some communities the industry's contribution is even more pronounced, where the local mill is the only major employer. Thus, the survival of many of these communities depends on the existence of the local mill. As well as having economic consequences, high unemployment can also have undesirable social and psychological effects. Social consequences, such as divorce, child abuse, etc., increase in times of high unemployment (Howell and Bentley, 1980). Although much of the redundant workforce eventually find replacement jobs, the jobs tend to be lower-paying and in many cases part-time (Rothstein, 1986), with no pension or life insurance (Bluestone, 1985). Also, the search for jobs is generally longer in times of recession (Rothstein, 1986) and for the less skilled and older age groups (Haber et al., 1963; Foltman, 1968).

Although employment levels in the region's wood sector have been increasing in recent years, it has been suggested that the trend is beginning to level off (Oregon Labor Trends, 1987). It is forecasted that stumpage prices will start to increase at a much faster rate. In addition, interest rates are also thought to have bottomed out and to be about to rise again. The combined effect of these increases will result in lower demand for wood products leading to lower employment levels in this sector. In 1986 unemployment levels in some of the smaller timber dependent communities of the Douglas-fir region were around 20 percent (Oregon and Washington State Employment Divisions). The strong 
dependency of the Pacific Northwest's economy on the wood products industry adds further support for implementing more effective measures. Public policy may, therefore, be required to alleviate some of the impacts of unemployment. But if one is to accept the notion that resources are generally limited, then public policy needs to be designed to maximize its potential benefits. An examination of the level of unemployment provides only a partial perspective of the labour market; more detailed analysis with regard to the categories of unemployment, structural and cyclical, will be essential in guiding the formulation of effective policy measures. For example, a programme of labour retraining during a cyclical downturn may be futile.

The issue of structural and cyclical changes has been a subject of debate at least since the early 1960s when, despite high rates of growth in the economy, the level of unemployment remained relatively high (Miernyk, 1966). Most economists blamed a deficient level of aggregate demand as the main cause of unemployment. A small minority, however, attributed high levels of unemployment to changes in the structure of the economy. The significance of this dialogue rests on its policy implications. Proponents of the demand theory believe that increasing the level of aggregate demand will reduce unemployment. Structuralists, however, hold that a policy aimed at increasing the level of aggregate demand would leave the level of structural unemployment unaffected. Thus, the distinction between these two major components of unemployment is of extreme importance for policy purposes.

Decomposition of causes of unemployment into two categories of cyclical and structural can lead to a more efficient allocation of public resources. Bluestone et 
al. (1986) point out that if these causes are not separated then public policy "is likely to prove insufficient for regulating the orderly growth and development of employment opportunity" (p. 101). Inappropriate policy could actually have negative repercussions. It is argued that if the distinction between different components of regional unemployment is not made then a programme aimed at reducing unemployment may in fact create inflationary pressures on the labour market (Brechling, 1967; Sum and Rush, 1975; Cho and McDougall, 1978). For instance, if structural factors are the major cause of unemployment in a region, then public works programmes may not be an adequate measure. The chances of finding new employment after programmes have been implemented are rather slim. In contrast, such programmes may be most suitable in areas where the major components of unemployment are cyclical. Also, measures such as retraining programmes and mobility assistance are most effective in areas that suffer from high levels of structural unemployment.

The focus of public policy efforts should be spatially sensitive i.e., on smaller geographical units. Unemployment policies based on a national dimension may have negative repercussions; regions not only experience different unemployment rates, but their composition of unemployment varies as well. National unemployment policies generally fail to distinguish among the various components of regional unemployment and such a failure could create inflationary pressures on some local labour markets. Hence, policies will need to be region-specific to overcome some of these problems. Fearn claims that such an approach can lead to a more positive contribution to the economic health of those areas and the nation, and the cost effectiveness of national manpower programs would be improved (Fearn, 1975; P. 431). In addition, Engerman (1965) indicates that even 
policies aimed at reducing cyclical unemployment should be targeted on regional areas but controlled by the federal government. Hence, it has been decided to narrow the scope of analyses to a specific geographical region.

This research attempts to isolate the causes of employment decline in a single sector within a specific region, in two categories: cyclical and structural . While it is not intended directly to evaluate policy alternatives, it is hoped that it will serve as a vehicle for choosing more appropriate labour market policies. The efficacy of labour market policies depends upon a sound understanding of the nature of unemployment. Classification of the unemployed provides policy makers with more detailed information, allowing them to adopt more effective measures.

Obviously, one cannot formulate a regional manpower policy on the basis of the findings about one sector, despite the dominance of this particular sector in this region. Nevertheless, it could be used as the framework for undertaking similar types of studies of other major industries in the area. An understanding of the causes of this decline does not only assist in alleviating current problems, but could also help in facilitating future growth.

It is impossible to determine whether individual workers have been displaced through structural or cyclical factors. However, simulation analysis will provide reasonable estimates of various impacts. The above discussion has provided some guidelines regarding the basic components of structural and cyclical factors. In the case of this study, it may not be very easy to isolate the various factors in two separate groups. For instance, some variables, such as price of wood products, may have a strong cyclical component if examined in the short term and a 
structural component when analyzed over a longer period of time. However, generally, those elements that are associated with prices over the short run and demand for the wood products will be considered as cyclical, and variables associated with supply of timber and structure of the industry, such as productivity, will be regarded as structural. The modelling of this research is based on a cost function. A cost function has an advantage over a reduced form in the sense that direct factor relationships (substitution) are considered in the estimation procedure. The importance and relevance of elasticities of substitution and price elasticities for policy purposes are confirmed by Abt (1987), who states that:

Wood and labor demand are dependent on the complex interaction of significant substitution and technology effects. Since forest policy decisions are often concerned with employment effects and wood supply, it is important that the analytical base for policy decisions identify the influence of these interactions, (Abt, 1987; p.172).

The contribution of this research can be divided in two parts. First, the research provides empirical estimation of the causes of employment decline. Secondly, it provides a new specification for measuring structural and cyclical unemployment. This study is divided into five parts; in Chapter II the structure of the wood products industry is briefly described. Chapter III provides a review of the literature. In Chapter IV the theoretical framework of the model is developed as well as its specification and properties. Finally, Chapter V reports the findings of the research. Direct results of the model as well as simulation analysis and policy implications are discussed. 


\section{CHAPTER II}

\section{STRUCTURE OF THE WOOD PRODUCTS INDUSTRY}

\section{STUDY AREA}

The wood products industry is one of the oldest and largest industries in the Pacific Northwest. The industry in this region was first developed towards the end of the last century. The exhaustion of the timber supply in the East, coupled with the wave of new settlers to the West, led to the rapid expansion of the industry in this area. By the mid-1920s the Douglas-fir region had established itself as one of the leading lumber producing regions of the nation. The rise and dominance of the region's forest product industries continued until the 1970s. However, the rising supply of second-growth forests in the South has since shifted this balance in favour of the South.

More than 80 percent of the U.S. consumption of lumber and plywood is composed of softwood species (U.S.D.A., 1982). Softwoods are, by far, the predominant species of the Douglas-fir region, comprising around 95 percent of total timber harvested. Properties of softwood and hardwood and demand for their final products are different. The region's softwood resources are mainly Douglas fir species and, to a lesser extent, hemlock, cedar and pine. On the eastern side of the Pacific Northwest most of the resources are drawn from such species as red alder, maple, ash and oak.

The Douglas-fir region, the focus of this study, is defined as the parts of 


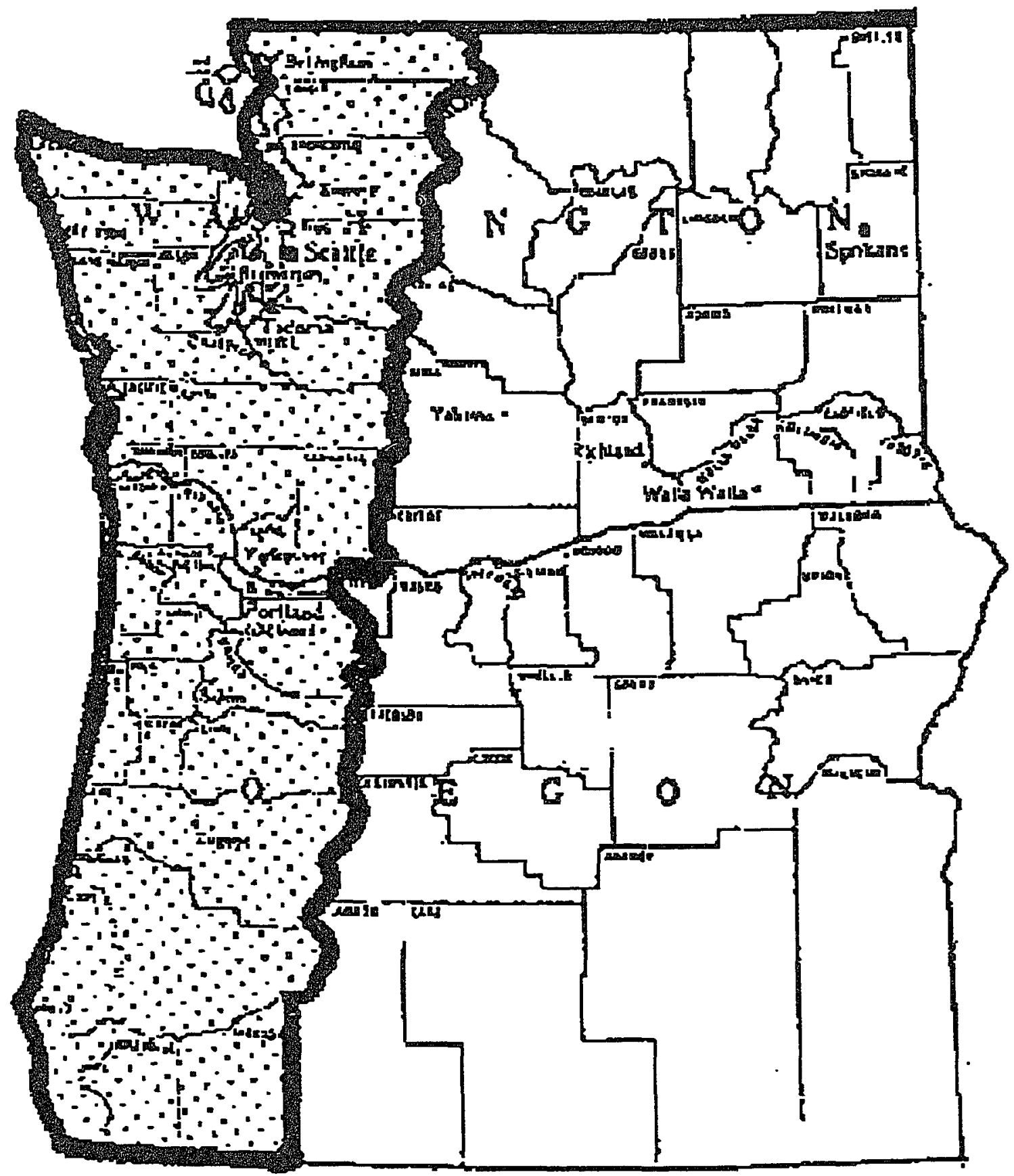

Figure 1. Sub-region boundaries of the Pacific Northwest. Shaded area shows the Douglas-fir sub-region. 
Oregon and Washington lying west of the Cascade Range (see Figure 1). The region is comprised of 38 counties, equally divided, in the states of Oregon and Washington. The area accounts for over 1.8 percent of total U.S. land and 4.5 percent of U.S. forest land (Mead, 1960). The relationship between the forest products industry and the Douglas-fir region can be viewed by simply examining the proportion of forest land in the region; over 80 percent of the area's 35 million acres of land is forest and over 70 percent is commercial forest land. Furthermore, there are more trees per acre in the Douglas-fir region than in any other forest region in the country.

It is generally thought necessary to subdivide the Pacific Coast region when examining the wood sector. The western part is studied because of the relative importance of the industry in this area (see Figure 2). Areas of northern California have been excluded for several reasons. First, the species that are grown are not the same. Second, the California economy has generally behaved differently from Washington and Oregon during the recent recessions. Third, economic data is not available for northern California.

In addition to homogeneity of timber resources, similarities in the employment of production technologies are another important yardstick in delineating a region for economic analysis. Wall and Oswald (1975) confirm that there are basic differences between the two halves of the region which will lead to unequal patterns of employment and raw material relationships. In fact, Merrifield and Haynes (1985) found that production technologies for lumber and plywood industries are different on each side of the Pacific Northwest region. 
Figure 2. Employment Dependency of the Pacific Northwest's Planning Districts on Lumber and Wood Products Industry.

Source: Schallau, C.H., and Maki, W.R. 1986, p.7 
It should be noted that demand for wood varies by type of species. For example, softwood products are primarily used in the construction industry. In contrast, the major source of demand for hardwood products is the furniture industry. The experience and pattern of behaviour for the products should, therefore, not be expected to be similar. Hence, the separation of various industries within the wood products sector may be required to prevent substantial flaws in the analysis.

\section{EMPLOYMENT TRENDS}

Since 1951, when employment levels in the Douglas-fir region's lumber and wood product sector reached an all time peak of over 123,000 , there has been a steady decline in employment. Between 1951 and 1984 employment in the Douglas-fir region's lumber industry declined by almost 60 percent, slightly less than the 66 percent experienced by the U.S. lumber industry. The region's plywood industry, however, seems to have incurred a larger proportion of national decline. During the 1964-84 period, employment in the Douglas-fir region's plywood industry fell by 42 percent, in comparison to a decline of less than 19 percent in its national counterpart. Although employment levels began to rise again in the early seventies, in the Washington-fir region's wood products industry they actually reached their all-time peak of 46,634 in the late seventies, they declined sharply after 1979. Between 1979 and 1985, employment levels in the Western Washington region's lumber and wood products industry declined by over 15,000 . The corresponding figure for the Western Oregon region is a little under 15,000. Overall, between 1979 and 1985, employment levels in the Douglas-fir region's wood products industry fell by 27 percent and are projected to decline even further by the turn of the century (Wall, 1973). Although both the 
lumber and plywood industries in this region have experienced a general decline in labour utilization, the relative loss in the plywood industry has been exacerbated by the relative gain of other regions of the country. In the case of the lumber industry, however, most of the gain has accrued to forest regions outside the country, in Canada.

Between 1958 and 1975 output per worker in sawmills and planing mills rose by an average annual rate of 2.7 percent (Duke and Huffstater, 1977). The level of change was found to fluctuate in various sub-periods, increasing at higher rates in the late fifties and early sixties, and slowing down in the late sixties. During the seventies, however, no particular pattern was observed: rather, some unusual swings, positive and negative, were observed each year. In the region's lumber industry, output per employee more than doubled during the sample period, 195186. During this time span employment declined by more than a half while the level of output remained relatively stable. As for the plywood industry, between 1963 and 1986, output per employee increased by around 75 percent. For the same period change in output per worker for the lumber industry is less impressive, an increase of only 42 percent. Most of this improvement in the plywood industry at face value seems attributable to a declining utilization of labour. Furthermore, an examination of the output-employment ratio in two separate sub-periods, 1963-78 and 1979-86, illustrates a different.pattern. During the first sub-period the ratio for the lumber and plywood industries increased by 5 and 19 percent respectively. In comparison, the second sub-period shows increases of 33 percent and 44 percent for the respective industries.

Duke and Huffstater (1977) point out that the high concentration of trees in 
this region allows local mills to operate with greater economies of scale. They argue that this regional advantage, in terms of scale economies, has meant greater relative efficiency of mills and thus a reduction of the manpower requirement. However, any implications of scale economies bringing about lower employment levels in the industry does not seem totally valid. First, over the last ten years, the region's share of total output has declined while the South's relative share has risen sharply. This so called relative efficiency does not therefore seem reflected in any relative gain in output. Second, although economies of scale can lead to lower average costs, it is not certain that larger firms are optimal. Mead (1966), for example, found medium size lumber plants to be optimal.

Although Duke and Huffstater's argument may have some validity, there is little doubt that there have been more important variables that have caused this decline in employment levels.

\section{MANUFACTURING PROCESS}

It has already been indicated that much of the employment decline in the pacific Northwest wood products industry has been attributed to increased automation in the production process. Thus it is deemed necessary to provide a brief description of technological changes that have taken place in the production process of lumber and plywood industries.

\section{Plywood Industry}

Plywood is a thin sheet of wood constructed from several layers of veneer. The process of manufacturing plywood is unique and highly technical. Briefly, logs are categorized by grade and length, preconditioned by some application of hot water and steam, and peeled and converted into veneer which is then clipped 
around the edges, sorted, dried, graded and glued into panels. Over the years the industry has undergone several radical technological changes: the advent of waterresistant glues as substitutes for tapes, use of the spindless lathe to cut smaller logs, computerized tray and lathe synchronization, the programmable logic controller, and the development of infrared drying systems (Baldwin, 1984). The declining supply of old growth timber and increasing use of wafer board and oriented strand board, types of structural panel, have forced the industry to develop new production techniques, enabling the utilization of species other than Douglas fir. The new lathe has allowed the industry to peel logs of small diameter which previously were not usable. The use of smaller and cheaper logs has enabled the industry to remain competitive in the face of growing competition.

Since World War II, the plywood industry has been one of the fastest growing industries in the Douglas-fir region, despite the industry's relative decline at the turn of the last decade. Plywood production has soared from 2533 million square feet (m.s.f.) in 1950 to 8706 m.s.f. in 1986 (American Plywood Association, 1987). Production of softwood plywood in the U.S. has increased substantially since 1950, rising from 2554 m.s.f. to around 21000 m.s.f. in 1986. Thus, the share of the Douglas-fir region has gradually declined. In 1950 the Douglas-fir region produced over 90 percent of total U.S. output, with the eastern half of the Pacific Northwest and northern California supplying the rest. By 1986 the region's contribution had fallen to a mere 40 percent, almost on a par with the Southern Pine region (American Plywood Association 1987).

Technological advancement is often accompanied by declines in the labour input. In the plywood industry, however, modern technology has led to overall 
expansion of the industry in this country, attributed mainly to the use of new species. This gain by the industry has not been equally distributed among the forest regions of the U.S.. Deployment of smaller logs has meant less reliance on this region's species. The nature of this industry requires that production be undertaken at or around the source of raw material. Subsequently the region's plywood industry has suffered.

\section{Lumber Industry}

Lumber is simply sawn timber converted into planks, beams or boards. The lumber industry is the largest consumer of timber in the region. Before the $1940 \mathrm{~s}$ the lumber industry consumed over 80 percent of the region's total log production, however, its relative share has steadily declined over the years.

The production process consists of sorting the incoming logs and removing the outer bark to clear the surface of any foreign substance; resawing; trimming; grading; drying; and stacking them for shipping. This industry, however, has not undergone as much technical innovation as the plywood industry. Nonetheless, there have been significant improvements. For instance, the development of edger saws, which eliminate unmerchantable slabs, has resulted in a more efficient use of logs. Other major improvements in the manufacturing process include the debarking of logs into square cants that are then used as raw material in the manufacturing of pulp and paper. Also, there has been an increasing trend toward land storage of logs, as opposed to pond storage, allowing a smoother operating process and less requirement for labour. This change has been attributed to the development of large capacity loading tractors (Duke and Huffstuter; 1977). In addition, there has been substantial automation at the sorting and the stacking stages of the operation. 


\section{DEMAND FOR THE FINAL PRODUCT}

As the demand for labour is a derived demand, any analyses of an industry's employment changes require an examination of demand for the industry's end product. In addition, demand for the products has a strong cyclical component which must be included in the analyses.

The uses for wood and the share of various sources of its demand have fluctuated over time. In the early days, wood was the major source of energy for both residential and industrial purposes. Only the use of fossil fuel caused the consumption of wood for energy purposes to decline. Also, wood was used extensively for the construction of rail networks. In the early parts of the twentieth century around 25 percent of the wood produced in the U.S. was used for the purpose of railroad ties (Congress of the U.S., 1983).

Generally, demand for lumber and plywood can be placed in three categories: construction, manufacturing and shipping. Construction is, however, the single most important source of demand for wood, especially for softwood products. Demand from construction can be divided into the three sub-groups of residential (housing), non-residential and repairs and remodeling. Furthermore, about 97 percent of lumber and over 90 percent of plywood consumed in residential construction and repairs are from softwood species (U.S.D.A., 1982). Although, in the postwar era, major changes have occurred in the construction industry including the use of alternative building materials such as aluminium and plastic, and the utilization of prefabricated components, allowing a more efficient use of wood, new housing remains the major source of demand for lumber and plywood. 
Traditionally, lumber was the sole wood product used in the construction industry. Over the years, there has been a growing competition from plywood and, in more recent years, from other wood-based panel products. An examination of U.S. production figures for softwood lumber and plywood shows that lumber output has remained relatively stable over the sample period in comparison to a ten fold increase in plywood levels.

Tables I and II show a breakdown of final markets for lumber and plywood. As the above tables indicate, the largest share of the market is held by residential construction which, in 1986, consumed about 37 percent of lumber and plywood produced in this country (Western Wood Products Assoc., 1986; American Plywood Assoc., 1987). Although, total consumption of lumber and plywood is projected to increase until the early parts of the next century, due mainly to the expected increase in household formation, their relative share in the construction market is expected to decline (U.S.D.A., 1982).

\section{SUMMARY}

The previous section has provided an overview of the wood products sector in the Pacific northwest region. A summary examination of the industry was considered necessary so that more complex issues in the later parts are better understood. The lumber and plywood industries are by far the dominant industries in the sector and an analyses of these two industries will provide a sufficient understanding of the nature and impact of employment decline on the region's economy. 
TABLE I

DEMAND BY END USE MARKET (\%)

LUMBER

\begin{tabular}{|c|c|c|c|c|c|c|c|c|c|c|}
\hline & 1953 & 1978 & 1979 & 1980 & 1981 & 1982 & 1983 & 1984 & 1985 & 1986 \\
\hline Residential Construction & 46.4 & 44.7 & 40.2 & 35.8 & 32.4 & 33.2 & 41.1 & 38.9 & 37.6 & 36.8 \\
\hline Non Residential Construction & 27.6 & 14.3 & 15.8 & 17.5 & 18.9 & 19.8 & 14.8 & 15.3 & 15.9 & 15.0 \\
\hline Repair and Remodeling & 22.7 & 19.6 & 21.2 & 24.4 & 25.4 & 26.1 & 23.9 & 26.3 & 27.9 & 28.5 \\
\hline All Other & & 21.2 & 22.8 & 22.3 & 23.3 & 20.9 & 20.1 & 19.4 & 18.8 & 19.7 \\
\hline
\end{tabular}

Number may not add due to rounding

Source: Stanford Research Institute

American Plywood Association

Western Wood Products Association 
TABLE II

DEMAND BY END USE MARKET (\%)

PLYWOOD

\begin{tabular}{|c|c|c|c|c|c|c|c|c|c|c|c|c|}
\hline & 1953 & 1976 & 1977 & 1978 & 1979 & 1980 & 1981 & 1982 & 1983 & 1984 & 1985 & 1980 \\
\hline Residential Construction & 50.0 & 42.0 & 44.0 & 41.7 & 43.3 & 37.8 & 37.7 & 35.0 & 36.9 & 37.7 & 40.3 & 40.0 \\
\hline Non Residential Construction & & 12.2 & 12.2 & 12.3 & 13.4 & 15.3 & 14.5 & 15.5 & 15.7 & 16.2 & 15.0 & 15.3 \\
\hline Repair and Remodeling & & 12.2 & 12.2 & 12.3 & 14.6 & 15.3 & 14.8 & 16.0 & 16.0 & 15.8 & 16.3 & 16.4 \\
\hline All Other & & 33.6 & 31.6 & 33.7 & 28.7 & 31.6 & 33.0 & 33.5 & 31.4 & 30.3 & 28.4 & 28.3 \\
\hline \multicolumn{13}{|c|}{ Number may not add due to rounding } \\
\hline \multicolumn{13}{|c|}{ Source: } \\
\hline
\end{tabular}




\section{CHAPTER III}

\section{REVIEW OF THE LITERATURE}

Apart from a few studies in the seventies (Wall, 1973; Wall and Oswald, 1975; Stevens, 1970), there has not been any other work that has explicitly dealt with the issue of employment changes in the region's wood products sector. Previous studies have focused interest on locational differences in labour costs and the employment effects of declining stocks of timber. Little work has been done in analysing the causes of job losses. This research attempts to decompose the causes of recent employment decline in the Douglas-fir region's lumber and plywood industries into two categories of structural and cyclical forces. The following section examines the theoretical aspects of structural and cyclical unemployment. This discussion is followed by a critical analysis of the methodology that has been employed in previous research as well as an examination of previous studies on the structure of the lumber and plywood industries.

\section{THEORETICAL REVIEW}

Cyclical unemployment is caused by deficient levels of aggregate demand. As demand for output declines there is a subsequent fall in demand for labour, as less labour is required to produce a smaller quantity of output. In general, cyclical changes are defined as:

A type of fluctuation found in the aggregate economic activity of nations,....a cycle consists of expansions occurring at about the same time in many economic activities, followed by similarly general recessions, contractions and revivals (Burns and Mitchell, 1946, p.3). 
Cyclical fluctuations are recurring events, which implies that job losses that occur during an economic downturn will be compensated for by new opportunities during an upturn. In other words, disturbances in the level of aggregate demand will balance over time. Under such circumstances, public policy is used for stabilizing the economy. Countercyclical policies are devised to revive the economy of the area by investment in the distressed industries, and provision and aid for new investment in other sectors of the economy.

Under the demand-deficient hypothesis the appropriate measures for reducing unemployment involve monetary and fiscal policies; most of these measures are of national dimension. One popular form of countercyclical policy that can also be regionally targeted is a public works programme (Vaughan, 1976; Vernez et al., 1977). Investment in public works projects will create temporary employment that could help reduce unemployment during recessionary periods. In contrast to cyclical fluctuations, structural changes are irreversible. Structural changes are usually referred to as alterations in the structure of the economy. They have been defined as; "a break in secular trends and a shift toward a significantly different order and configuration of social, economic, and political life" (Soja, 1986; p. 178).

Vaughan (1976) notes a number of attributes that may account for structural movements in an economy: technological changes, adjustments in world trade patterns, changes in consumer demands. Exhaustions of raw materials and locational shifts of industries are other important elements of structural change. The impact and degree of influence of these changes vary depending on the industry concerned and the region of analysis. Structural policies are comprised 
of retraining programmes and assistance in search for new employment. This type of policy is intended to increase labourers' chances of redeployment by improving and expanding their vocational skills (Kolbe, 1985).

Previous studies on decomposition of unemployment have generally looked at the problem from a national perspective. There are, however a number of studies which have examined this problem at regional levels, while these studies fail to analyze the behaviour of different industries within various regions they have generally found significant differences in the structure of unemployment across regions. This dispersion in the structure of unemployment indicates that a national policy aimed at reducing unemployment will not be equally effective in all regions. In fact, it has been argued that regions are actually becoming more and more varied (Syron, 1978; Browne, 1978 (a) (b)). Further, cyclical changes do not take place simultaneously across regions; they show a lead or lag relationship with the national cycle (Borts, 1969; Cho and McDougall, 1978). Therefore, it seems that appropriate labour market policies can only be implemented when the nature and degree of the problem are evaluated at a more disaggregated, homogenous unit of analysis.

There is a clear reason for decomposition of unemployment at the subnational level. Kaliski (1968) notes that even when the national rate of unemployment approaches the full employment level, some regions will achieve "overfull employment" while others will suffer from structural unemployment. This type of unemployment, he argues, will not be reduced by a mere increase in aggregate demand and requires specific labour market policies. Kaliski adds that it is not possible to deal effectively with the problem of local unemployment from 
the national or larger regional levels. This point is echoed by Fluckiger et al. (1986) in their decomposition of unemployment in Switzerland. They state that:

In order to make a realistic analysis of unemployment, the global view of the labour market seen as a homogeneous market should be abandoned (Fluckiger et al., 1986, p. 17).

Also, in light of the findings by Bluestone et al. (1986) individual examination of industries may be necessary. In their analysis of 92 manufacturing industries it was found that in about one third of them cyclical factors were a cause of change and in the rest of them they had no expianatory power. Moreover, the authors indicate that some of their results would have been different if a less aggregate approach had been undertaken. For instance, they suggest analyzing a specific sector and only using the exchange value of those countries that are involved in the trade of that sector's products with the United States, as opposed to using a general index of the value of the country's exchange rate. It has also been argued that structural developments generally involve some unique problems (Helmstadter, 1979), implying that different sectors will have varying experiences at various stages.

THE ISSUE OF STRUCTURAL AND CYCLICAL UNEMPLOYMENT IN THE LUMBER AND PLYWOOD INDUSTRIES

Stevens (1986) points out that until 1979 employment in Oregon's wood industry had generally moved up and down with the business cycle. Furthermore, he argues that the decline in employment after 1979 was caused by high interest rates and a severe national recession. The home-construction industry consumes around 40 percent of lumber and plywood produced in the country. The 
recession at the turn of the decade coupled with high mortgage rates caused a decline in housing construction. In fact, between 1979-82 housing starts fell by nearly 40 percent (Scaggs, 1983). This situation is more serious for producers in the Northwest, as the Southern region has enjoyed a net in-migration caused by the movement of new firms into the area and expansion of existing establishments (Scaggs, 1983; Strathman, 1985). Such analyses would seem to imply that employment cutbacks in the region's lumber and plywood industries, after 1979, were temporary. However, Stevens goes on to suggest that most of the employment loss will not be regenerated; implying that the industry has undergone some structural changes.

Apart from the decrease in demand for the region's lumber and plywood from the construction industry, it seems that other variables have also had significant impacts on the industry's employment levels. These issues will be discussed in the next section and the extent of their impacts will be evaluated in later chapters.

The issue of productivity in the region's forest products industries has been a subject of much discussion since the turn of the decade. Productivity is measured as the ratio of output to inputs; any increase in productivity is expressed in a reduction of levels of inputs or increases in output. Kendrick states that:

The basic objective of productivity estimates is to obtain....measures of the impact on production of investments and other variables that advance knowledge, improve technology and organization, and otherwise enhance the productive efficiency of the factors of production", (Kendrick, 1973, p. 11).

As discussed earlier, technological change is an important contributor to 
structural unemployment. Technological progress and industrial change are inevitable in a dynamic economy. The long run survival of most competitive industries depends on their ability to increase productivity and become more efficient. Increased productivity can eventually help the industry in this region to regain its market dominance by reducing costs and making them more competitive. Economic change will often involve the destablization of local labour markets, and thus the increasing of the existing pool of unemployed, at least in the short run, although it has also been argued that job losses are not necessarily inevitable with adoption of improved technology and increased productivity (U.S. Employment Service, 1968).

Tyler (1983) holds that the problem of regional unemployment generally stems from a decline in an area's exports. It is argued that this will eventually lead to lower productivity in relation to other competing regions. Relatively lower productivity implies that the region's costs per unit of output are greater than those of other competing regions. This certainly holds true for the region's timber industry. Increased factor costs will generally lead to higher total costs unless input requirements are reduced. An examination of the relative costs of factor inputs for the lumber and plywood industries indicates a shift in the comparative advantage of the Southern region (Merrifield and Haynes, 1985; Strathman, 1985). Such an advantage is not attributed to the warm climate of the South but to its level of non-unionized labour; Goodman points out that:

over the past ten years, most of the job growth has shifted to the least unionized parts of the country, both North and South (Goodman, 1979, p. 33-34).

Furthermore, the increasing cost of stumpage in this area relative to the 
Southern Pine region has resulted in a decline in sales for this region's wood products. In a study of the Pacific Northwest's lumber and plywood industries, Merrifield and Haynes (1985) concluded that a reason for the decline in the industries' employment in the early 1980s was higher stumpage, labour, and transportation costs in comparison to those of other competing regions. Schallau (1985) suggests that higher stumpage prices have been caused by declining supplies of private timber. The decreasing supply of timber in this region over the years is generally conceived as one of the major factors in increasing structural unemployment in this industry.

The issue of locational shifts can be viewed in a similar context; economic activity is also spatially dynamic. Changes in the cost of factor inputs and the evolution of new production techniques will eventually lead to a change in the comparative advantage of one region over another. This movement in location of production has been observed for most of the wood products. Historically, the balance of production has shifted from the North-East to the Southern states and then west to the Pacific coast and is now moving back to the South. In addition to competition from the Southern Pine region the mills in the area have been competing with the Canadians who, until recently, were benefiting from government subsidies and a favourable exchange rate. Another factor that has been given credit for the rising share of Canadian lumber in the.United States is the availability of lower transportation costs for Canadian producers (U.S. Dept. of Commerce, 1984). It is argued that the Canadians have access to cheaper foreign flagships. American producers have been prohibited by the Jones Act (1920) from using foreign vessels on intercoastal trade. Exports of forest products from this region do not constitute any significant volume in relation to total production. On 
the other hand there are significant import flows of certain forest products. Schallau and Maki (1986) indicate that employment in the Pacific Northwest's forest products industry is influenced by variations in the United States and Canadian exchange rates. The share of Canadian lumber in the merican market has increased from around 18 percent in 1970 to over 33 percent in 1985. During this period the United States dollar generally enjoyed a favourable exchange rate against the Canadian dollar.

In order to quantify the impact of timber supply shifts on employment in the wood products industry it may be necessary to examine private and public supplies separately. The behaviour of private timber suppliers, like that of any other private organization, is based on economic gain. The supply of public timber has been considered to be related to the Forest Service budget for timber sale preparation and availability of timber (McKillop, 1967; Haynes et al., 1981). Connaughton et al., however, argue that the supply of public timber is related to market conditions, since:

The decision to harvest public timber.....is made by private timber purchasers, not the public land management agencies (Connaughton et al., 1987, p. 12).

\section{METHODOLOGICAL REVIEW}

The first step of this study involves the isolation of cyclical from structural causes of employment decline. Previous works on this issue have utilized unemployment or employment changes as the indicator of analysis (Thirlwall, 1966; Brechling, 1967; Casetti et al., 1971; King et al., 1972; Vernez et al., 1977; King and Clark, 1978; Bluestone et al., 1986). These works are not useful for the 
purpose of this research for a variety of reasons.

The work by Vernez et al. (1977) attempted to evaluate the impact of public works programmes on the cyclically unemployed. The level of cyclical unemployment was estimated by subtracting the level of employment at the point of the cycle's upturn, the trough, from the level of employment at the cycle's peak, and then the level was trend-adjusted using a five-year moving average.

A more common approach that has been utilized for categorizing the unemployed is the unemployment-vacancy (U-V) method (Thirlwall, 1969, 1974; Armstrong and Taylor, 1981; Hannah, 1983). Basically, this technique uses data on unemployment and job vacancies to separate the various categories. This approach, however, suffers from serious problems. First, it is based on a wrong presumption that equilibrium in the labour market takes place when unemployment levels equal job vacancies (Armstrong and Taylor, 1981). Holden and Peel (1975) add that it is totally incorrect to draw any inferences about the determinants of unemployment based on vacancy rates. Second, it is assumed that structural unemployment exists only if there are job vacancies. But job vacancies fall during periods of recession, which, wrongly implies that structural unemployment is caused by a decline in the level of aggregate demand. Third, it has been suggested that this method underestimates levels of structural unemployment (Thirlwall, 1974; Armstrong and Taylor, 1981; Taylor and Bradley, 1983). Since not all vacancies occur in the location of the unemployed, such a crude measure tends to overestimate the amount of frictional unemployment at the expense of structural unemployment. Also, it has been noted that there is an under-recording of vacancies (Taylor and Bradley, 1983). Thus there would be an 
underestimation of structural as well as frictional unemployment, since, by definition, these types of unemployment exist only if there are vacancies. Finally, recorded vacancies are not an accurate reflection of job vacancies (Turvey, 1977).

Gordon (1964) employed a simple index of "common sense" to measure structural unemployment. Essentially, the difference between the ratio of a sector's unemployment to the national unemployment rate and the sector's fraction of total labour force is used as a measure of change in structural unemployment. This method has been heavily criticized on grounds of inconsistency (Borus, 1965; Stoikov, 1966). In addition, a decrease in a sector's relative unemployment rate does not necessarily mean that structural factors have been at work. Also, it is not possible to undertake a statistical test of significance for this type of approach (Stoikov, 1966).]

Gilmer and Pulsipher (1986) used a different kind of index to evaluate structural and cyclical causes of unemployment. They utilized Lawrence's (Lawrence, 1984) index of change:

$I=\frac{1}{2} \sum_{i=1}^{N} \frac{s_{2}-s_{1}}{y} \times 100$

where $l$ is an index of structural change over a period of $y$ years, $N$ is the number of industries and $S_{2}, S_{1}$ are the share of each industry in manufacturing at the end and beginning of the period. Obviously, if the share of each industry remained constant over time the value of the index would be zero. The obvious problem with this model seems to be its underlying presumption that regions are equally sensitive to cyclical changes, since it does not incorporate any variables indicative of geographical location of industries. Furthermore, like the Gordon 
technique, it is not possible to undertake a statistical test of significance.

A number of studies, however, have employed empirical analysis to measure the various components of unemployment (Knowles and Kalachek, 1961; Thirlwall, 1966; Brechling, 1967; Casetti et al., 1971; King et al., 1972; Fearn, 1975). The national unemployment rate has generally been used as the indicator of aggregate economic activity and regional unemployment levels have been regressed against national unemployment rates to isolate the two components.

The basic motivation behind Thirlwall's (1960) study was the failure of government policy to improve economic conditions in designated areas. It was assumed that there were two attributes that led to variations in levels of regional unemployment: the industrial mix of regions and the sensitivity of industries between regions. In order to measure unemployment sensitivity of regions to cyclical fluctuations, regional unemployment levels were regressed against national rates. A similar regression was run between the percentage unemployed in various industries and the national unemployment rate to determine how different industries were affected by cyclical changes. A rank correlation exercise was undertaken to analyse variations in regional unemployment rates. This involved the use of some form of a shift-share approach so as to differentiate the proportion of labour force in each industry in relation to its national rate. Such a piecemeal approach cannot portray the whole picture. Furthermore, it fails to identify the sensitivity of each industry in different regions; industries perform differently in various regions.

In a similar type of analysis, Brechling (1967) attempted to isolate the causes 
of regional unemployment into three categories: cyclical, structural and regional cyclical. The basic relationship was expressed as:

$\mu_{j t}=c_{j}+a_{j} \mu_{r(t+n j)}+b_{j} t+d_{j} t^{2}+R_{j t}$

where $\mu_{j t}$ is unemployment rate in region $j$ in time $t ; c_{j}$ is the structural component in period $0 ; \mu_{T(t+n j)}$ is national unemployment rate at time $t$ and $n j$ is the length of lead or lag for region $j$, which will be positive if it leads the nation and negative if it lags the national cycle; $b_{j}$ and $d_{j}$ are indicators of a quadratic time trend, thus the value of these two coefficients shows the rate of change in structural unemployment over time. Structural unempioyment is measured as the sum of the value of the coefficients for each observation. $R_{j}$ is the residual and reflects the regional cyclical component. The major deficiency of this model is similar to that of Thirlwall's; it, also, fails to account for differences in regional industrial composition. To overcome this inadequacy, Casetti et al. (1971) replaced the national unemployment variable with a "weighted national series", $w_{j t}$ which reflects the unemployment rate in city $j$ over time. Thus the new equation had the following form:

$\mu_{j t}=c_{j}+b_{j} t+d_{j} t^{2}+a_{j} W_{j t+n j}$

where coefficient $a_{j}$ is an estimate of city $j$ 's sensitivity to national changes. The underlying presumption of this model is that unemployment rates in each city's industries are the same as the national average. Such an assumption, however, fails to account for differences between regions.

In addition to the problems discussed above, differences in the industrial mix of regions and the performance of regional industries equal to a national average, 
the Brechling-type models have also been criticized from two other standpoints. First, Hyclak and Lynch (1980) suggest that the national unemployment rate is an inaccurate indicator of cyclical fluctuations. They argue that national unemployment is not only affected by cyclical factors, but also by structural and frictional forces in the economy. For instance, changes in the level of national unemployment could stem from changes in the composition and size of the labour force. The size of the work force may increase as a result of a "baby boom" a generation earlier, a decline in the educational and skill requirements for labour; etc. Instead, they prefer using a GNP gap, which is the difference between potential GNP and the real GNP. The notion of potential GNP is related to the level of output when the economy is at the equilibrium level of unemployment. It is assumed that there is an inverse relationship between the level of aggregate demand and the GNP gap. Bluestone et al. (1986) also used a GNP gap and an index of exchange rate as indicators of cyclical changes. The residuals of the regression were then used to measure structural changes.

It seems, however, that there are problems regarding the accuracy of potential GNP. As it is an estimated figure, alternative approaches will project different results. For example, a comparison of two different techniques employed by the Council of Economic Advisers $(1962,1977)$ showed estimates of the potential GNP to vary by as much as $\$ 57.8$ billion (Rasche and Tatom, 1977). Furthermore, inclusion of the GNP gap could create additional statistical problems. The value of potential GNP is estimated on the basis of future changes in employment and/or productivity. Thus any statistical analysis of employment that is dependent on some value of employment could cause a bias in the value of the coefficient. 
Second, Tiller and Bednarzik (1983) argue that a model which relies strongly on a time series approach renders itself susceptible to misspecification bias, since a deterministic trend function can not adequately portray the composition of regional unemployment. They favour a frequency domain approach using spectral techniques. But there are some questions regarding the application of this technique to economic problems. For instance, it has been argued that to work in the frequency domain one requires observations that are regular and of high frequency (Hamermesh, 1969). Hence, the use of such a technique for cyclical analysis may be inappropriate. It has therefore been indicated that such an approach may be more effective in analysing seasonal variations. In addition, it has been stated that:

Interpretation of spectral statistics is still ambiguous in terms of traditional time domain properties (Cho and McDougall, 1978, $\mathrm{p}$ 74).

Moreover, it has been noted that the use of spectral analysis may involve some loss of information (Wold, 1967).

Finally, apart from the Bluestone et al. (1986) and Gilmer and Pulispher (1986) studies, the models described have all utilized unemployment data in their analyses and it is generally agreed that local unemployment data do not provide an accurate measure of unemployment levels (Ullman, 1963; Vaughan, 1976; Howland, 1979).

\section{ESTIMATION PROCEDURES IN THE PACIFIC NORTHWEST WOOD PRODUCTS INDUSTRY}

In contrast to the studies reviewed, this research will examine a specific sector, over time, in a single region - a focus clearly indicated by past studies. Further, the methodology employed for analyzing structural and cyclical unemployment, is designed to avoid the pitfalls of much of the previous work. 
Instead of relying on a simple regression technique, a cost function is used in this research. Such an approach is suggested by the work of Merrifield and Haynes, 1983; 1985; Merrifield and Singleton, 1986; who have primarily studied the wood products industry in the Northwest. The general focus of these studies has been on market-to-market elasticity measures. Basically, this has involved measuring the responsiveness of changes in the resource market to changes in the product market and vice versa. For instance, what would happed to lumber prices if there is a proportional change in housing starts and by the same notion, what effect does a percentage change in timber inventory have on the end product. Perhaps the lack of interest in the issue of employment is caused by the studies' period of analysis. The observation period in these studies does not cover the massive redundancy era of the late seventies and early eighties. Unemployment in the region was not of great concern until the turn of the last decade when mill closures and job rationalization affected many timber dependent communities. Furthermore, apart from the Merrifield and Haynes (1985) study, the two subregions of the Pacific Northwest have not been examined separately; some of the problems associated with analyzing this region as one unit have been discussed earlier in this report. Moreover, in the latter study, employment data for the period after 1971 were actually projected using the Wall-Oswald technique.

The dynamic cost approach employed by Merrifield and Singleton (1986) was not used for a number of reasons. A static specification assumes that all inputs adjust instantaneously and may, therefore, appear restrictive in the short-run. However, it has been argued that elasticities of factor substitution based on time series data yield short-term estimates (Nadiri and Rosen, 1973; Griffin and Gregory, 1976). As time series data have been employed in this study such a 
restriction should not have any significant effects on our findings. Furthermore, Brown and Christensen (1981) point out that it may not be possible to implement dynamic models empirically as changes may not necessarily be a result of internal costs of adjustment. In the case of this study, for instance, changes in levels of stumpage may occur as a result of new government or Forest Service initiatives. Moreover, on discussing the shortcoming of their model, Merrifield and Singleton (1980) indicate that capital adjustment levels are affected by market expectations; any dynamic approach will need to incorporate additional variables reflecting uncertaintities in both the product and factor markets. Thus, creating additional problems.

\section{SUMMARY}

The preceeding section has involved a discussion on the issue of structural and cyclical forces. This has included the importance and relevance of separating the two factors, as well as an argument for adopting a different approach for decomposing the two factors. Obviously discrepancies may arise in categorizing individual variables. For instance the rate of exchange between the U.S. and Canadian dollars seems to be a cyclical element when viewed over a short time period. However, over the long run, this variable can be regarded as structural. This review has also shown why it is necessary to narrow the scope of analysis to a smaller geographic region, thus paving the way for the focus of this study. 


\section{CHAPTER IV}

\section{EMPIRICAL IMPLEMENTATION}

\section{THEORETICAL FRAMEWORK}

Employment levels are generally determined in labour markets. The level of employment in any time period is a function of quantity of labour supplied and quantity demanded:

$\mathrm{E}=f\left(L_{D}, L_{s}\right)$

where $\mathbf{E}$ represents employment, $L_{D}$ and $L_{S}$ reflect demand and supply of labour respectively. Economic theory suggests that the supply of labour depends upon the wage rate. Then, by definition, supply of labour in each sector is not only dependent on level of wages in that particular sector, but also, on the going rates in other related sectors of the economy. The industry's labour supply function is assumed to have the following relationship:

$L_{s}=f(w, m w)$

where $W$ is average wage rate for labour and $M W$ is average wages in all manufacturing industries.

According to economic theory, a producer's input demands are derived from the underlying demand for the commodity which he produces (Henderson and Quandt, 1971). Hence, the level of employment demanded is dependent on the quantity of final product. It may therefore be useful to start the analysis of an 
industry's demand for a factor input by examining the industry's production function:

$Q=f(L, K, R)$

where $L$ is the level of employment, $K$ is the stock of capital and $R$ is the quantity of timber. It is generally perceived that the structure of the wood products industry approximates one of perfect competition. Assuming that firms in the industry are profit maximizers, then the optimal solution is given by maximizing the function:

$\pi=P Q-Z$

where $\pi$ represents profits, $P$ is the price of the final product, $Q$ is the total output and $Z$ reflects total cost. If the expressions for $Q=f(L, K, R)$ and $Z=W L+i K+c R$ are substituted into the profit maximization equation, the following profit function is derived:

$\pi=P f(L, K, R)-w L-i K-c R$

where $w, i$ and $c$ are the wage rate for labour, the rental price of capital and the stumpage cost of timber respectively. The first-order condition for profit maximization requires setting the partial derivatives of with respect to the three inputs equal to zero:

$$
\begin{aligned}
& \frac{\partial \pi}{\partial L}=P f_{L}-W=0 \\
& \frac{\partial \pi}{\partial K}=P f_{K}-i=0 \\
& \frac{\partial \pi}{\partial R}=P f_{R}-C=0
\end{aligned}
$$


where $P f_{L}, P f_{k}, P f_{r}$ are the value of the marginal products of labour, capital and raw material respectively. The first order conditions, therefore, require that the price of each factor be equal to the value of its marginal product. Alternatively, demand for factors of production could be derived through a cost minimization approach, where total cost is minimized subject to a given level of output:

$Z=W L+i K+c R-\lambda f(L, K, R)$

Necessary conditions for minimization are:

$$
\begin{aligned}
& \frac{\partial Z}{\partial K}=i-\lambda f_{K}=0 \\
& \frac{\partial Z}{\partial L}=w-\lambda f_{L}=0 \\
& \frac{\partial Z}{\partial R}=c-\lambda f_{R}=0
\end{aligned}
$$

Where $f_{L}, f_{K}$ and $f_{R}$ are marginal products of the three inputs. A necessary condition for minimizing costs at the optimal level of output requires that the prices of inputs be equal to their marginal products. It can then be shown that at the optimal level of output, $\lambda=P$. From the above sets of equations, it can be seen that:

$$
\begin{aligned}
& W^{\prime}=P f_{L}=\lambda f_{L} \\
& i=P f_{K}=\lambda f_{K} \\
& c=P f_{R}=\lambda f_{R}
\end{aligned}
$$


The corresponding input demand functions can then be obtained by solving the above first-order conditions for the three inputs (Henderson and Quandt, 1971). Hence, the labour demand function is:

$L_{D}=f(P, w, i, c)$

Unfortunately, direct estimation of the above equation can lead to the problem of simultaneity, which will result in correlation between the error term and the endogenous variables. In such circumstances, ordinary least-squares technique will lead to biased and inconsistent estimates. In fact, the labour demand equation was estimated in various forms and the observed coefficients were generally inconsistent. However, changes in factor demand can be inferred from an industry's production or cost functions; through estimates of elasticity of factor substitution and indices of technological change. Hence, it was decided to undertake a functional approach in order to avoid the problem of simultaneity. Although this approach will not permit direct quantification of each type of unemployment it will be possible to quantify the various categories of employment decline through simulation analysis.

\section{ESTIMATION PROCEDURE}

\section{Production Functions}

Basically, a production function reflects the technical relationship between possible output levels and an alternative combination of factor inputs. A production function defines the quantity of output $(Q)$ as a function of quantities of inputs $\left(x_{1}, x_{2}\right)$

$a=f\left(x_{1}, x_{2}\right)$ 
where various combinations $x_{1}$ of $x_{2}$ and will produce different output levels. The deployment of various input levels is, obviously, subject to available technology and price of inputs. Given the above production function, the technical rate of substitution (TRS) between $x_{1}$ and $x_{2}$ is the amount by which one factor input must be increased following a decline in another factor input, without varying the level of output:

$\operatorname{TRS}_{x_{1} x_{2}}=\frac{-\partial x_{2}}{\partial x_{1}}=\frac{\partial f / \partial x_{1}}{\partial f / \partial x_{2}}$

where $\partial f \partial x_{1}$ and $\partial f / \partial x_{2}$ represent the marginal product of factor inputs $x_{1}$ and $x_{2}$ respectively. Estimation of the production function necessitates the development of some of its properties (Intriligator, 1978). Generally it is assumed that the production function satisfies the following: The first-order condition requires that the marginal products of the inputs be non-negative, i.e.,

$$
\begin{aligned}
& \frac{\partial f}{\partial x_{1}} \geq 0 \\
& \frac{\partial f}{\partial x_{2}} \geq 0
\end{aligned}
$$

The second condition requires that the Hessian matrix of partial derivatives be negative semidefinite, i.e.

$$
\begin{aligned}
& \frac{\partial^{2} f}{\partial x_{1}^{2}} \leq 0 \\
& \frac{\partial^{2} f}{\partial x_{2}^{2}} \leq 0
\end{aligned}
$$


$\frac{\partial^{2} f}{\partial x_{1}^{2}} \cdot \frac{\partial^{2} f}{\partial x_{2}^{2}}-\left(\frac{\partial^{2} f}{\partial x_{1} \partial x_{2}}\right)^{2} \geq 0$

There are a number of techniques through which the parameters of a production function can be estimated. Until recently, the two most widely used functional forms had been Cobb-Douglas (Cobb and Douglas, 1928) and the Constant Elasticity of Substitution (CES) (Arrow et al., 1961). However, since its inception in 1971 the Transcendental Logarithmic function (Translog) (Christensen et al., 1971, 1973) has been used extensively (Berndt and Christensen, 1973; Berndt and Wood, 1975; Humphrey and Moroney, 1975; Christensen and Greene, 1976; Merrifield and Haynes 1985; Merrifield and Singleton, 1986).

The general problem with the Cobb-Douglas function is its a priori restrictions on elasticity of substitution between factor inputs, and Hicks neutral technical change (Stier, 1980). A Cobb-Douglas function maintains an assumption that the elasticity of substitution between inputs is constant and equal to unity. As this research intends to evaluate structural changes, and since technological progress and relative changes in factor utilization are such an important component of it, a priori restriction of the kind held by the Cobb-Douglas function will not allow testing of certain hypotheses.

The elasticity of factor substitution is a pure reflection of the curvature of the isoquants. Further, production technology relates the process through which inputs are converted into output. A neutral technical change implies changes in levels of output while maintaining the ratio of factor inputs (see Figure 3). The diagram below illustrates that, despite an increase in the level of output and inputs the curvature of the two isoquants has remained equal, hence suggesting that 
Hick's rate of technical change has been neutral. A presumption of this type, as held by the Cobb-Douglas theory, has a strong influence on factor demand estimations. A neutral technical change implies that there has been no change in structure of production. Even estimates of the elasticity of substitution may not reflect the true picture of changes in factor usages. Stier (1980) points out, factor substitution may not necessarily be a result of changes in production technology but a reflection of relative factor price changes. Further, the assumption of constant elasticity of substitution would make it impossible to infer any conclusions about changes in factor demand using the Cobb-Douglas technique.

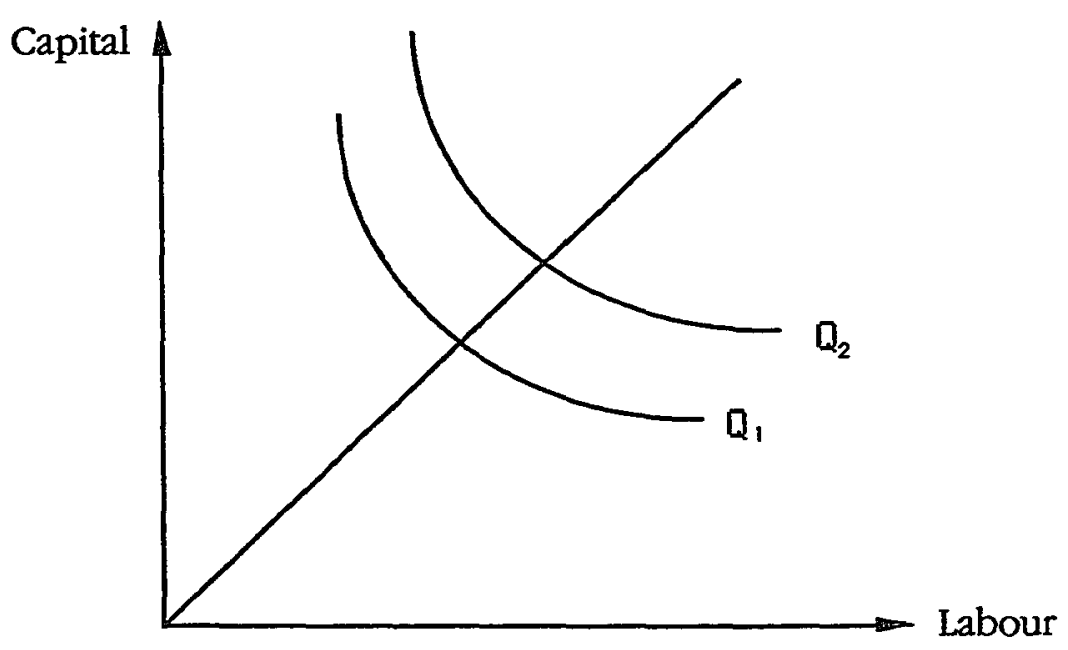

Figure 3. Indifference Curves

The CES function, however, assumes constant, but not unitary, elasticity of substitution. This implies that the partial elasticity of substitution between all pairs of inputs is identical (Uzawa, 1962). Although the CES function is an improvement over the Cobb-Douglas technique, and is considered adequate in the case of two inputs, its restriction on equality of substitution between each pair of factors is unreasonable. 
The choice of functional form depends on a number of factors. Varian (1984) recommends choosing a function that is :

"Simple, flexible......meets economically reasonable restrictions and does not present unreasonable estimation problems" (Varian, 1984, p. 172).

A translog function was chosen in preference to other functional forms as it seems to represent a more generalized form of production function. A translog function is generally considered more flexible, i.e., it does not predetermine the range of values of estimated parameters. In otherwords, it does not impose a priori restrictions on substitution possibilities between factor inputs. This is of utmost importance for the purposes of this study. Since direct estimation of the labour demand equation was not possible, structural changes would need to be inferred from the estimated elasticities and technological changes. The overall advantages of the translog function over the other two functional forms, CobbDouglas and CES, are summarized by Burgess (1975), who states that:

The assumption that the translog production function provides an exact representation of the technology in the relevant range would appear to be less restrictive, and presumably more acceptable on a priori grounds.....[it] reduces to the Cobb-Douglas form when all second order terms vanish......[and] provides a second-order approximation to the CES form with nonlinear restrictions on the parameters (Burgess, 1975, p. 106).

This type of function represents the logarithm of output as a quadratic function of the logarithm of factors of production. In general, the translog production function for inputs has the following form:

$\ln Q=\alpha+\sum_{i=1}^{n} \beta_{i} \ln X_{i}+\frac{1}{2} \sum_{i=1}^{n} \sum_{j=1}^{n} \beta_{i j} \ln X_{i} \ln X_{j}$

where $Q$ represents output, $x_{j}$ is the ith input, and $\alpha$ and $\beta$ are parameters to be estimated. Varian (1978) notes that in any empirical analysis all available information should be included. However, in estimating a production function the 
quality of factor inputs are not considered; a rise in output may not, necessarily, be a result of an increase in the level of inputs but an improvement of their quality. Thus, the estimated values could be biased. Furthermore, Jorgensen (1986) holds that:

This approach [production function] has the disadvantage of imposing constraints on patterns of production, hereby frustrating the objective of determining these patterns empirically (Jorgensen, 1986, p. 1843).

Jorgensen argues that the dual formulation avoids such arbitrary constraints. The theory of duality allows for an alternative approach to production theory. Duality implies that the cost function is a complete representation of the production function. In other words, all relevant information about the production process that is included in the production function is depicted in the cost function. Researchers are therefore inclined to estimate cost functions, as these functions embody factor prices, and infer the underlying technological changes.

The general specification for the translog cost function can be expressed as :

$$
\begin{aligned}
& \ln C=\alpha_{0}+\sum_{i} \beta_{i} \ln P_{i}+\frac{1}{2} \sum_{i} \sum_{j} \beta_{i j} \ln P_{i} \ln P_{j} \\
& +\lambda_{Q} \ln Q+\frac{1}{2} \lambda_{Q Q}(\ln Q)^{2}+\sum_{i} \lambda_{i} \ln Q \ln P_{i} \\
& +\gamma_{T} T+\frac{1}{2} \gamma_{T T}(T)^{2}+\sum_{i} \gamma_{i T} \ln P_{i}
\end{aligned}
$$

where $C$ is total cost, $Q$ is industry output, $T$ is an index of technology, and $\beta_{s}$ $\gamma_{s}$ and $\lambda_{s}$ are parameters to be estimated. According to Sheperd's lemma, the derived demand equations for factor inputs can be obtained by partial differentiation of total cost with respect to factor prices:

$$
\frac{d c}{d P_{i}}=x_{i}
$$


where $P_{i}$ is the price of input $i, x_{i}$ is the cost minimizing level of input $i$. In a logarithmic form:

$\frac{d \ln C}{d \ln P}=\frac{d C}{d P_{i}} \cdot \frac{P_{i}}{C}$

By substituting (1) in (2) the cost share of the ith input can be obtained:

$\frac{d \ln C}{d \ln P_{i}}=\frac{P_{i} x_{i}}{C}=S$

where $S_{i}$ is the cost share of the ith factor input:

$S_{i}=\beta_{i}+\frac{1}{2} \sum_{j} \beta_{i j} \ln P_{j}+\lambda \ln Q+\gamma_{i} T$

A necessary condition for a cost function is that it be linear homogeneous in factor prices. In other words, for a given level of output, total cost must increase proportionately with input prices. This requires the imposition of the following restrictions on the parameters:

$$
\begin{aligned}
& \sum_{i} \beta_{i}=1 \\
& \sum_{i} \beta_{i j}=0 \\
& \sum_{i} \lambda_{i}=0 \\
& \sum_{i} \gamma_{i}=0
\end{aligned}
$$

Similar restrictions are imposed on the share equations, which implies that:

$$
\sum_{i} S_{i}=1
$$


Furthermore, the quadratic approximation of this function requires that the cross partial derivatives be symmetric:

$\beta_{i j}=\beta_{j i}$

The singularity of the system of equations requires that one of the share equations be omitted from the system. The stumpage equation was therefore omitted to form a non-singular system of equations. However, the preceding restrictions imply that the parameters of any share equations can be obtained from the remainder.

As shown above, the cost shares are derived as the partial derivatives of the total cost function. The cost shares of each factor can then be given as:

$$
\begin{aligned}
& S_{R}=\beta_{R}+\beta_{R R} \ln P_{R}+\beta_{R K} \ln P_{K}+\beta_{R L} \ln P_{L}+\lambda \ln Q+\gamma_{i} T \\
& S_{K}=\beta_{K}+\beta_{K R} \ln P_{R}+\beta_{K K} \ln P_{K}+\beta_{K L} \ln P_{L}+\lambda n Q+\gamma_{I} T \\
& S_{L}=\beta_{L}+\beta_{L R} \ln P_{R}+\beta_{L K} \ln P_{K}+\beta_{L L} \ln P_{L}+\lambda \ln Q+\gamma_{I} T
\end{aligned}
$$

Since the share equations sum to unity, the following conditions can be imposed on estimates of parameters (Berndt and Christensen, 1973):

$$
\begin{aligned}
& \beta_{R}+\beta_{K}+\beta_{L}=1 \\
& \beta_{R R}+\beta_{R K}+\beta_{R L}=0 \\
& \beta_{K R}+\beta_{K K}+\beta_{K L}=0 \\
& \beta_{L R}+\beta_{L K}+\beta_{L L}=0
\end{aligned}
$$


By symmetry:

$\beta_{R K}=\beta_{K R} \quad \beta_{R L}=\beta_{L R}$ and $\beta_{L K}=\beta_{K L}$

Hence:

$\beta_{R K}=-\left(\beta_{K K}+\beta_{L K}\right)$

$\beta_{R L}=-\left(\beta_{K L}+\beta_{L L}\right)$

Then:

$\beta_{R R}=-\left(\beta_{K R}+\beta_{L R}\right\}$

Conventionally, the direct partial elasticity of substitution between factors $x_{i}$ and $x_{j}$ is given by:

$\delta_{i j}=-\frac{\partial \ln \left(\frac{x_{i}}{x_{j}}\right)}{\partial \ln \left(\frac{P_{i}}{P_{j}}\right)}$

when output and all inputs except $x_{i} x_{j}$ are held constant. According to Uzawa (1962), the Allen partial elasticities of substitution $\delta_{i j}$ between factor inputs can be obtained from the cost function:

$\delta_{i j}=\frac{C C_{i j}}{C_{i} C_{j}}$

Where

$c_{i}=\frac{\partial}{\partial \mathrm{P}_{i}}$ $C_{i f}=\frac{\partial^{2} C}{\partial \mathrm{P}_{1} \partial \mathrm{P}_{i}}$ 
For the translog cost function, the Allen partial elasticity of substitution is given by:

$$
\begin{array}{ll}
\delta_{i j}=\frac{\beta_{i j}+S_{i}\left(S_{i}-1\right)}{S_{i}^{2}} & i j=K, L, R \\
\delta_{i j}=\frac{\beta_{i j}+S_{i} P_{j}}{S_{i} S_{j}} & i=K, L, R
\end{array}
$$

The Allen partial elasticity of substitution measures the rate at which factor inputs can be substituted for one another for a given level of output. Generally, high values of elasticities of substitution can be regarded as a reflection of substantial possibility for structural changes and lower values will imply little or no change.

The price elasticity of demand $E_{i j}$ is generally defined as:

$E_{i j}=\frac{\partial \ln X_{i}}{\partial \ln P_{j}}$

where output and all input prices except $P_{j}$ are held constant. For the translog cost function, the price elasticity of demand for factors of production is given as:

$$
\begin{aligned}
& E_{i j}=S_{i} \delta_{i j} \\
& E_{i j}=S_{j} \delta_{i j}
\end{aligned}
$$

Duality allows the estimation of factor productivity through the cost function. Conversely, technological changes and fluctuations in factor prices lead to shifts in the cost function. Thus, productivity can be viewed as the rate of change of total cost:

$$
\frac{\partial \ln C}{\partial T}=\gamma_{T}+\gamma_{T T} T+\gamma_{T O} \ln Q+\sum_{i} \gamma_{\pi} \ln P_{i}
$$


However, productivity growth is correctly expressed as the rate of reduction in total cost with respect to time, holding output and prices of factor inputs constant. Symbolically:

$-\frac{\partial \ln C}{\partial T}=-\left[\gamma_{T}+\gamma_{\pi} T+\gamma_{T D} \ln Q+\gamma_{\pi} \ln P,\right]$

As the above specification of productivity growth assumes that output is held fixed, it is appropriate to use an alternative measure of total productivity which shows the negative rate of returns to scale of total cost diminution. In other words, it is the ratio of cost diminution and the elasticity of cost with respect to output.

Symbolically:

$\frac{\partial \ln Q}{\partial T}=\frac{\partial \ln C}{\partial T} / \frac{\partial \ln C}{\partial \ln Q}=-\frac{\gamma_{T}+\gamma_{T T} T+\gamma_{T a} \ln Q+\sum_{T} \gamma_{t t} \ln P_{1}}{\lambda_{a}+\gamma_{T Q} T+\gamma_{a Q} \ln Q+\sum \lambda_{t a} \ln P_{1}}$

Factor productivity, which reflects the productivity growth of individual inputs in total productivity, can then be obtained by assuming other factor inputs held constant. Symbolically:

$\partial \ln \left(\frac{a}{x_{1}}\right) / \partial T=(\partial \ln Q / \partial T)-\left(\partial \ln x_{t} / \partial T\right)=(\partial \ln Q / \partial T)-\left(\gamma_{t} s_{1}\right)$

Returns to scale refer to the relationship between output and inputs, it is generally defined as a proportion of change in output resulting from proportionate change in all factor inputs. The nature of returns to scale will influence the way in which the cost of production varies with different levels of output. For instance, increasing returns to scale denote that a change in output requires a smaller proportional change in inputs. Gollop and Roberts (1981) suggest that the elasticity of cost with respect to output can be expressed as a measure of scale 
economies. Hence:

$R T S=\frac{\partial \ln Q}{\partial T} /-\frac{\partial \ln C}{\partial T}=1 / \frac{\partial \ln C}{\partial \ln Q}$

If the observed value equals unity then it is characterized as constant returns to scale. Estimates of greater and less than unity demonstrate increasing and decreasing returns to scale, respectively. ${ }^{1}$

\section{DATA CONSTRUCTION AND SOURCES}

Estimation of a translog cost function requires data on prices and quantities of output and inputs. Data were assembled for the period 1950-86 for the Douglas-fir region. All the required data on volume and value of forest products were obtained from the U.S. Department of Agriculture Forest Service. The price of raw material (logs) is the value of timber harvested in the Douglas-fir region. Employment data for SIC 2421, sawmills and planing mills, and 2432, 2435 and 2436 , veneer and plywood mills, were obtained from Wall and Oswald (1975) and through Oregon and Washington State Employment Divisions. It should be added, however, that employment data for the plywood industry were not available prior to 1963 . Thus, analysis of this industry is focused on the post 1963 period. Levels of $\log$ inputs were derived through a simple multiplication of levels of output for each industry by the recovery conversion factor, for the Douglas fir region, for each industry. The recovery conversion factor is a simple ratio used by the Forest Service to determine the product yields of timber it reflects the square fleet of plywood and board feet of lumber obtained per cubic feet of log input. This index was also provided by the forest service.

${ }^{1}$ Returns to scale can also be calculated using the formula ${ }^{1-\frac{\partial \ln C}{\partial \ln Q}}$ and this was used for the purpose of this study (see Christensen and Greene, 1976). 
The change in SIC coding in 1975 subdivided the veneer and plywood industry (2432) into softwood (2436) and hardwood (2435). Such a change can create problems if time series analyses are undertaken. However, in order to counteract this problem, industry analysts suggest summing SICs 2435 and 2436 and continuing to treat them as SIC 2432. They point out that veneer and plywood plants in this region have utilized various combinations of hardwood and softwood in their production processes and it may not actually be possible to categorize individual plants into specific groups. Furthermore, many plants switch back and forth in their usage of softwood and hardwood depending on the market demand. More importantly, it should be remembered that the softwood plywood industry is by far the more dominant of the two, employing over 95 percent of the total work force in the region's plywood industry. Labour prices are the average annual wages for the lumber and wood products industry; they have not been adjusted to consider the number of hours and days worked. The numbers reflect the average of the states of Oregon and Washington and were obtained from the state employment divisions.

One of the simplest and most reliable methods of measuring levels of capital stock is the perpetual inventory approach:

$K_{t}=I_{t}+(1-\mu) K_{t-1}$

where, $K_{t}$ is the capital stock in time $t, l_{t}$ is the level of investment in the same period and $\mu$ is the rate of capital depreciation. In constructing a time series of capital stock, observation of levels of capital expenditure, rate of economic depreciation and a benchmark level of capital stock for the industry were required. However lack of investment data at the county level and incidents of missing values in state data meant extra estimation procedures. 
Missing values, at the state level, where either estimated by regressing available observations on new capital expenditure against a set of exogenous variables (see Merrifield and Singleton, 1986, P. 226), or were extrapolated using previous observations. The list of regressors included output of the industry, average earnings in the lumber and wood products industry, price of output, rental cost of capital, the real interest rate (Economic Report of the President, 1987) and a time trend. The real interest rate was obtained by dividing the federal bank discount rate by the implicit price deflator. The rental cost of capital was estimated using the same technique as Merrifield and Singleton (1986):

$c_{k}=P_{k}(r+\mu) /(1-T)$

where $C_{k}$ is the rental cost of capital, $P_{k}$ is the opportunity cost of one dollar's worth of capital and is measured by the implicit price deflator for non-residential fixed investment, $r$ is the prime rate charged by banks, (Economic Report of the President 1987) $\mu$ is the rate of capital depreciation for the industry and was obtained from Merrifield (1982), and $T$ represents the federal corporate marginal tax rate.

There has been much controversy over an appropriate measure of economic depreciation (Kendrick, 1976; Young and Musgrave, 1980; Hulten and Wykoff, 1980; Coen, 1980). Nonetheless it is generally agreed that there is no single acceptable method of estimating depreciation rates. For the purpose of this study an average annual depreciation rate of 1097 was used; thus, constant geometric depreciation was assumed. This rate had been computed by Merrifield (1982) for the Pacific Northwest forest products industry. Data on the marginal tax rate were obtained from Auerbach (1983). Missing observations for 1983 to 1986 were 
forecasted by the ordinary least squares technique and, for the 1950-52 period, were computed by averaging the ratio of Auerbach's estimates to Seater's (1982) over the period 1953-75 and then multiplying this ratio by Seater's figures for 1950 to 1952.

The earliest observation of the level of capital stock, at the state level, is for 1958 and it is only available at the two digit level Standard Industrial Classification (SIC) from the Census of Manufacturers and Annual Survey of Manufacturers. The available information, therefore, had to be adjusted to apply to three digit SIC from the Census of Manufacturers and Annual Survey of Manufacturers. Benchmarks for the lumber and plywood industries were established by adjusting capital stock levels for the lumber and wood products (SIC 24) to the average ratio of investment for lumber (SIC 242) and plywood (SIC 243) industries to SIC 24 for the sample period (see Merrifield and Singleton, 1986).

The second problem, lack of expenditure data at the county level, meant formulating a proportional measure to derive capital expenditure data for the Douglas-fir region. An index had to be developed to use state investment data to estimate county level investments. Although the census of manufacturers, printed every five years, provides expenditure data for selected counties it contains many missing values, a result of disclosure laws.

Since expenditure data at the state level are available for most of the sample period, levels of investment for the Douglas-fir region were estimated on the basis of the ratio of annual rate of change in output in the Douglas-fir region to that for the Pacific Northwest. The ratio of changes in output was chosen in preference to 
a ratio of output to avoid problems of collinearity. In view of recent employment decline in the wood products industry, output was considered a more accurate reflector of investment changes than employment. The annual rate of change in output for the two sub-regions, Douglas-fir and Ponderosa-pine, and for the Pacific Northwest region were then calculated. However, in converting state investment data to a lower level of aggregation a minor problem was encountered. The rate of change in the sub-region was, occasionally, greater than that in the rate for the Pacific Northwest. Hence, the ratios obtained, between the sub-region and the Pacific Northwest region, were greater than one; this problem occurred in both positive and negative cases. This would have implied that the level of investment in the sub-region could be greater than the Pacific Northwest. In order to overcome this problem, hypothetical output levels were calculated for each time period. As a large portion of investment is for replacement of old capital, hypothetical output levels were estimated on the assumption that volume of output declines if no new investment is undertaken in the industry. These hypothetical levels were then computed on the basis of the rate of capital depreciation for the industry. More simply, if no new investment was injected into the area, a region's output was assumed to decline by the same rate as capital depreciation. This hypothetical level was considered as the base for each year and, if actual output was less than the base level, then it was assumed that the region did not benefit from any new investment. However, when actual output exceeded the hypothetical level, investment between the two sub-regions was allocated on the basis of the difference between the actual level of output and the hypothetical level. Also, in times of negative movements in the rate of change in output, the reverse ratio was utilized and positive signs were assigned to each value. This meant allocating a greater percentage of the investment to the region with a 
smaller negative value. A higher negative value implies that the level of output in the region has declined by a greater percentage thus, by definition a smaller proportion of investment was attracted to the region. 


\section{CHAPTER V}

\section{EMPIRICAL RESULTS}

The estimation procedure in this section is based on a simple model of the cost function with three factor inputs, labour $(L)$, capital $(K)$ and the raw material $(R)$ :

$C=f\left(P_{L}, P_{K}, P_{r}, Q, T\right)$

where $C$ is total cost, $P_{L^{\prime}}, P_{K^{\prime}}, P_{r}$ reflect prices of labour, capital and stumpage respectively, $Q$ is level of output and $T$ denotes time. Generally, the cost function relates factor prices to cost of the output. It shows the minimum total cost with input prices $\left(P_{P} P_{k}, P_{p}\right)$ required to produce a given level of output (a).

The parameters of the total cost function are jointly estimated with the cost share equations. Since the cost share equations are derivatives of the total cost function they do not contain any error terms. Disturbance terms are, therefore, added to the total cost and the share equations to account for any random error. Furthermore, since the cost shares always add to unity it suggests that their disturbances are not mutually independent. This implies that the covariance matrix is singular, and therefore, one of the equations must be omitted from the system of equations. In this case the raw material equation was $S_{r}$ deleted. However, symmetry allows the estimation of the parameters of $S_{r}$ to be derived from the other two equations. The estimated system of equations can be 
expressed as follows:

$$
\begin{aligned}
& \ln C=\alpha_{a}+\sum_{i} \beta_{i} \ln P_{i}+\frac{1}{2} \sum_{i} \sum_{j} \beta_{I J} \ln P_{i} \ln P_{J} \\
& +\lambda_{a} \ln Q+\frac{1}{2} \lambda_{a O}(\ln Q)^{2}+\sum_{i} \lambda_{i} \ln Q \ln P_{i} \\
& +\lambda_{T} T+\frac{1}{2} \lambda_{T \pi}\left(T^{2}\right)+\sum_{i} \lambda_{I T} \ln P_{i} \\
& S_{K}=\beta_{K}+\beta_{K R} \ln P_{R}+\beta_{K K} \ln P_{K}+\beta_{K L} \ln P_{L}+\lambda \ln Q+\gamma_{i} T \\
& S_{L}=\beta_{L}+\beta_{L R} \ln P_{R}+\beta_{L K} \ln P_{K}+\beta_{L L} \ln P_{L}+\lambda \ln Q+\gamma_{i} T
\end{aligned}
$$

where the notations are as above. The system of equations is estimated by Zeliner's seemingly unrelated equation procedure (Zellner, 1962). The iteration of this technique, until convergence, ensures a non-singular residual covariance matrix (Kmenta and Gilbert, 1968), resulting in maximum likelihood estimates; this allows invariance as to the deletion of any one of the share equations.

Tables III and IV present estimates of the translog cost function for the lumber and plywood industries respectively. A number of parameters have no direct economic interpretation but are required for deriving elasticities of substitution and price elasticities and for testing the possible forms of the cost function, i.e., homotheticity, homogeneity, etc. The cost function appears well behaved the predicted share values are all positive (see Tables V.- VIII); and own price elasticities are negative with the exception of one. A cost function is considered well behaved if it is monotonic (increasing) and concave in input prices. Berndt and Wood (1975) hold that the first condition is satisfied if the fitted cost shares are non-negative. The second condition requires that the Hessian matrix is negative at every data point. But, as Hunt (1984) has pointed 
TABLE III

\section{LUMBER INDUSTRY}

COST FUNCTION

$\underline{\text { Coefficient }}$

53.318

$-0.40156$

$-0.39585$

1.797409

0.15904

0.077903

$-0.2284762$

$-0.004235$

$-0.154881$

$-0.073668$

$-7.6865$

0.7114

$-0.029938$

0.020868

$-0.0508$

0.46412

0.0021127

$-0.0064752$

0.002093

0.0043822

$-0.037306$ $\underline{\text { T-Ratio }}$

3.6753

$-1.9574$

$-1.9281$

4.3892

11.315

2.9515

$-20.531$

$-0.30879$

$-15.2539$

$-4.0861$

$-3.1789$

3.5287

1.8275

1.102

$-1.5732$

4.5708

6.9338

$-6.3525$

1.8898

3.0544

$-4.461$

\section{$\underline{\mathrm{R}^{2}}$}

S.E.E

0.97

0.90

0.08

0.021

0.033

0.83

Labour Share Equation

Capital Share Equation 
TABLE IV

\section{PLYWOOD INDUSTRY COST FUNCTION}

Coefficient

$\alpha_{0}$
$\beta_{K}$
$\beta_{L}$
$\beta_{R}$
$\beta_{K K}$
$\beta_{L L}$
$\beta_{R R}$
$\beta_{K L}$
$\beta_{K R}$
$\beta_{L R}$
$\lambda_{Q}$
$\lambda_{Q Q}$
$\lambda_{Q L}$
$\lambda_{Q K}$
$\lambda_{Q R}$
$\gamma_{T}$
$\gamma_{T T}$
$\gamma_{T L}$
$\gamma_{T K}$
$\gamma_{T R}$
$\gamma_{T Q}$
68.795

0.017964

0.69946

0.2825765

0.18944

0.15491

$-0.2349987$

$-0.054672$

$-0.1347633$

$-0.1002353$

$-10.103$

0.89564

$-0.07735$

0.0023255

0.07502

0.53794

0.0015989

$-0.001432$

0.0010280

0.000404
$-0.041913$ $\underline{\text { T-Ratio }}$

1.8571

0.0328

1.5423

0.6353

8.2137

5.5967

$-41.9863$

$-2.2535$

$-18.0837$

$-13.3355$

$-1.6999$

1.8774

$-1.8587$

0.0491

2.0900

1.8142

1.2771

$-0.4235$

0.2945

0.2009

$-1.752$

S.E.E

0.040

0.010

0.014

Labour Share Equation

0.99

0.97

0.97

Capital Share Equation 
TABLE V

SHARE OF FACTOR INPUTS

(OBSERVED VALUES)

LUMBER INDUSTRY

$\begin{array}{llll}\text { Year } & \text { Labour } & \text { Capital } & \text { LOG } \\ & & & \\ 1951 & 0.4476673 & 0.1489198 & 0.4034129 \\ 1952 & 0.4019805 & 0.2000475 & 0.3979719 \\ 1953 & 0.4170481 & 0.2260418 & 0.3569101 \\ 1954 & 0.4020651 & 0.2500158 & 0.3479191 \\ 1955 & 0.4118048 & 0.2108601 & 0.3773351 \\ 1956 & 0.3355157 & 0.2058787 & 0.4586055 \\ 1957 & 0.3125075 & 0.2584922 & 0.4290003 \\ 1958 & 0.2881974 & 0.2860301 & 0.4257725 \\ 1959 & 0.302025 & 0.2775406 & 0.4204344 \\ 1960 & 0.2760134 & 0.2977078 & 0.4262788 \\ 1961 & 0.275281 & 0.2931543 & 0.4315647 \\ 1962 & 0.3101393 & 0.2436073 & 0.4462534 \\ 1963 & 0.3026893 & 0.2551537 & 0.442157 \\ 1964 & 0.3235704 & 0.2225454 & 0.4538842 \\ 1965 & 0.302309 & 0.2240553 & 0.4736357 \\ 1966 & 0.2841005 & 0.199942 & 0.5159575 \\ 1967 & 0.2320682 & 0.2023816 & 0.5655502 \\ 1968 & 0.2451648 & 0.2060527 & 0.5487825 \\ 1969 & 0.2444691 & 0.2115996 & 0.5439313 \\ 1970 & 0.2585034 & 0.2687992 & 0.4726974 \\ 1971 & 0.2658472 & 0.2318428 & 0.5023101 \\ 1972 & 0.263287 & 0.186806 & 0.549907 \\ 1973 & 0.2535806 & 0.2538137 & 0.4926057 \\ 1974 & 0.2247897 & 0.279349 & 0.4958613 \\ 1975 & 0.2457642 & 0.2389527 & 0.5152831 \\ 1976 & 0.2165098 & 0.2414922 & 0.5419979 \\ 1977 & 0.1955208 & 0.2390215 & 0.5654577 \\ 1978 & 0.1751032 & 0.3023619 & 0.5225349 \\ 1979 & 0.1818344 & 0.3112745 & 0.5068911 \\ 1980 & 0.1779536 & 0.405474 & 0.4165724 \\ 1981 & 0.1883313 & 0.4217171 & 0.3899516 \\ 1982 & 0.204276 & 0.521561 & 0.274163 \\ 1983 & 0.2042531 & 0.4337331 & 0.3620138 \\ 1984 & 0.2051568 & 0.4636562 & 0.3311871 \\ 1985 & 0.2193229 & 0.4256384 & 0.3550387 \\ 1986 & 0.2004982 & 0.3746999 & 0.4248019\end{array}$


TABLE VI

SHARE OF FACTOR INPUTS

(OBSERVED VALUES)

PLYWOOD INDUSTRY

Labour Capital Log

$\begin{array}{llll}1963 & 0.443557 & 0.2579601 & 0.298483 \\ 1964 & 0.4717629 & 0.220029 & 0.3082081 \\ 1965 & 0.4643418 & 0.2066745 & 0.3289837 \\ 1966 & 0.4410365 & 0.1889786 & 0.3699849 \\ 1967 & 0.3849551 & 0.1873352 & 0.4277096 \\ 1968 & 0.3841827 & 0.2163248 & 0.3994924 \\ 1969 & 0.3725456 & 0.2230385 & 0.404416 \\ 1970 & 0.3678836 & 0.2834568 & 0.3486596 \\ 1971 & 0.3629093 & 0.2841177 & 0.3529729 \\ 1972 & 0.368305 & 0.22386 & 0.407835 \\ 1973 & 0.3726443 & 0.226174 & 0.4011817 \\ 1974 & 0.3468368 & 0.2549914 & 0.3981718 \\ 1975 & 0.3236076 & 0.2646678 & 0.4117246 \\ 1976 & 0.2976684 & 0.2403295 & 0.4620021 \\ 1977 & 0.277198 & 0.2381731 & 0.484629 \\ 1978 & 0.2535987 & 0.2983952 & 0.4480161 \\ 1979 & 0.2603593 & 0.3143057 & 0.4253349 \\ 1980 & 0.2507726 & 0.3909309 & 0.3582965 \\ 1981 & 0.2570204 & 0.4082178 & 0.3347618 \\ 1982 & 0.2865067 & 0.4718193 & 0.2416739 \\ 1983 & 0.29417 & 0.3962938 & 0.3095362 \\ 1984 & 0.2699444 & 0.4572289 & 0.2728267 \\ 1985 & 0.2624411 & 0.4621565 & 0.2754024 \\ 1986 & 0.2460756 & 0.4268021 & 0.3271223\end{array}$


TABLE VII

SHARE OF FACTOR INPUTS

(PREDICTED VALUES)

\section{LUMBER INDUSTRY}

\begin{tabular}{llll} 
Year & Labour & Capital & \multicolumn{1}{c}{ LOG } \\
& & & \\
1951 & 0.3936598 & 0.1810206 & 0.4253195 \\
1952 & 0.3878537 & 0.2256871 & 0.3864593 \\
1953 & 0.3907978 & 0.2578509 & 0.3513513 \\
1954 & 0.3887456 & 0.255102 & 0.3561524 \\
1955 & 0.3779055 & 0.2114143 & 0.4106803 \\
1956 & 0.3421661 & 0.1828239 & 0.47501 \\
1957 & 0.3380376 & 0.2157687 & 0.4461936 \\
1958 & 0.3406695 & 0.251926 & 0.4074045 \\
1959 & 0.3434139 & 0.2644532 & 0.3921329 \\
1960 & 0.3249818 & 0.266062 & 0.4089563 \\
1961 & 0.3222637 & 0.2744159 & 0.4033204 \\
1962 & 0.3277639 & 0.2485284 & 0.4237077 \\
1963 & 0.3268829 & 0.2678238 & 0.4052933 \\
1964 & 0.3257367 & 0.2536283 & 0.420635 \\
1965 & 0.3142323 & 0.2272819 & 0.4584859 \\
1966 & 0.2926975 & 0.2088854 & 0.4984171 \\
1967 & 0.2646772 & 0.2090835 & 0.5262393 \\
1968 & 0.2740815 & 0.2099584 & 0.51596 \\
1969 & 0.2518776 & 0.2158813 & 0.5322411 \\
1970 & 0.2631241 & 0.2704789 & 0.466397 \\
1971 & 0.2628649 & 0.2503331 & 0.486802 \\
1972 & 0.2520854 & 0.2060458 & 0.5418687 \\
1973 & 0.2496755 & 0.2287447 & 0.5215799 \\
1974 & 0.2312374 & 0.2298264 & 0.5389362 \\
1975 & 0.2216404 & 0.2074977 & 0.5708619 \\
1976 & 0.2099475 & 0.2210557 & 0.5689968 \\
1977 & 0.0983295 & 0.2034962 & 0.5981743 \\
1978 & 0.1911811 & 0.2341656 & 0.5746533 \\
1979 & 0.1876683 & 0.268946 & 0.5433858 \\
1980 & 0.1796443 & 0.3246419 & 0.4957138 \\
1981 & 0.1799481 & 0.3592472 & 0.4608048 \\
1982 & 0.2046081 & 0.4568664 & 0.3385255 \\
1983 & 0.2093034 & 0.4457681 & 0.3449285 \\
1984 & 0.2122335 & 0.4828565 & 0.30491 \\
1985 & 0.2091822 & 0.4782411 & 0.3125768 \\
1986 & 0.198191 & 0.4631857 & 0.3386233
\end{tabular}


TABLE VIII

SHARE OF FACTOR INPUTS

(PREDICTED VALUES)

PLYWOOD INDUSTRY

$\begin{array}{llll} & \text { Labour } & \text { Capital } & \text { Log } \\ 1963 & 0.4657333 & 0.2398462 & 0.2944205 \\ 1964 & 0.4661199 & 0.2180318 & 0.3158484 \\ 1965 & 0.4529963 & 0.2056695 & 0.3413343 \\ 1966 & 0.4256779 & 0.2012044 & 0.3731177 \\ 1967 & 0.3913796 & 0.2300092 & 0.4085284 \\ 1968 & 0.3930003 & 0.2222412 & 0.3847585 \\ 1969 & 0.3721402 & 0.2392558 & 0.3886039 \\ 1970 & 0.3820037 & 0.2901452 & 0.3278511 \\ 1971 & 0.3749272 & 0.2742813 & 0.3507915 \\ 1972 & 0.3691717 & 0.2092003 & 0.421628 \\ 1973 & 0.3577363 & 0.2447629 & 0.3975009 \\ 1974 & 0.3319756 & 0.2754847 & 0.3925398 \\ 1975 & 0.3187069 & 0.2875467 & 0.3937464 \\ 1976 & 0.2948562 & 0.2497304 & 0.4554133 \\ 1977 & 0.2741982 & 0.2347603 & 0.4910415 \\ 1978 & 0.253207 & 0.2650843 & 0.4817087 \\ 1979 & 0.2444788 & 0.3072164 & 0.4483048 \\ 1980 & 0.2472086 & 0.3633501 & 0.3894413 \\ 1981 & 0.2485594 & 0.392641 & 0.3587995 \\ 1982 & 0.2933074 & 0.4657226 & 0.24097 \\ 1983 & 0.2774656 & 0.4262657 & 0.2962686 \\ 1984 & 0.275785 & 0.4593324 & 0.2649191 \\ 1985 & 0.2800077 & 0.4486706 & 0.2713217 \\ 1986 & 0.2559119 & 0.4274722 & 0.3166159\end{array}$


out this requirement can be satisfied if own price elasticities are non-positive. Denny and Fuss (1977) have noted that the translog share equations often have poor explanatory powers; however, the share equation regressions for both industries, have high $R^{2}$.

Duality implies that changes in production technology can be described equally well by the cost function. The estimated value of $\gamma_{T}$ represents the negative of the rate of technical change. In other words, it shows the negative of the rate of growth of total cost with respect to time with output and factor prices held constant. The bias of technical change shows the change in the share of an input in the value of output. A neutral technical change would indicate a shift in the cost function with factor shares remaining unchanged. But a biased technical change suggests that factor shares do not remain unchanged. As Jorgensen (1986) notes, however, the biases of technical change are not necessarily a result of changes in the production technology but can be caused by factor substitution. The effects of bias of technical change can be obtained by examining the parameters $\gamma_{T L}, \gamma_{T K}$ and $\gamma_{T R}$, which reflect the logarithmic second partial derivative of the cost function with respect to time and the factor inputs. If the estimated coefficient has a positive value then technical change is using more of the factor and if negative then it has the opposite effect.

The results suggest that Hick's neutrality of technical change does not hold for either industry. These parameters show the relative change in the share of each factor with respect to time. The coefficients tend to suggest that in both industries, technological change has been labour-saving and capital-and log-using. In the case of the plywood industry, the coefficients are not significant. The 
predicted share values suggest that the share of capital has increased substantially during the sample period. Further, similar analysis were undertaken using nominal prices instead of real prices, and the values of $\gamma_{T L}$, and $\gamma_{T K}$ were found to be highly significant. One possible reason for the insignificance of these parameters in the plywood industry could be the relatively shorter sample period for this industry. In fact, reducing the sample range for the lumber industry produces similar results. Coefficients $\gamma_{T L}$ and $\gamma_{T K}$ are no longer significant, although their signs remain the same. In addition, the own price elasticity for logs also changes its sign to positive. $\gamma_{T T}$ shows the constant rate of change of the negative of the rate of technical change which is the derivative of the negative of the rate of technical change. In other words, it shows the rate of acceleration (deceleration) of technical change. If $\gamma_{T T}$ is $>0$ the rate of technical change is decreasing over time and if $\gamma_{T \tau}$ is $<0$ then it is increasing. The obtained values indicate that the rate is decreasing for both industries. A test of homotheticity was undertaken by restricting parameters $\lambda_{i Q}=0$. Parametric restrictions are examined by the log likelihood ratio test. The hypothesis that the production function is homothetic cannot be rejected at the one percent significance level.

Most of the bias towards greater log usage could be attributed to the increasing utilization of small diameter logs. But unfortunately there are no readily available data on the changing pattern of timber usage. The general decline in the availability of old growth, high quality timber and the rising trend in the use of new growth, low quality, timber have meant a greater proportional requirement of logs for any given level of output. Abt (1987) argues that either the greater proportional use of stumpage is attributable to increasing utilization of marginal logs or the major share of output is produced by the more inefficient 
mills. Other studies of the Pacific Northwest Lumber and Plywood industries (Stier, 1980; Gerber and White, 1982; Merrifield and Haynes, 1985; Merrifield and Singleton, 1986; Abt, 1987) have also shown similar types of results, although with some inconsistencies. For instance, Merrifield and Singleton (1986) found that technological change has been log-and capital-using and labour-saving for the plywood industry, but for the lumber industry labour and log have switched roles. This discrepancy is attributed to the fact that technological changes may not have been fully implemented. Merrifield and Haynes (1985) showed that in the plywood industry technological change was labour-saving and capital-using for the Douglas-fir region and capital-saving for the Ponderosa-pine region. As for the lumber industry they found no significant technological change in the Douglas-fir region and only log saving for their Ponderosa-pine region. However, Stier's (1980) study on the U.S. forest products found technological change to be utilizing less labour but deploying greater capital. Similar results were exhibited by Gerber and White (1982). In a recent study of several forest regions of the U.S., Abt (1987) concluded that the bias of technological change in the Western region has been capital-using and log saving.

Tables IX and X show the Allen partial elasticities of substitution and price elasticities; both elasticities are evaluated at mean values. The partial elasticities of substitution denote the degree by which a factor can be substituted for another; they indicate possible changes in factor usage as a result of movements in factor prices. The results provide further support for the employment of a translog function as opposed to a Cobb-Douglas or a CES function, as the estimated elasticities are different from zero or one. The evidence indicates substitution possibilities between capital and labour as well as logs and labour. Capital and 
TABLE IX

ALLEN PARTIAL ELASTICITIES OF SUBSTITUTIONS

\begin{tabular}{|l|ccc|}
\hline \multirow{4}{*}{ Labour } & Labour & Capital & Log \\
\cline { 2 - 4 } & & & \\
\hline Capital & $-0.605^{*}$ & $0.452^{*}$ & $0.185^{* *}$ \\
& {$[0.247]$} & {$[0.260]$} & {$[0.061]$} \\
Log & & -0.222 & $-0.232^{* *}$ \\
& & {$[0.288]$} & {$[0.068]$} \\
& & & 0.020 \\
& & & {$[0.042]$} \\
\hline
\end{tabular}

\begin{tabular}{|c|c|c|c|}
\hline \multicolumn{4}{|c|}{ Lumber Industry } \\
\hline & Labour & Capital & $\log$ \\
\hline Labour & $\begin{array}{l}-1.592^{* *} \\
{[0.357]}\end{array}$ & $\begin{array}{c}0.966^{* *} \\
{[0.181]}\end{array}$ & $\begin{array}{l}0.412^{* *} \\
{[0.147]}\end{array}$ \\
\hline Capital & & $\begin{array}{l}-1.525^{* *} \\
{[0.136]}\end{array}$ & $\begin{array}{l}-0.265^{* *} \\
{[0.081]}\end{array}$ \\
\hline $\log$ & & & $\begin{array}{c}-0.094^{*} \\
{[0.055]}\end{array}$ \\
\hline
\end{tabular}

Notes: Numbers in parenthesis are the standard errors. * and ** indicate significance at the 0.95 and 0.99 confidence level respectively. Standard errors were calculated using the formula S.E. $\left(\sigma_{i j}\right)=S . E .\left(\beta_{i j}\right) / S_{i} S_{j}$ 
TABLE $X$

OWN AND CROSS PRICE ELASTICITIES

\begin{tabular}{|l|ccc|}
\hline \multicolumn{4}{|c|}{ Plywood Industry } \\
\hline \multirow{4}{*}{ Labour } & Labour & Capital & Log \\
\cline { 2 - 4 } & & & \\
\hline \multirow{3}{*}{ Capital } & $-0.203^{*}$ & $0.135^{*}$ & $0.068^{* *}$ \\
& {$[0.083]$} & {$[0.077]$} & {$[0.022]$} \\
& $0.152^{*}$ & -0.066 & $-0.086^{* *}$ \\
& {$[0.087]$} & {$[0.086]$} & {$[0.025]$} \\
& $0.062^{* *}$ & $-0.069^{* *}$ & 0.007 \\
& {$[0.021]$} & {$[0.020]$} & {$[0.015]$} \\
\hline
\end{tabular}

\begin{tabular}{|c|c|c|c|}
\hline \multicolumn{4}{|c|}{ Lumber Industry } \\
\hline & Labour & Capital & $\log$ \\
\hline Labour & $\begin{array}{l}-0.442^{* *} \\
{[0.097]}\end{array}$ & $\begin{array}{c}0.256^{* *} \\
{[0.050]}\end{array}$ & $\begin{array}{c}0.186^{* *} \\
{[0.066]}\end{array}$ \\
\hline Capital & $\begin{array}{c}0.262^{* *} \\
{[0.049]}\end{array}$ & $\begin{array}{l}-0.162^{* *} \\
{[0.050]}\end{array}$ & $\begin{array}{l}-0.120^{4 *} \\
{[0.036]}\end{array}$ \\
\hline $\log$ & $\begin{array}{c}0.114^{* * *} \\
{[0.040]}\end{array}$ & $\begin{array}{l}-0.072^{* * *} \\
{[0.023]}\end{array}$ & $\begin{array}{l}-0.042^{*} \\
{[0.0247]}\end{array}$ \\
\hline
\end{tabular}

Notes: Numbers in parenthesis are the standard errors. *. and ** indicate significance at the 0.95 and 0.99 confidence level respectively. Standard errors were calculated using the formula S.E. $\left(\sigma_{i j}\right)=S . E .\left(\beta_{i j}\right) / S_{i} S_{j}$ 
logs are found to be complements. Moroney and Trapani (1981) hold that:

In a three input model there can be at most one pair of complementary inputs (Moroney and Trapani, 1981, p. 56).

More specifically, capital and labour display substantial substitutability particularly in the lumber industry. The high substitution elasticities between capital and labour seem to have led to a rise in labour productivity, to the detriment of employment in both industries. High elasticities of substitution can have positive consequences. A rise in the price of one factor will allow the industry to utilize more of their other inputs in place of the more expensive factor. This pattern is clearly evident in both the Lumber and Plywood industries. The rising cost of labour has induced the industry to substitute capital for labour; the rapid rise in output since 1982 has not been met by any substantial increase in employment. Previous studies of the U.S. lumber and wood products industries have reported capital-labour substitution rates ranging as low as 0.105 (Stier, 1980) and as high as 2.54 (Humphrey and Moroney, 1975). The estimated elasticities obtained in the present study are generally lower than those found by Merrifield and Haynes (1985). However, as mentioned earlier, in the latter study employment data for part of the sample period were projected. It is therefore believed that estimated elasticities obtained in this study are more accurate. An examination of elasticities of substitution between capital and labour, over time, show an interesting pattern for the plywood industry. The lumber industry however displays a steady high rate, an indication of further substitution possibilities between capital and labour in this industry, although there was a small increase between 1978-82. In 1978 the elasticity of substitution between these two factors in the plywood industry was as low as 0.18 . By 1986 it had reached a rate of 0.60 and it gradually declined to a level of 0.50 in 1986 , almost 
equal to its 1963 level. Most of the technological improvements in the lumber industry have occurred in the recent years in contrast to the steady progress over the years in the plywood industry. This has meant more constraint in terms of substitution possibilities in recent years as the industry had reached a stable state of technology. Labour and logs show a small degree of substitutability, although the rate in the lumber industry is slightly higher. Substitutability between these two factors is also obtained in the study by Merrifield and Haynes (1985) although their rates are generally lower. Capital and logs are found to be complements; the two industries tend to display similar degrees of complementarity between these factors. Merrifield and Fiaynes (1985) have also found complementarity between logs and equipment in the Ponderosa-pine region's lumber and plywood industries although their analysis of the west-side of the region showed substitution possibilities between the same pair of inputs. There is no logical explanation for this difference in the pattern of substitution between the two parts of the Pacific Northwest. This inconsistency in the latter study adds further support to the relative superiority of the data employed and hence, findings of the present research.

The own price elasticity of demand reflects the change in a factor's utilization as a result of a proportionate change in that factor's price. The presence of negative own price elasticity of substitution suggests the presence of cost-minimizing behaviour in the industry. The estimated own price elasticities of substitution have the expected negative signs, except for logs in the plywood industry. Although the sign for this factor fluctuates over the years the value at the mean is non-negative. However, the coefficient is found not to be significant. Merrifield and Haynes (1985) have reported similar results for the Pacific 
Northwest east-side lumber industry. Factor demand for all three inputs is inelastic, with demand for logs being the least elastic. Estimates of substitutability have shown labour and capital to be highly substitutable and to a lesser extent labour and stumpage. By examining estimates of cross price elasticities of demand, it is therefore possible to deduce the level of mitigation in employment rate that can come about as a result of movements in prices of other inputs.

Estimation of the retum to scale showed that both industries have enjoyed increasing returns to scale over time (see Table XI). Although the rates were shown to have declined between 1979 and 1982. This decline in the industries" economies is not surprising in view of their relative stagnation in adopting new technology. However, if the two industries had not undergone their technological transformation it is probable that their rates of returns to scale would have approached constancy or even have been decreasing.

The issue of cyclical unemployment was examined by analyzing the annual percentage change in levels of output and inputs. The results were then traced against movements in the business cycle (see Tables XII and XIII and Figures 4 and 5). Both industries displayed similar characteristics in terms of their cyclical behaviour. Production levels and utilization of all three factors of production are reduced during downturns in the economy. Clearly cyclical forces do have an effect on levels of employment in both industries. But, the magnitude of this impact is not very great and is purely a temporary phenomenon; deployment of other factors of production, capital and logs, are also reduced during downturns in the economy. In fact, the percentage rate of decline in log and, less frequently, capital utilization exceeds that in labour despite the finding of this research that 
TABLE XI

RETURNS TO SCALE

PLYWOOD INDUSTRY

$\begin{array}{lc}\text { YEAR } & \text { RTS } \\ 1963 & 1.623948 \\ 1964 & 1.700596 \\ 1965 & 1.707704 \\ 1966 & 1.686413 \\ 1967 & 1.619715 \\ 1968 & 1.705022 \\ 1969 & 1.593187 \\ 1970 & 1.604219 \\ 1971 & 1.692534 \\ 1972 & 1.752499 \\ 1973 & 1.749944 \\ 1974 & 1.626275 \\ 1975 & 1.650983 \\ 1976 & 1.787462 \\ 1977 & 1.838332 \\ 1978 & 1.878009 \\ 1979 & 1.841573 \\ 1980 & 1.639928 \\ 1981 & 1.617229 \\ 1982 & 1.509239 \\ 1983 & 1.73836 \\ 1984 & 1.745505 \\ 1985 & 1.740832 \\ 1986 & 1.846893\end{array}$

\section{LUMBER INDUSTRY}

YEAR

RTS

1951

1952

1953

1954

1955

1956

1957

1958

1959

1960

1961

1962

1963

1964

1965

1966

1967

1968

1969

1970

1971

1972

1973

1974

1975

1976

1977

1978

1979

1980

1981

1982

1983

1984

1985

1986
2.32082

2.335927

2.274686

2.214586

2.220713

2.120429

2.046668

2.07136

2.110145

2.016492

1.952497

1.959811

1.964141

1.966051

1.942646

1.884568

1.822492

1.884919

1.764062

1.773534

1.855324

1.879099

1.907523

1.896997

1.808511

1.904106

1.94549

1.969611

1.958732

1.840742

1.817034

1.753856

2.004424

2.035931

1.999183

2.063764 
TABLE XII

\author{
LUMBER INDUSTRY \\ PERCENTAGE CHANGE
}

$\begin{array}{lcccc}\text { Date } & \text { Output } & \text { Employment } & \text { Capital Stock } & \text { Raw Material } \\ 1951 & 0.0000000 & 0.0000000 & 0.0000000 & 0.0000000 \\ 1952 & 0.05167853 & -0.03988974 & 0.1232169 & 0.05188658 \\ 1953 & -0.05948932 & -0.06298056 & -0.01375782 & -0.05957713 \\ 1954 & -0.04833896 & 0.1212559 & 0.1232168 & -0.04836512 \\ 1955 & 0.04128387 & 0.08045608 & 0.1232168 & 0.03435941 \\ 1956 & -0.09538134 & -0.1307727 & -0.08894578 & -0.09550157 \\ 1957 & -0.09052325 & -0.1505324 & 0.03159068 & 0.09028336 \\ 1958 & 0.05815575 & -0.1091631 & -0.02088767 & 0.05803212 \\ 1959 & 0.08178341 & 0.05763266 & 0.03051265 & 0.08187582 \\ 1960 & -0.08640062 & -0.07334044 & -0.02745779 & -0.09257883 \\ 1961 & -0.05006032 & -0.1247734 & -0.1097 & -0.05020226 \\ 1962 & 0.0416507 & 0.007034383 & 0.02583799 & 0.04177296 \\ 1963 & 0.03827879 & -0.03375114 & 0.006132343 & 0.03846153 \\ 1964 & 0.04215098 & 0.03445713 & -0.004743275 & 0.03467344 \\ 1965 & 0.001577264 & -0.02318594 & 0.1942497 & 0.001523228 \\ 1966 & -0.05073122 & -0.005315592 & -0.0808629 & -0.05019069 \\ 1967 & -0.04728044 & -0.07121971 & -0.08296049 & -0.04723779 \\ 1968 & 0.08930344 & 0.01950496 & 0.2258148 & 0.0890758 \\ 1969 & -0.1530029 & -0.008163845 & -0.1097 & -0.1574075 \\ 1970 & -0.007279697 & -0.03975951 & 0.09872814 & -0.009157051 \\ 1971 & 0.1234385 & 0.0307096 & 0.0800927 & 0.07024008 \\ 1972 & 0.05475632 & 0.06501302 & 0.1054833 & 0.05440439 \\ 1973 & 0.02567051 & 0.06851361 & 0.4609067 & 0.01883668 \\ 1974 & -0.04078214 & 0.002955008 & 0.1633626 & -0.04099662 \\ 1975 & -0.01481654 & -0.08376366 & -0.1097001 & -0.1483652 \\ 1976 & 0.1379734 & 0.0771066 & 0.09662397 & 0.120079 \\ 1977 & 0.05695746 & 0.03235851 & 0.2344676 & 0.057996 \\ 1978 & 0.005570714 & 0.001616966 & 0.2521577 & 0.001661212 \\ 1979 & -0.04725834 & -0.02036571 & -0.1097 & 0.04975131 \\ 1980 & -0.1912899 & -0.09057202 & -0.02912109 & -0.1989531 \\ 1981 & -0.07997065 & 0.05561557 & -0.0890123 & -0.08169901 \\ 1982 & -0.1271132 & -0.1110291 & -0.08173027 & -0.08540969 \\ 1983 & 0.449662 & 0.07371742 & 0.04173063 & 0.3878082 \\ 1984 & 0.04978573 & 0.03807793 & 0.02545296 & 0.04392588 \\ 1985 & -0.03205667 & -0.07511265 & -0.1085087 & -0.03312433 \\ 1986 & 0.1339618 & 0.009462071 & 0.00574261 & 0.1675922 \\ & & & & \end{array}$


TABLE XIII

\section{PLYWOOD INDUSTRY PERCENTAGE CHANGE}

$\begin{array}{lcccc}\text { Date } & \text { Output } & \text { Employment } & \text { Capital Stock } & \text { Raw Material } \\ 1963 & 0.0000000 & 0.0000000 & 0.0000000 & 0.0000000 \\ 1964 & 0.1284756 & 0.1028946 & 0.04476660 & 0.1152648 \\ 1965 & 0.02081570 & 0.0255481 & 0.01596942 & 0.02094972 \\ 1966 & -0.02798592 & -0.004215393 & -0.1097003 & -0.02872777 \\ 1967 & -0.0732099 & -0.08466475 & -0.1096999 & -0.07323944 \\ 1968 & 0.11156030 & 0.008085932 & 0.2222525 & 0.09726444 \\ 1969 & -0.1357922 & -0.03134434 & -0.1073399 & -0.1357341 \\ 1970 & 0.0244049 & -0.06578666 & 0.1476215 & 0.02403846 \\ 1971 & 0.0947072 & 0.0470661 & 0.2360777 & 0.07981221 \\ 1972 & 0.0607847 & 0.0403898 & 0.1102031 & 0.06086957 \\ 1973 & -0.01677610 & -0.01315078 & -0.1097002 & -0.01639344 \\ 1974 & -0.17586600 & -0.08275526 & -0.08426564 & -0.1763889 \\ 1975 & -0.02107751 & -0.10843170 & 0.01225064 & -0.03372681 \\ 1976 & 0.1340298 & 0.0676737 & 0.2507614 & 0.1343805 \\ 1977 & 0.0295473 & 0.3000209 & 0.1695301 & 0.02923077 \\ 1978 & 0.0178961 & 0.0256775 & 0.2638493 & 0.004484305 \\ 1979 & -0.07332757 & -0.03605119 & -0.1097001 & -0.07440476 \\ 1980 & -0.23010180 & -0.16054750 & -0.08780904 & -0.2299035 \\ 1981 & -0.06130732 & -0.06256878 & -0.03436593 & -0.06054280 \\ 1982 & -0.09522435 & -0.11796680 & -0.07651623 & -0.09333333 \\ 1983 & 0.3009348 & 0.0519103 & 0.09435698 & 0.2843137 \\ 1984 & 0.0253559 & -0.03364889 & 0.1440933 & 0.02480916 \\ 1985 & 0.0125629 & -0.06411251 & 0.1022407 & 0.01303538 \\ 1986 & 0.1369988 & 0.0147684 & 0.05898554 & 0.1360294\end{array}$




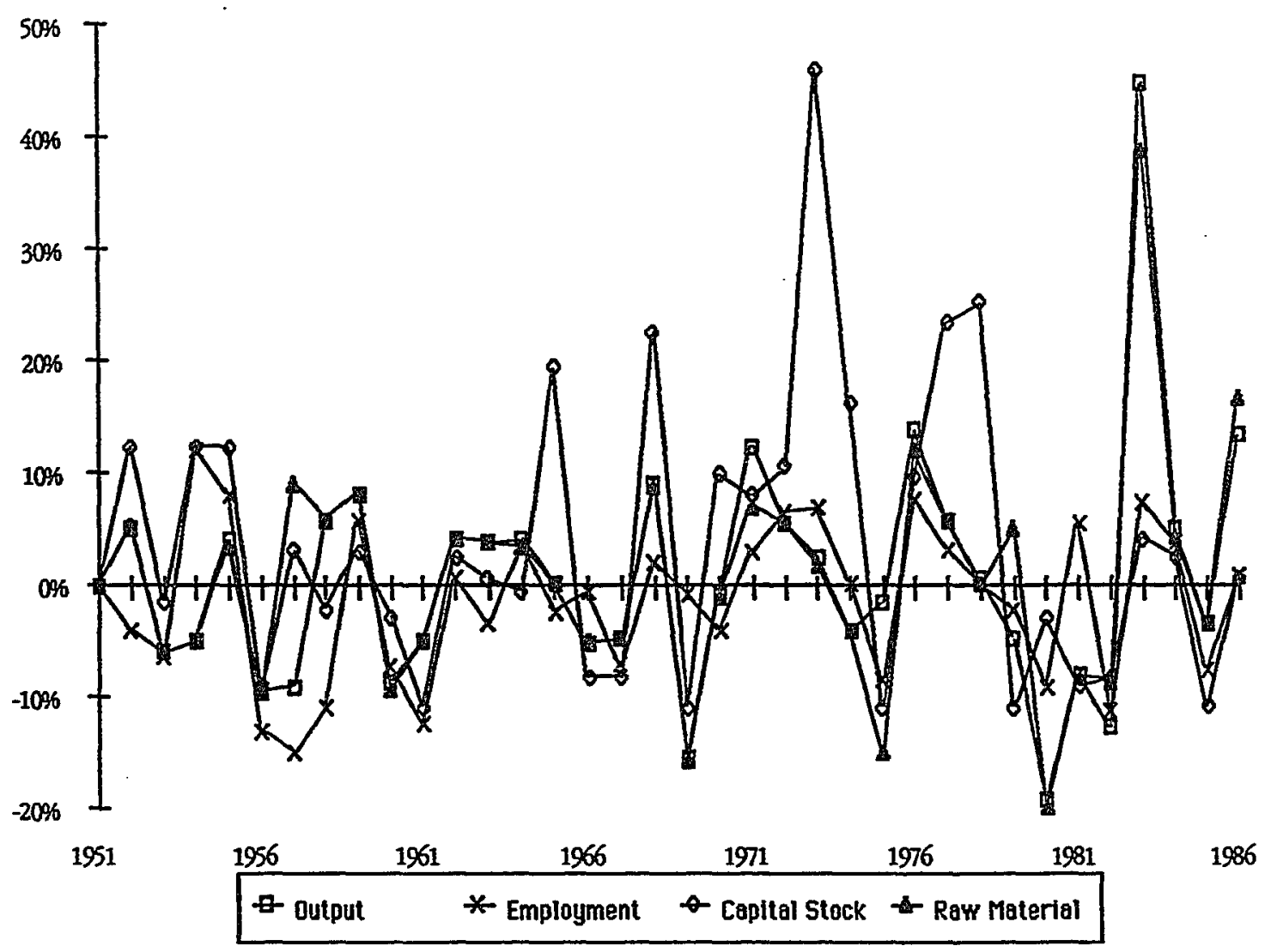

Figure 4. Percentage Change in Factors of Input and Output in the Lumber Industry 


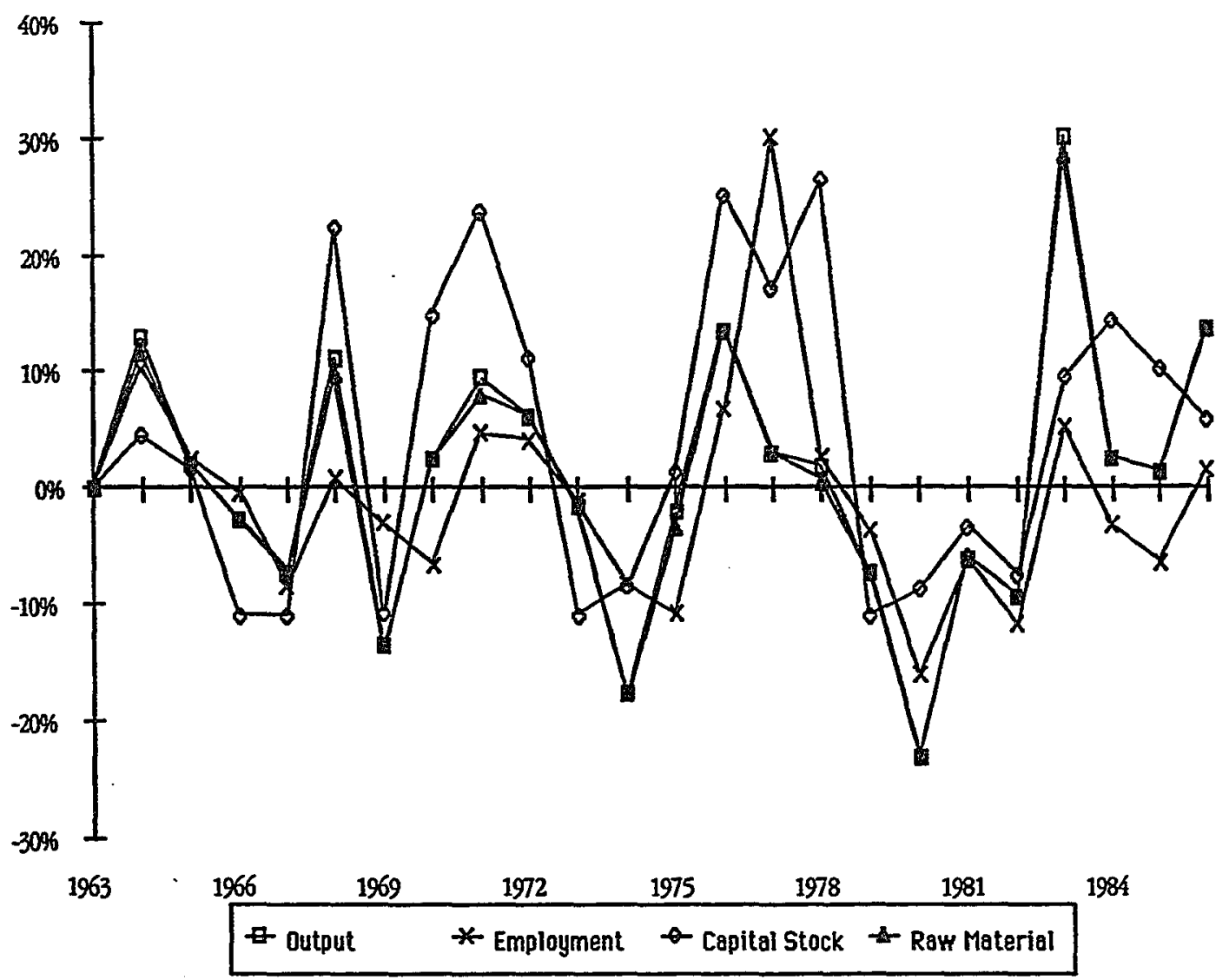

Figure 5. Percentage Change in Factors of Input and Output in the Plywood Industry 
technological changes in both industries have been capital-and log-using and labour-saving.

In order to check on the above analyses the original model was expanded to include a variable reflecting cyclical changes. A composite index of coincident indicators (Business Conditions Digest, 1988) was deployed to capture cyclical variations in employment. In general, the signs, the magnitudes and the significance of the variables did not change much; neither did the elasticities of substitution and price elasticities of demand. In conclusion, it can be said that much of the decline in employment, in both the softwood lumber and plywood industries, can be attributed to structural changes that have occurred in these industries. Increasing utilization of capital and higher labour productivity seem to have been most responsible for this decline. In order to assess the accuracy of the model plots of observed and predicted values were depicted on each other (See Appendix A). Overall, the figures show that the model has performed satisfactorily and, therefore, changes that have occurred in the two industries are adequately explained by the model.

\section{SIMULATION EXPERIMENTS}

Simulation analyses were undertaken in order to quantify the various causes of employment change. A number of hypothetical situations were simulated; they involved either changes in prices of factor inputs or changes in the share of factors of production. The former types of experiment will, basically, indicate what would have happened to employment had the economy not experienced a cyclical downturn. The residuals were then considered to be caused by structural 
factors. Movements in prices are generally thought to be an indicator of cyclical changes. The data tend to suggest that the rising surge in wages began as early as 1975, although employment decline did not follow until 1979. It was therefore decided to experiment with various simulations in two different time periods, first the period 1975-1986 and second, the period 1978-86. In addition, two different types of simulations were undertaken. The first involves the impact of changes in the price of a single variable. The second type looks at simultaneous changes in values of two variables. As discussed earlier the simulations on prices were undertaken in order to quantify employment losses that were attributed to the downturn in the economy. The percentage by which prices were simulated were based on the actual price changes during the corresponding periods.

The first experiment involved the reduction of wages by an annual rate of 8.8 percent during the 1975-86 period, the same rate by which wages increased during this time span. In the lumber industry, such a change would have increased employment by more than 5.0 percent from its present level. As for the plywood industry, this change in prices would have resulted in an 11.5 percent increase in employment in 1986. However, employment in both industries would still have been well below its 1978 levels, 24 percent in the plywood industry and 17 percent in the lumber industry. The second experiment assumed wages to have risen by only a half of their original increase, 4.4 percent. The results indicate that employment levels in 1986 would have increased by 6 percent in the plywood industry and by less than 4 percent in the lumber industry. The results show that expected employment would have been 18 percent and 29 percent below their 1978 levels for the lumber and plywood industries respectively. Since most of the recent employment loss occurred after 1978, it was decided to 
examine the consequence of a 4.4 percent wage decline, after 1978, on employment. It is shown that employment would be up by 2 and 5 percent from its 1986 levels, for the lumber and plywood industries respectively. Again, it would be down by more than 20 percent and by 30 percent from its 1978 levels for the respective industries.

Between 1975 and 1986 log prices rose by an annual average of 3.6 percent. The rate of increase would have been much greater had it not been for a sharp decline after 1981; prices increased by an average 11.4 percent a year between 1975-81. A 3.6 percent decline in log prices between 1975 and 1986 was found to have no effect on employment rates. Further, an 11.4 percent decline in prices during the 1975-86 period also was shown to have no effect on employment.

The other type of simulation consisted of a simultaneous change in wages and log prices. First, a 4.4 percent annual decline in wages between 1975-86 and a fall of 11.4 percent per annum in log prices between 1975-81 showed that employment would have been 4 and 6 percent above their 1986 levels for the lumber and plywood industries respectively. Second, an annual drop of 11.4 percent in log prices for the 1975-81 period and an 8.8 percent annual decrease in wages between 1975 and 1986, showed that employment rates, in 1986, would be up by 11.5 percent in the plywood industry and by 5 percent in the lumber industry.

Employment in the lumber and plywood industries declined by 20 percent and 33 percent respectively between 1979 and 1986. The calculation of the simulation were therefore based on the assumption that any difference between 
these values and the estimated values that resulted from the simulations would be regarded as structural unemployment.

The simulation experiments discussed above show that as a result of various decreases in factor prices employment levels in the lumber and plywood industries would have been up be 5 and 11.5 percent respectively from their actual levels in 1986 . This is well below the rate by which they actually declined. As suggested above the data shows that between 1979 - 86 employment declined by 20 percent in the lumber industry. The simulations show that if prices had remained constant, employment levels in 1986 would only have been 5 percent above their present level; reflecting a mere 25 percent of the actuall loss. The corresponding figures for the plywood industry are 33 and 11.5 percent; slightly over a third of the actual decline. Overall, the simulations demonstrate that even if wages and stumpage prices had remained stable in the past ten years of the sample period employment levels would still have declined substantially.

Simulation analyses were also carried out to identify the causes of labour productivity changes. Although the research has found productivity to have increased for both industries, (see Table XIV) it is not clear whether this has been caused by increasing capital investment or merely by reduction in labour inputs. The increase in labour productivity during the $1979-82$ period is probably attributable to the substantial reduction in employment during this period. The results suggest that labour productivity tends to increase during cyclical downturns; this pattern holds for all the cycles in the sample period. It should be pointed out, however, that cyclical movements are recorded on a monthly basis and the findings of this study are based on annual observations. Thus, the 
TABLE XIV

ESTIMATES OF PRODUCTTVITY GROWTH OF LABOUR

Plywood Industry

Lumber Industry

$\begin{array}{llll}1963 & 0.01910148 & 1951 & -0.007075149 \\ 1964 & 0.01106161 & 1952 & -0.005035675 \\ 1965 & 0.01050409 & 1953 & -0.004068268 \\ 1966 & 0.01310665 & 1954 & -0.002076103 \\ 1967 & 0.02112006 & 1955 & -0.002879657 \\ 1968 & 0.01201059 & 1956 & 0.004889668 \\ 1969 & 0.02331462 & 1957 & 0.009458976 \\ 1970 & 0.02026797 & 1958 & 0.01056732 \\ 1971 & 0.01155925 & 1959 & 0.008056479 \\ 1972 & 0.006846635 & 1960 & 0.01444219 \\ 1973 & 0.006606331 & 1961 & 0.01739827 \\ 1974 & 0.01768356 & 1962 & 0.01335176 \\ 1975 & 0.01539470 & 1963 & 0.01387572 \\ 1976 & 0.005837578 & 1964 & 0.01200254 \\ 1977 & 0.003417530 & 1965 & 0.01449937 \\ 1978 & 0.001816958 & 1966 & 0.01963807 \\ 1979 & 0.003181432 & 1967 & 0.03019778 \\ 1980 & 0.01700856 & 1968 & 0.02410892 \\ 1981 & 0.01796827 & 1969 & 0.03347171 \\ 1982 & 0.02580049 & 1970 & 0.03142525 \\ 1983 & 0.004005211 & 1971 & 0.02465915 \\ 1984 & 0.003144845 & 1972 & 0.02314713 \\ 1985 & 0.002727827 & 1973 & 0.02294612 \\ 1986 & -0.002326774 & 1974 & 0.02785604 \\ & & 1975 & 0.03078863 \\ & & 1976 & 0.02940947 \\ & & 1977 & 0.03065313 \\ & & 1978 & 0.03414336 \\ & & 1979 & 0.03398142 \\ & & 1980 & 0.04314129 \\ & & 1981 & 0.04327938 \\ & & 1982 & 0.04557015 \\ & & 1984 & 0.02885615 \\ & & 1985 & 0.02754041 \\ & & 1986 & 0.02710357 \\ & & & \\ & & & 16300\end{array}$


implications may not be totally correct due to incompatibility of the data.

Simulation exercises were performed to find the impact of the decline in labour input on labour productivity. The analyses were carried out holding employment levels constant or increased by a certain percentage, meanwhile capital investment was held at its actual levels. A number of experiments were undertaken. First, it was found that if employment had remained constant at its 1979 level then labour productivity in 1986 would have been down by around 20 percent and 38 percent, from their actual levels, for the lumber and plywood industries, respectively. By the same notion, productivity levels in 1982 would have been down by only 13 and 4.2 percent from their actual levels, for the respective industries. Another experiment involved increasing the annual labour input by the same annual average by which it had decreased during the period $1979-86$. The results showed that labour productivity figures for 1986 would have been down by 2.7 and 7.8 percent for the lumber and plywood industries respectively. The corresponding figures were 2.9 percent for the labour industry and 4.7 percent for the plywood industry.

Between 1979 and 1982 employment levels in the lumber and plywood industries declined by an annual average of 7.9 and 10.2 percent for the respective industries. Simulation experiments were carried out increasing labour input by similar amounts for the same period. It was found that levels of labour productivity in 1982 would have been down by around 4 percent and 1.2 percent for the lumber and plywood industries respectively. Also simulation work was undertaken by increasing labour force by an annual average of 1 percent for the two time periods, $1979-82$ and $1979-86$. The results indicated that such a rise 
would have meant that productivity levels in 1982 would have been down by 0.5 percent and 1.3 percent from their actual levels for the lumber and plywood industries respectively. Similarly, a 1 percent average annual increase between 1979 - 86 showed productivity levels would have been lower than their actual levels by 1 and 1.8 percent for the respective industries. It is clear that employment levels have an effect on levels of productivity, however, other factors have also contributed towards the growth in labour productivity. It seems that productivity would still have risen, though at a lesser rate, despite an increase in the amount of labour per unit of capital. This is probably a result of more efficient labour or capital inputs or, more probably, a combination of both.

\section{IMPLICATIONS AND CONCLUSION}

To reiterate, employment levels in both industries have fluctuated with the business cycle; however, much of the decline, in both industries, is attributed to changes in the structure of production. The data indicate that the recession at the end of 1979 was followed by a substantial decline in levels of inputs and outputs. However, after the upturn at the end of 1982, production levels in both industries began to pick up again and by 1986 they were above their 1979 levels. Actually, production levels in the lumber industry had not been as high since 1955, and for the plywood industry production figures had reached the steady level that had been maintained throughout the sixties and the seventies before the start of the recession. Meanwhile, employment in the plywood industry had reached an all time low of 19,583 in 1986, about 66 percent of its 1979 level. Employment in the lumber industry did not decline as much, going down by 20 percent from its 1979 level. Employment reductions in the industry, however, would have been much 
greater had it not been for the rapid increase in output over this time span. Furthermore, estimates of labour productivity growth show productivity to have increased over the sample period in both industries, independent of any changes in factor inputs. The rate seems to have risen sharply after 1979, though the rate of increase seems to have declined rapidly between 1982 and 1983 . Although the lumber industry shows a steady rate of increase since 1983, labour productivity has continued to rise at a decreasing rate in the plywood industry and shows a negative rate for 1986.

Simulation analyses haye indicated that some of the growth in labour productivity is attributed to a reduction in the labour force. However, the present model does not have the capability to quantify the reduction in employment, in the lumber and plywood industries, that has been caused by the growth in labour productivity is attributed to a reduction in labour force. The simulation analyses have shown what would have happened to labour productivity had employment levels remained constant at their 1979 levels and if they had declined by smaller percentages than they actually did. However, there does not seem to have been any consistent pattern. Even when expanding the focus of the analyses to include all the years in between 1979 and 1986, greater variations and discrepancies were shown to appear. The changes in labour productivity that were brought about by the above simulation were also checked against capital injections for the corresponding periods and, again, no regular pattern could be identified.

The results of this study strongly point towards structural changes in both the lumber and plywood industries. The industries can best be characterized as increasing their usage of capital and reducing their use of labour. It should be 
noted that the increasing utilization of capital also implies adoption of more advanced machinery that requires less manpower for any unit of output. This change towards greater capital intensiveness is probably attributable to the fact that the region's industries had begun to lose their market competitiveness. High wages and rising log prices were probably contributing factors in reducing these industries' competitiveness. The data suggest that the rapid increase in wages occurred between 1975 and 1976 but the down surge in employment did not take place until 1979. With regard to capital injection, both industries reached new peaks in 1978 and gradually declined after this period. However, the cost of capital had already begun rising in 1973 and continued to do so until the end of the recession. It therefore seems that relative price movements were not the only factors affecting the utilization of capital.

The facts tend to indicate that the industries had started preparing for a change in their structure of production in the early seventies, in order to regain their competitiveness in the national and international markets, and the adoption of new technology was completed by the end of the decade when a further rise in the cost of capital was followed by a decline in the usage of the input. Even during the uptum of the cycle capital investment levels did not reach their record pre-recession highs except in the plywood industry in 1986.

The simulation experiments showed that although labour price changes have an impact on employment rates they could not, by themselves, recoup much of the loss that had occurred after 1978. This is not surprising in view of the low price responsiveness of this input. Also, very low cross price elasticities between labour and logs meant that changes in log prices had no effect on employment 
levels. This is probably attributable to the relatively fixed requirement of this input for any given output. Thus, although higher factor prices were responsible for the decline in employment, much of this change is due to the high substitution possibilities between capital and labour. The findings suggest that of the recent employment decline in the lumber and plywood industries around one-quarter and one-third, respectively, could be attributable to cyclical factors. The residuals, around 75 percent and 66 percent for the respective industries, are assumed to be a cause of structural factors.

Similar experiments were carried out for the various cycles in the sample period. In the lumber industry, it was found that during the 1951-54 and during the downtum almost all the employment losses were cyclical. However, only around forty percent of the employment loss during the recession of 1957-61 could have been caused by cyclical forces, and nearly two-thirds could be accounted for during the 1969-70 and 1973-75 cycles. In the plywood industry, all the employment loss of late 1969 was considered cyclical and under fifty percent of the decline of the mid-seventies was attributed to cyclical factors.

Estimates of elasticities suggest that any decline in the use of the other two factors should increase the rate of employment. This is contrary to the popular notion that stumpage supply shortages have been the major cause of employment decline in this region. Generally, government policy on the forest industry has been focused primarily on the supply of timber. The general presumption was that a regular supply of timber would preserve employment in timber dependent communities. The Sustained Yield Forest Management Act (1944), The Conservation Reserve Soil Bank Program (1956), The Forest Industries Program 
(1973), etc., have all aimed at maintaining a steady flow of stumpage. The Sustained Yield Act, for instance, was enforced primarily to maintain and enhance community stability. The results of the present study show, however, that employment could decline in spite of a sustained yield policy. The data show that employment levels declined sharply despite a simultaneous increase in timber supply.

These findings provide heartening support for the environmentalists. Their growing concern about the depletion and lowered quality of forests in the Pacific Northwest has been a growing issue in the recent past. Forest resource managers have always had a difficult task in maintaining a balance between the needs of timber dependent communities and environmentalists, who have feared the possible exhaustion of timber resources. It therefore seems that some of the existing forest management policies may not be as effective as once thought and perhaps there is a need for re-examining some of the older measures and formulating new policies that are consistent with changes in the structure of the wood products industry.

The general direction of these industries in adopting labour saving technologies implies that further increases in production are necessary if employment is to reach its pre-1979 levels. This could involve an expansion of the industries' export markets, nationally and internationally, as well as development of new product markets. At present, around forty percent of the industries' final products are geared towards the housing market. Although it has been found that cyclical factors have had less of an impact on the recent employment decline in the two industries, there is no doubt that in order to avoid 
the volatility of the national housing market both the lumber and plywood industries will have to look for alternative markets for their products. This would require further development of these products for non-residential purposes. In terms of an overall policy for the redundant work force it seems that in light of the existing move towards the deployment of modern technology, worker retraining may be one of the more appropriate measures. The fact that the increasing output in the two industries since 1982 has not been accompanied by a significant rise in employment levels reinforces the need for such measures.

One of the more obvious shortcomings of the study relates to unavailability of data for the earlier years, 1951-62, for the plywood industry. It is believed that the relatively shorter sample periods for this industry have been a likely cause for the insignificance of some of the parameters. Further, it is thought if distinction on quality of log inputs, i.e. old growth and new growth, had been possible then in would have been possible to answer some of the proposed questions with greater certainty. 


\section{LITERATURE CITED}

Abt, R.C. 1987. 'An Analysis of Regional Factor Demand in the U.S. Lumber Industry', Forest Science, Vol. 33,P. 164-173.

American Plywood Association. End Use Marketing Profiles For Structural Panels, Economics Reports E. series. Tacoma, Washington: American Plywood Association.

American Plywood Association 1987. Regional Distribution and Production Patterns of the Structural Panel Industry, Economics Report No. E43. Tacoma, Washington: American Plywood Association.

Armstrong, G.H. and Taylor, R.J. 1981. "The Measurment of Different Types of Unemployment'. In J. Creedy (Ed.), The Economics of Unemployment in Britain. London: Butterworths.

Arrow, K.J., Chenery, H.B., Minhas, B.S., Solow, R.M. 1961. 'Capital-Labor Substitution and Economic Efficiency', Inl of Economic and Statistics, Vol. 43, P. 225-250.

Auerbach, A.J. 1983. 'Corporate Taxation in the U.S.', Brookings Paper on Economic Activity, No.2, P. 451-513.

Baldwin, R.F. 1984. Operations Management in the Forest Products Industry. San Francisco: Miller Freeman Publications.

Berndt, E.R. and Christensen, L.R.1973. "The Translog Function and the Substitution of Equipment, Structures, and Labor in U.S. Manufacturing 1929-68', Inl of Econometrics, Vol. 1, P. 81-114.

Berndt, E.R., and Field, B.C. 1981. Modeling and Measuring Natural Resource Substitution. Cambridge, Mass.: The MIT Press.

Berndt, E.R., and Wood, D.O. 1975. "Technology, Prices and the Derived Demand for Energy', The Review of Economics and Statistics, Vol. 57, P.259-268.

Bluestone, B. 1985. In 'Do We Need an Industrial Policy?', Harper's, Vol. 270, P. 35-48.

Bluestone, B., Harrison, B. and Clayton-Matthews, A. 1986. 'Structure vs Cycle in the U.S. Manufacturing Job Growth', Industrial Relations, Vol. 25, P. 101-117.

Borts, G.H. 1969. 'Regional Cycles of Manufacturing Employment in the United States, 1914-1953', Inl of American Statistical Assoc., Vol. 55, P. 151-211. 
Borus, M.E. 1965. 'Criticism and Comment: Has Structural Unemployment Worsened', Industrial Relations, Vol. 4, P. 111-114.

Brechling, F. 1967. 'Trends and Cycles in British Regional Unemployment', Oxford Economic Papers, Vol. 19, P. 1-21.

Brown, R.S. and Christensen, L.R. 1981. 'Estimating Elasticities of Substitution in a model of Partial Static Equilibrium: An Application to U.S. Agriculture, 1947 to 1974', in Berndt, E.R. and Field, B.C. (Eds.), Modeling and Measuring Natural Resource Substitution. Cambridge, Mass: The MIT Press.

Browne, L.E. 1978 (a). 'Regional Unemployment Rates - Why Are They So Different', New England Economic Review, July-Aug, P. 5-26.

Browne, L.E. 1978 (b). 'Regional Industry Mix and the Business Cycle', New England Economic Review, Nov-Dec, P. 35-53.

Burgess, D.F. 1975. 'Duality Theory and Pitfalls in The Specification of Technologies', Inl of Econometrics, Vol. 3, P. 105-121.

Bums, A.F. and Mitchell, W.C. 1946. Measuring Business Cycles. N.Y.: National Bureau of Economic Research.

Business Conditions Digest 1988, Monthly Issue. U.S. Department of Commerce, Bureau of Economic Analysis.

Casetti, E., King, L., Jeffrey, D. 1971. 'Structural Imbalance in the U.S. UrbanEconomic System, 1960-1965', Geographical Analysis, Vol. 3, P. 239-255.

Cho, D.W. and McDougall, G.S. 1978. 'Regional Cyclical Patterns and Structure, 1954-1975', Economic Geography, Vol. 54, P. 66-74.

Christensen, L.R., Jorgenson, D.W., and Lau, L.J. 1971. 'Conjugate Duality and the Transcendental Logarithmic Function', Econometrica, Vol. 39, P. 255-256.

Christensen, L.R., Jorgenson, D.W., and Lau, L.J. 1973. 'Transcendental Logarithmic Production Frontiers', Review of Economics and Statistics, Vol. 55, P. 28-45.

Christensen, L.R., and Greene, W.H. 1976. 'Economies of Scale in U.S. Electric Power Generation', Inl. of Political Economy, Vol. 84, P. 655-676.

Cobb, C.W., and Douglas, P.C. 1928. 'A Theory of Production', in American Economic Review, Vol. 18, P. 139-165.

Coen, R.M. 1980. 'Alternative Measures of Capital and Its Rate of Return in the U.S. Manufacturing', in D. Usher (Ed.), The Measurement of Capital. Chicago: The University of Chicago of Press.

Congress of the United States. 1983. Wood Use: U.S. Competitiveness and Technology. Congress of the U.S., Office of Technology, Washington, D.C. 
Connaughton, K.P., Jackson, D.H. and Majerus, G.A. 1987. 'Estimating The Regional Supply and Demand for Stumpage', U.S. Dept. of Agr. Forest Service. In Process.

Council of Economic Advisers 1962. In, U.S. President, Economic Report of the President, P. 49-56.

Council of Economic Advisers 1977. In, U.S. President, Economic Report of the President, P. 52-56.

Cowing, T.G. and Stevenson, R.E. (Eds.) 1981 Productivity Measurement in Regulated Industries. N.Y. Academic Press

Creedy, J. (Ed.) 1981. The Economics of Unemployment in Britain. London: Butterworths.

Denny, M., and Fuss, M. 1977. 'The Use of Approximation Analysis to Test for Separability and the Existence of Consistent Aggregates', American Economic Review, Vol. 67, P. 404-418.

Duke, J., and Huffstutler, C. 1977. 'Productivity in Sawmills Increases as Labor Input Declines Substantially', Monthly Labor Review, Vol. 100, April, P. 33-37.

Economic Report of the President 1987. U.S. Government Printing Office.

Engerman, S. 1965. 'Regional Aspects of Stabilisation Policy'. In R.A. Musgrave (Ed.), Essays in Fiscal Federalism. Washington, D.C.: The Brookings Institution.

Fearn, R. M. 1975. 'Cyclical, Seasonal and Structural Factors in Area Unemployment Rates', Industrial and Labor Relations Review, Vol. 28, P. 424-431.

Fluckiger, Y., Schonenberger, A., and Zarrinnejadan, M. 1986. 'Measuring Different Types of Unemployment in Switzerland', Schweizeriche Zeithschrift Fur Wolkwirtschaft and Statistik, Vol. 122, March, P. 17-34.

Foltman, F.F. 1968. White-and Blue-Collars in a Mill Shutdown: A. Case Study in Relative Redundancy. Ithaca: Cornell University.

Gerberb, B.J., and White, D.E. 1982. 'Technical Change and Productivity Growth in the Lumber and Wood Products Industry', Forest Science, Vol. 28, P. 135-147.

Gilmer, R.W. and Pulispher, A.G. 1986. 'Cyclical and Structural Change in Southern Manufacturing: Recent Evidence From the Tennessee Valley: A Note', Growth and Change, Vol. 17, P. 61-69.

Gollop, F.M. and Roberts, M.J. 1981. 'Sources of Economic Growth in the US Electrical Power Industry' in T.G. Cowing and R.E. Stevenson (Eds.), Productivity Measurement in Regulated Industries. N.Y.: Academic Press.

Goodman, R. 1979. The Last Entrepreneurs: America's Regional Wars for Jobs and Dollars. N.Y.: Simon and Schuster. 
Gordon, R.A. 1964. 'Has Structural Unemployment Worsened ?', Industrial Relations, Vol. 3, P. 53-77.

Griffin, J.M. and Gregory, P.R. 1976. 'An Interindustry Model of Energy Substitution Responses', American Economic Review, Vol. 66, P. 845-857.

Griliches, Z., and Intriligator, M.D. 1986. Handbook of Econometrics, Vol. III. Amsterdam: Elsevier Science Publishers B.V.

Haber, W., Ferman L. and Hudson, R. 1963. 'The Impact of Technological Change'. The W.E. Upjohn Institute for Employment Research, Kalamazoo, Michigan.

Hamermesh, D.S. 1969. 'Spectral Analysis of the Relation Between Gross Employment Changes and Output Changes', Review of Economics and Statistics, Vol. 51, P. 62-69.

Hannah, S.P. 1983. 'Cyclical and Structural Determinants of the UV Curve Relation', Applied Economics, Vol.15, P. 141-151.

Haynes, R.W., Connaughton, K.P. and Adams, D.M. 1981. 'Projections of the Demand for National Forest Stumpage by Region, 1980-2030', U.S. Dept. of Agr. Forest Service, PNW-282.

Helmstadter, E. 1979. 'Directed Expansion with Full Employment: Structural Change as a Scientific and Policy-Making Task', IFO-Studien, Vol. 25, P. 1-18.

Henderson, J.M. and Quandt, R.E. 1971. Micro-Economic Theory: A Mathematical Approach. Tokyo: McGraw-Hill Kogakusha.

Holden, K. and Peel, D.A. 1975. 'The Determinants of Unemployment and the 'UV' Relationship', Applied Economics, Vol. 7, P. 251-255.

Howell, R.E. and Bentley, M.T. 1986. 'Assessing, Managing and Mitigating the Impact of Economic Decline: A Community Perspective', Western Regional Extension, Publication 91, June 1986.

Howland, M. 1979. 'The Business Cycle and Long-Run Regional Growth'. In W.C. Wheaton (Ed.), Interregional Movements and Regional Growth. Washington, D.C.: The Urban Institute.

Hulten, C.R., and Wykoff, F.C. (1980). 'Economic Depreciation and the Taxation of Structures in the U.S. Manufacturing Industries: An Empirical Analysis', in D. Usher (Ed.), The Measurement of Capital. Chicago: The University of Chicago Press.

Humphrey, D.B., and Moroney, J.R. 1975. 'Substitution Among Capital, Labor, and Natural Resource Products in American Manufacturing', Inl. of Political Economy, Vol. 83, P.57-83.

Hunt, L.C. 1984. 'Energy and Capital: Substitutes or Complements? Some Results for the U.K. Industrial Sector', Applied Economics, Vol. 16, P. 783-789. 
Hyclak, T., and Lynch, G. 1980. 'An Empirical Analysis of State Unemployment Rates in the 1970's', Jnl of Regional Science, Vol. 20, P. 377-386.

Intriligator, M.D. 1978. Econometric Models, Techniques, and Applications. Englewood Cliffs, N.J.: Prentice-Hall Inc.

Jackall, R., and Levine, H.M. (Eds.) 1984. Worker Cooperatives in America. Berkeley: University of California Press.

Jorgenson, D.W. 1986. 'Econometric Methods for Modeling Producer Behavior', in Z. Griliches and M.D. Intriligator, Handbook of Econometrics, Vol. III. Amsterdam: Elsevier Science Publishers B.V.

Kaliski, S.F. 1968. 'Structural Unemployment in Canada: Towards a Definition of the Geographic Dimension', Canadian Inl. of Economics, Vol. 1, P. 551-565.

Kmenta, J., and Gilbert, R.F. 1968. 'Small Sample Properties of Alternative Estimators of Seemingly Unrelated Regressions', Inl of American Statistical Association, Vol: 63, P. 1180-1200.

Kendrick, J.W. 1973. Postwar Productivity Trends in The United States, 1948-1969. N.Y.: National Bureau of Economic Research.

Kendrick, J.W. 1976. The Formation and Stocks of Total Capital. N.Y.: National Bureau of Economic Research.

King, L. J., Casetti, E., Jeffrey, D. 1972. 'Cyclical Fluctuations in Unemployment Levels in U.S. Metropolitan Areas', Tiidschrift Voor Econ. En. Soc. Geografie, Vol. 63, P. 345-352:

King, L. J. and Clark, G. L. 1978. 'Regional Unemployment Patterns and the Spatial Dimensions of Macro-Economic Policy: The Canadian Experience 1966-75: Regional Studies, Vol. 12, P. 283-296.

Knowles, J. and Kalachek, E. 1961. Higher Unemployment Rates, 1957-60: Structural Transformation or Inadequate Demand. Washington, D.C.: U.S. Congress, Subcommittee on Economic Statistics of the Joint Economic Committee.

Kolbe, J. 1985. 'Recession Ripples: Helping the Displaced Worker- Seek a Brighter Future Elsewhere'. The Wall Street Inl, Tuesday Jan 29.

Lawrence, R.Z. 1984. Can America Compete. Washington, D.C.: The Brookings Institution.

McKillop, W.L.M. 1967. 'Supply and Demand For Forest Products-An Econometric Study', Hilgardia, Vol. 38, P. 1-87

Mead, W.J. 1966. Competition and Oligopsony in the Douglas Fir Lumber Industry. Berkeley: University of California Press. 
Merrifield, D.E. 1982. The Effects of Demand and Supply Shifts on Output Employment, and Stumpage Markets in the Pacific Northwest Forest Products. Unpublished Ph.D Thesis, Claremont Colleges, Claremont, California.

Merrifield, D.E., and Haynes, R.W. 1983. 'Production Function Analysis and Market Adjustments: An Application to the Pacific Northwest Forest Products Industry', Forest Science, Vol. 29, P. 813-822.

Merrifield, D.E., and Haynes, R.W. 1985. 'A Cost Analysis of the Lumber and Plywood Industries in Two Pacific North-West Sub-Regions', The Annals of Regional Science, Vol. 19, P. 16-29.

Merrifield, D.E., and Singleton, W.R. 1986. 'A Dynamic Cost And Factor Demand Analysis for the Pacific Northwest Lumber and Plywood Industries', Forest Science, Vol. 32, P. 220-233.

Miernyk, W.H. 1966. 'Foreword'. In E.G. Gilpatrick, Structural Unemployment and Aggregate Demand. Baltimore: The Johns Hopkins Press.

Moroney, J.R., and Trapani, J.M. 1981. 'Alternative Models of Substitution and Technical Change in Natural Resource Intensive Industries', in E.R. Berndt and B.C. Field, Modeling and Measuring Natural Resource Substitution. Cambridge, Mass.: The MIT Press.

Musgrave, R.A. (Ed.) 1965. Essays in Fiscal Federalism. Washington, D.C.: The Brookings Institution.

Nadiri, M.I. and Rosen, S. 1973. A Disequilibrium Model of Demand for Factors of Production. N.Y.

Oregon Labor Trends, June 1987. Oregon Employment Division.

Rasche, R.H. and Tatom, J.A. 1977. 'Energy Resources and Potential GNP', Federal Reserve Bank of St. Louis Review, Vol. 59, No. 6, P. 10-24.

Rothstein, L.E. 1986. Plant Closing: Power, Politics and Workers. Dover, Mass: Auburn House Publishing Co.

Sawers, L. and Tabb, W.K. (Eds.) 1984. Sunbelt-Snowbelt: Urban Development and Regional Restructuring. N.Y.: Oxford University Press.

Scaggs, M.B.W. 1983. 'Recent Employment Trends in the Lumber and the Wood Products Industry', Monthly Labor Review, Vol.106, Aug., P. 20-24.

Schallau, C.H. 1985. 'What's This About the Forest Industry Shifting to The South', Paper Presented at the Southern Forest Economic Workers Workshop. Athens, Georgia.

Schallau, C.H. and Maki, W.R. 1986. 'Economic Impacts of Interregional Competition in the Forest Products Industry During the 1970's: The South and the Pacific Northwest' U.S. Dept. of Agri., Forest Service, Research Papers PNW-350 
Seater, J.J. 1982. 'Marginal Federal Personal and Corporate Income Tax Rates in The U.S. 1909-75'. Inl of Monetary Economics, Vol. 10, P. 361-381.

Smith, N. and Feagin, J. (Eds.) 1986. Urban Change and Global Capitalism. London: Basil Blackwell.

Soja, E. 1986. 'L.A.'s The Place: Economic Restructuring and the Internationalistion of the Los Angeles Region'. In N. Smith and J. Feagin (Eds.), Urban Change and Global Capitalism. London: Basil Blackwell.

Stanford Research Institute 1954. America's Demand for Wood, A report by Stanford Research Institute, Stanford, California, to Weyerhaeuser Timber Company, Tacoma, Washington.

Stevens, J.B. 1976. The Oregon Wood Products Labor Force: Job Rationing and Worker Adaptation in a Declining Industry. Special report 529. Oregon Agricultural Experiment Station, Oregon State University.

Stier, J.C. 1980. 'Estimating the Production Technology in the U.S. Forest Products Industries', Forest Science, Vol. 26, P. 471-482.

Stoikov, V. 1966. 'Increasing Structural Unemployment Reexamined', Industrial and Labor Relations Review, Vol. 19, P. 368-376.

Strathman, J.G. 1985. 'Assessment of the Regional Lumber and Plywood Industries and Prospects for Future Power Demand'. Unpublished Paper.

Sum, A.M. and Rush, T.P. 1975. 'The Geographic Structure of Unemployment Rates', Monthly Labor Review, Vol. 98, March, P. 3-9.

Syron, R. 1978. 'Regional Experience During Business Cycles - Are We Becoming More or Less Alike?', New England Economic Review, Nov-Dec, P. 25-34.

Taylor, J. and Bradley, S. 1983. "Spatial Variations in the Unemployment Rate: A Case Study of North West England' Regional Studies, Vol 17, P113-124.

Thirlwall, A.P. 1966. 'Regional Unemployment as a Cyclical Phenomenon', Scottish Inl of Political Economy, Vol. 13, P. 205-218.

Thirlwall, A.P. 1969. 'Types of Unemployment: With Special Reference to Non Demand-Deficient' Unemployment in Great Britain', Scottish Inl of Political Economy, Vol. 16, P. 20-49.

Thirlwall, A.P. 1974. 'Types of Unemployment in the Regions of Great Britain', Manchester School of Economics and Social Studies, Vol. 42, P. 325-339.

Tiller, R.B. and Bednarzik, R.W. 1983. 'The Behaviour of Regional Unemployment Rates Over Time: Effects on Dispersion and National Unemployment', Inl of Regional Science, Vol. 23, P. 479-499.

Turvey, R. 1977. 'Structural Change and Structural Unemployment', International Labour Review, Vol. 116, P. 209-215. 
Tyler, P. 1983. 'The Impact of Regional Policy on Different Types of Industry and the Implications for Industrial Restructuring'. Social Science Research Council, Urban and Regional Economics Seminar Group: 'Redundancy and Recession: Restructuring the Regions?'.

Ullman, J.C. 1963. 'How Accurate Are Estimates of State and Local Unemployment', Industrial and Labor Relations Review, Vol. 16, P. 434-445.

United States Dept. of Agriculture Forest Service 1982. An Analysis of The Timber Situation in The U.S. 1952-2030, U.S. Dept. of Agri., Forest Resource Report No. 23.

United State Dept. of Commerce. 1984. A Competitive Assessment of the U.S. Solid Wood Products Industry. Washington, D.C.: U.S. Dept. of Commerce, International Trade Adminstration.

United State Employment Service. 1968. The Effects of Technological Change in the Lumber Industry. Washington, D.C.: Bureau of Employment Security, Automation Program Report No. 7.

Usher, D. (Ed.) 1980. The Measurement of Capital. Chicago: The University of Chicago Press.

Uzawa, H. 1962. 'Production Functions with Constant Elasticities of Substitution', Review of Economics and Statistics, Vol. 44, P. 291-299.

Varian, H.R. 1984. Microeconomic Analysis. N.Y.: W.W. Norton \& Company Inc.

Vaughan, R.J. 1976. Public Works as a Counter Cyclical Device: A Review of the Issues. Santa Monica: Rand Corp.

Vernez, G., Vaughan, R., Burright, B., Coleman, S. 1979. Regional Cycles and Employment Effects of Public Works Investments. Santa Monica: Rand Corp.

Wall, B.R. 1973. 'Employment Implications of Projected Timber Output in the Douglas-fir Region, 1970-2000', U.S. Dept. of Agr. Forest Service, Research Note PNW-211.

Wall, B.R. and Oswald, D.D. 1975. 'A Technique and Relationship for Projections of Employment in the Pacific Coast Forest Products Industries', U.S. Dept. of Agr. Forest Service, Research Paper PNW-189.

Wall, B.R. 1983. 'Future Timberland Area: A Crucial but llusive Variable in Timber Economy Models', Inl. of Forestry, Vol. 81, P. 721-722.

Western Wood Products Association. Statistical Yearbook of the Western Lumber Industry.

Wheaton, W.C. (Ed.) 1979. Interregional Movements and Regional Growth. Washington, D.C.: The Urban Institute. 
Wold, H.O. 1967. 'Review of Granger and Hatanaka, Spectral Analysis of Economic Time Series', Annals of Mathematical Stats., Vol. 38, P. 288-293.

Young, A.H., and Musgrave, J.C. 1980. 'Estimation of Capital Stock in the United States', in D. Usher (ed.), The Measurement of Capital Chicago: The University of Chicago Press.

Zellner, A. 1962. 'An Efficient Method of Estimating Seemingly Unrelated Regressions and Tests For Aggregation Bias', Inl of American Statistical Assoc. Vol. 57, P. 348-368. 
APPENDIX A

PLOTS OF OBSERVED AND PREDICTED VALUES 


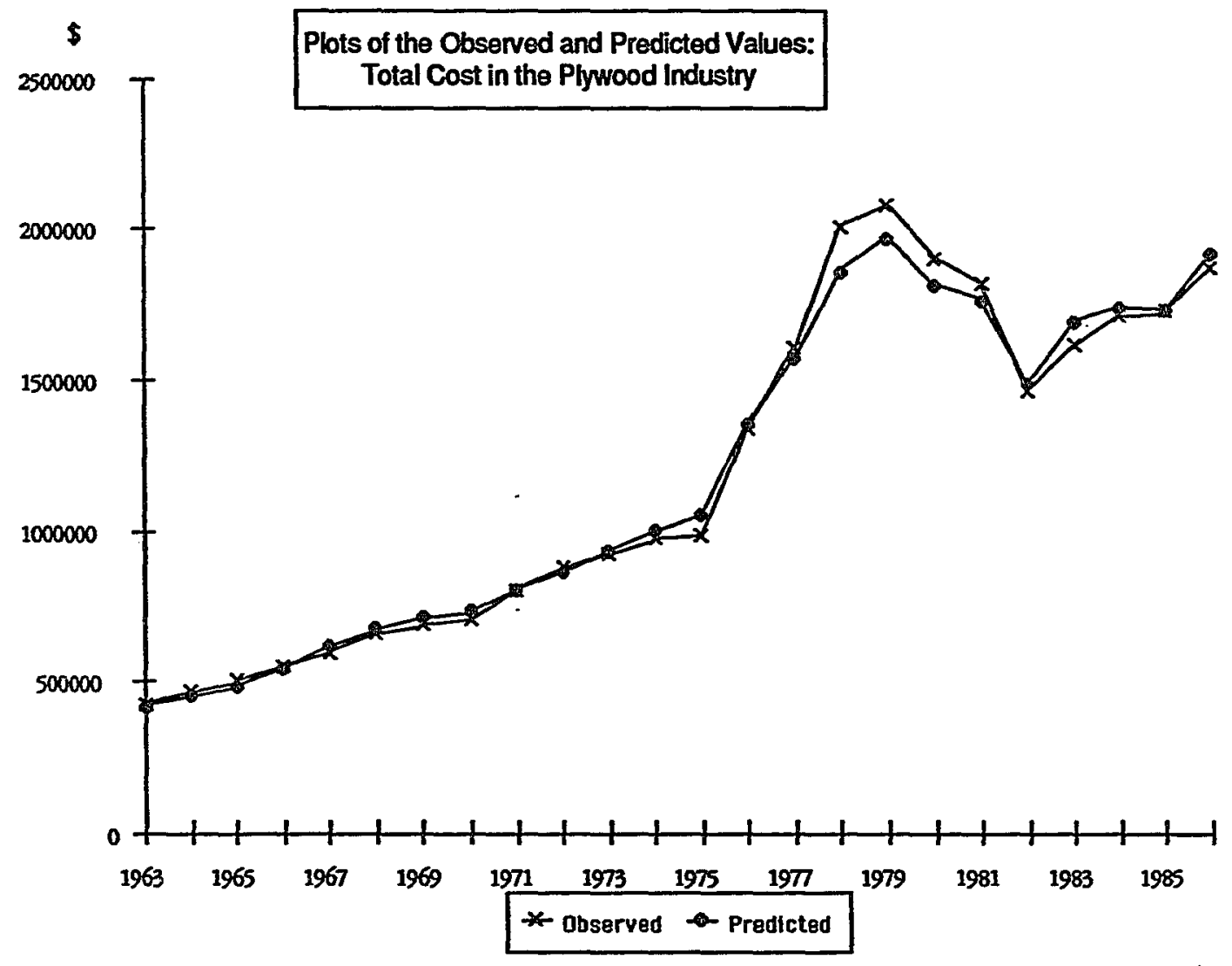




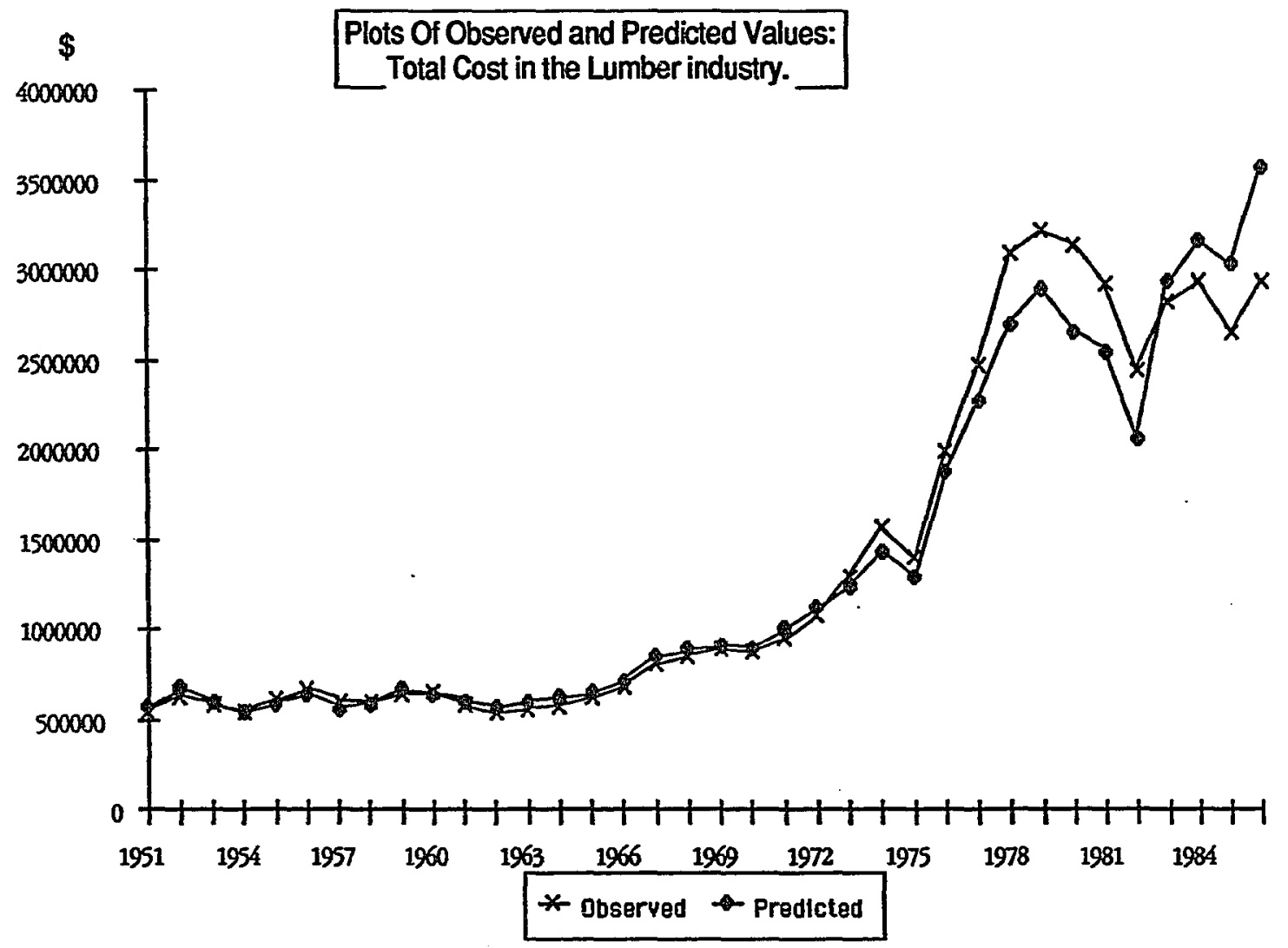




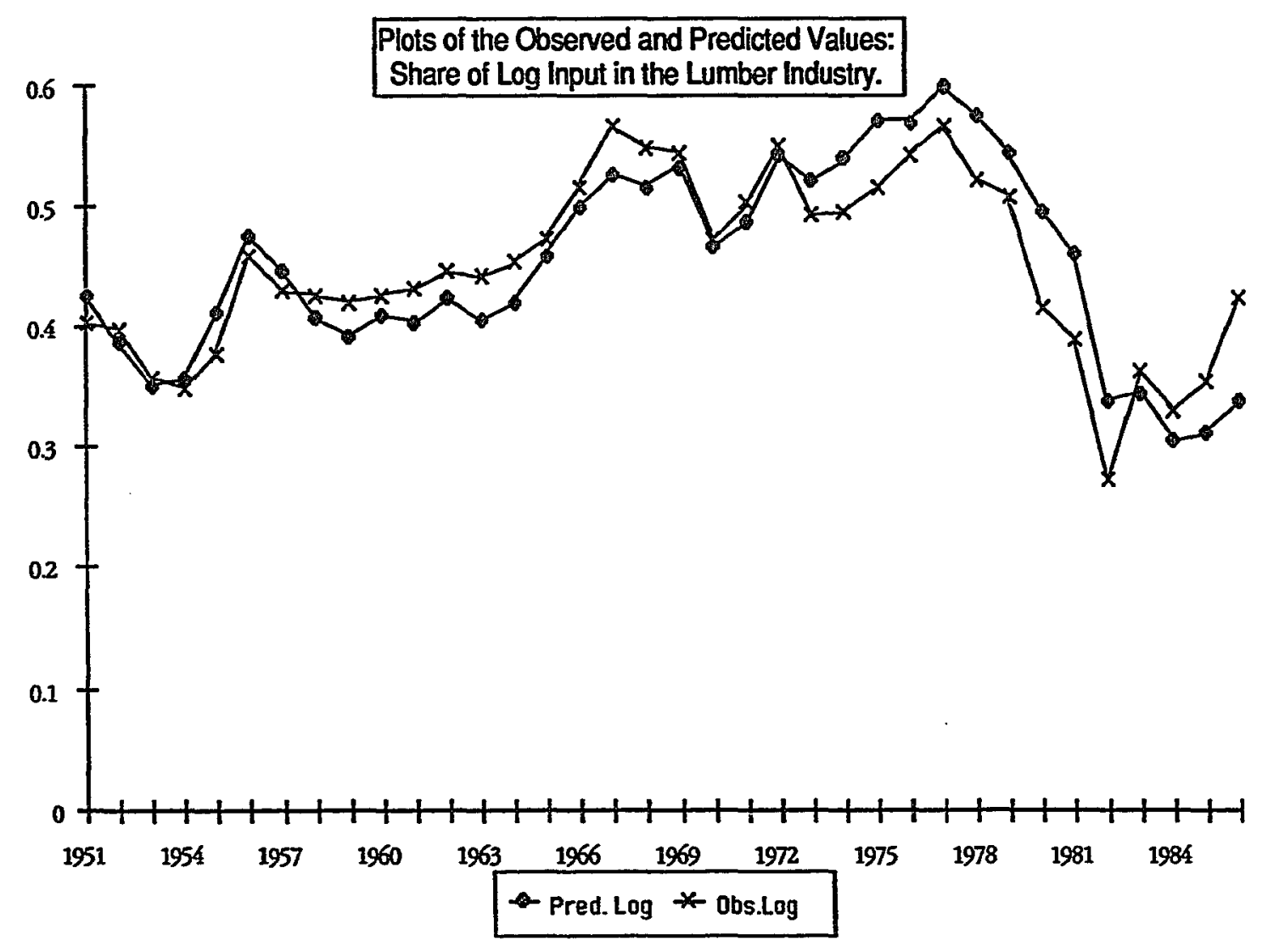




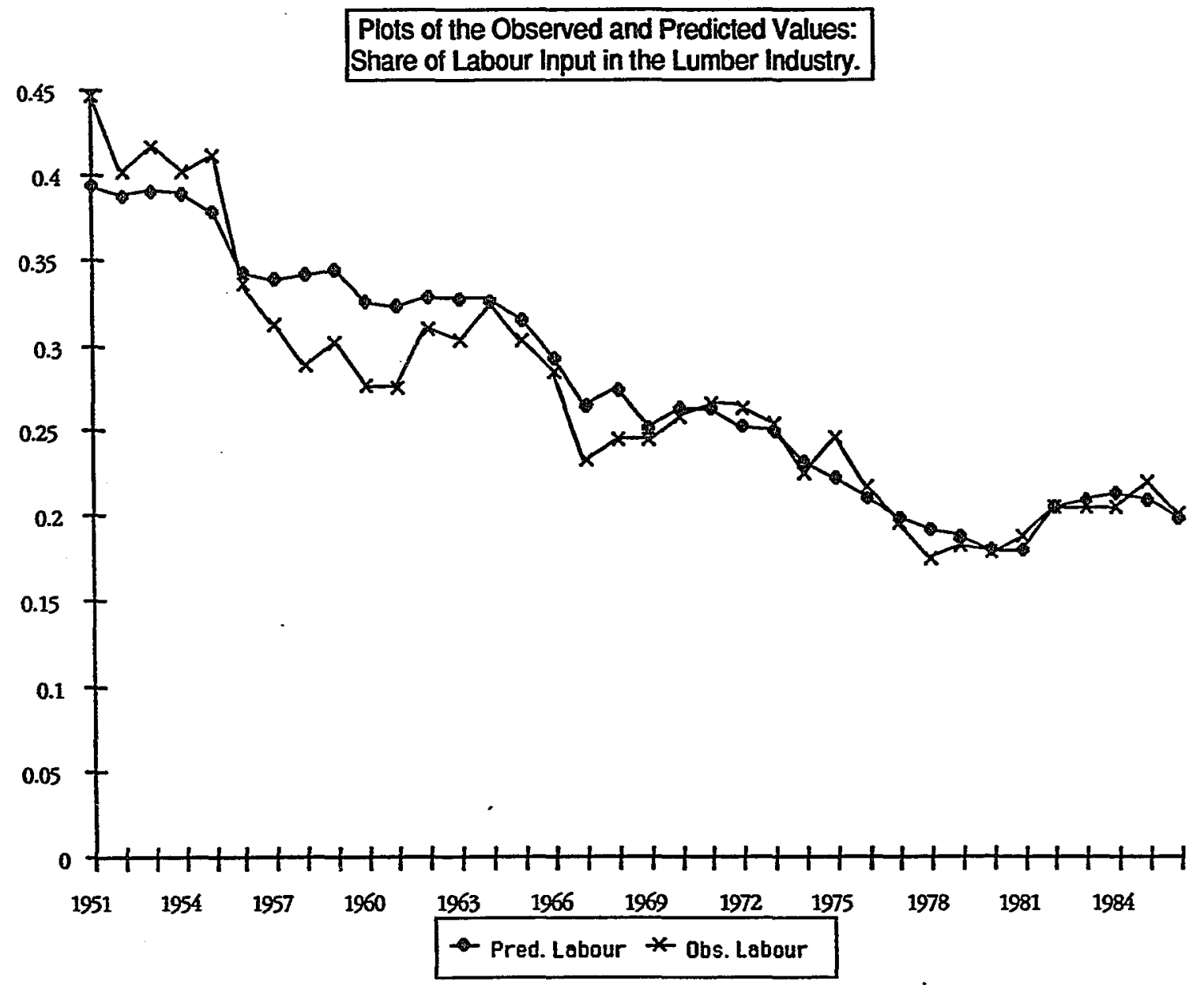




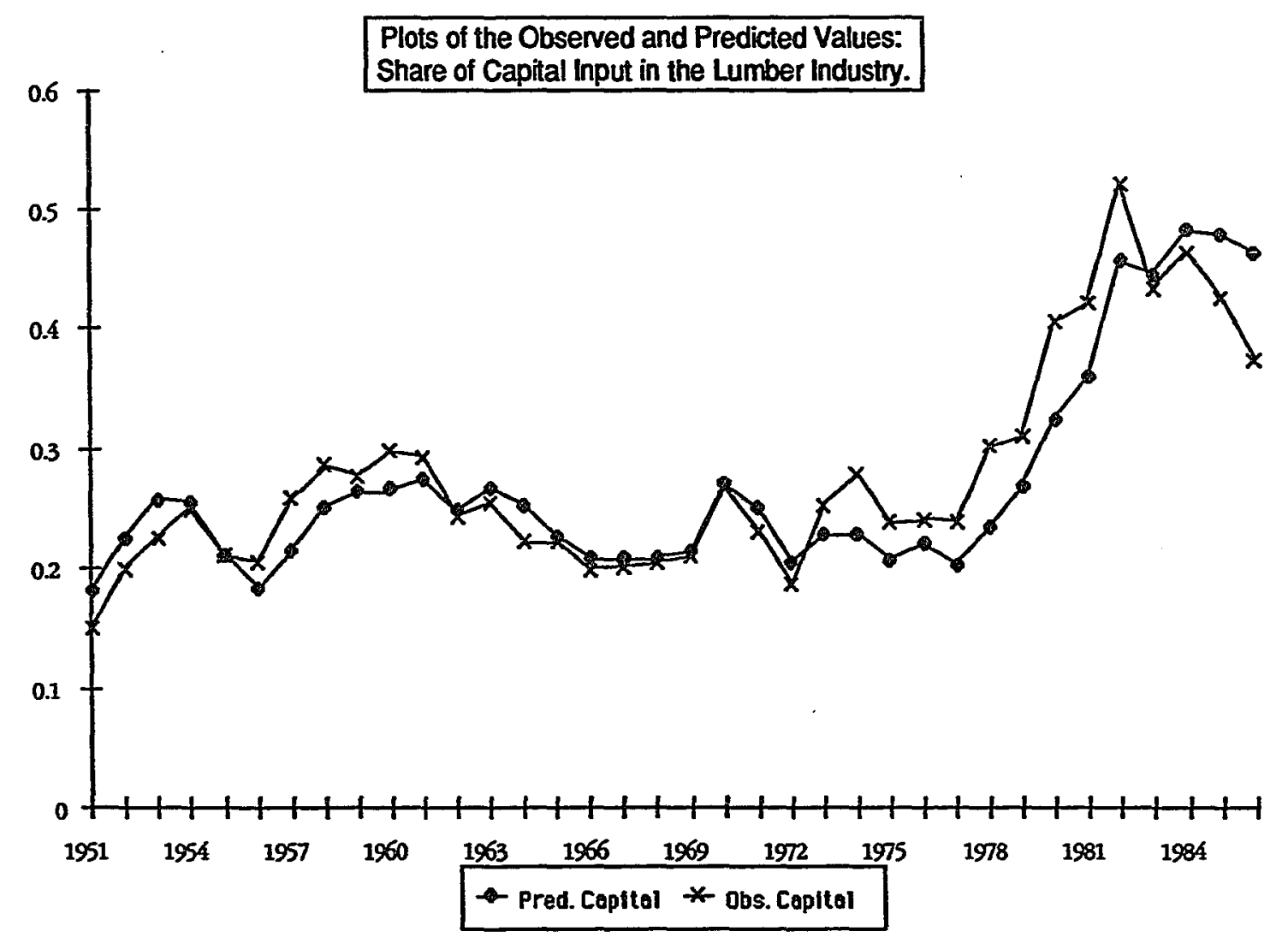


Plots of the Observed and Predicted Values:

Share of Log Input in the Plywood Industry.

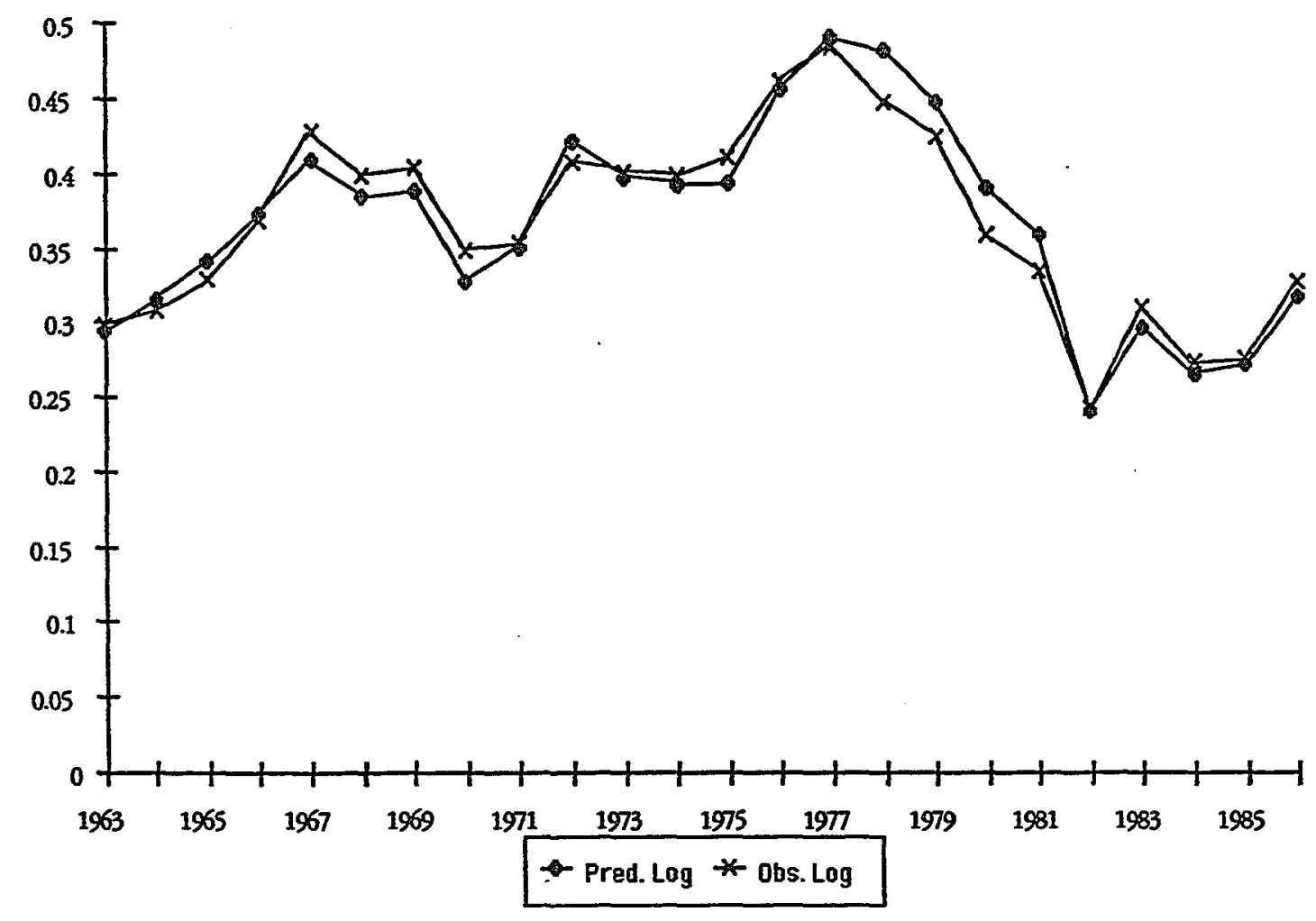




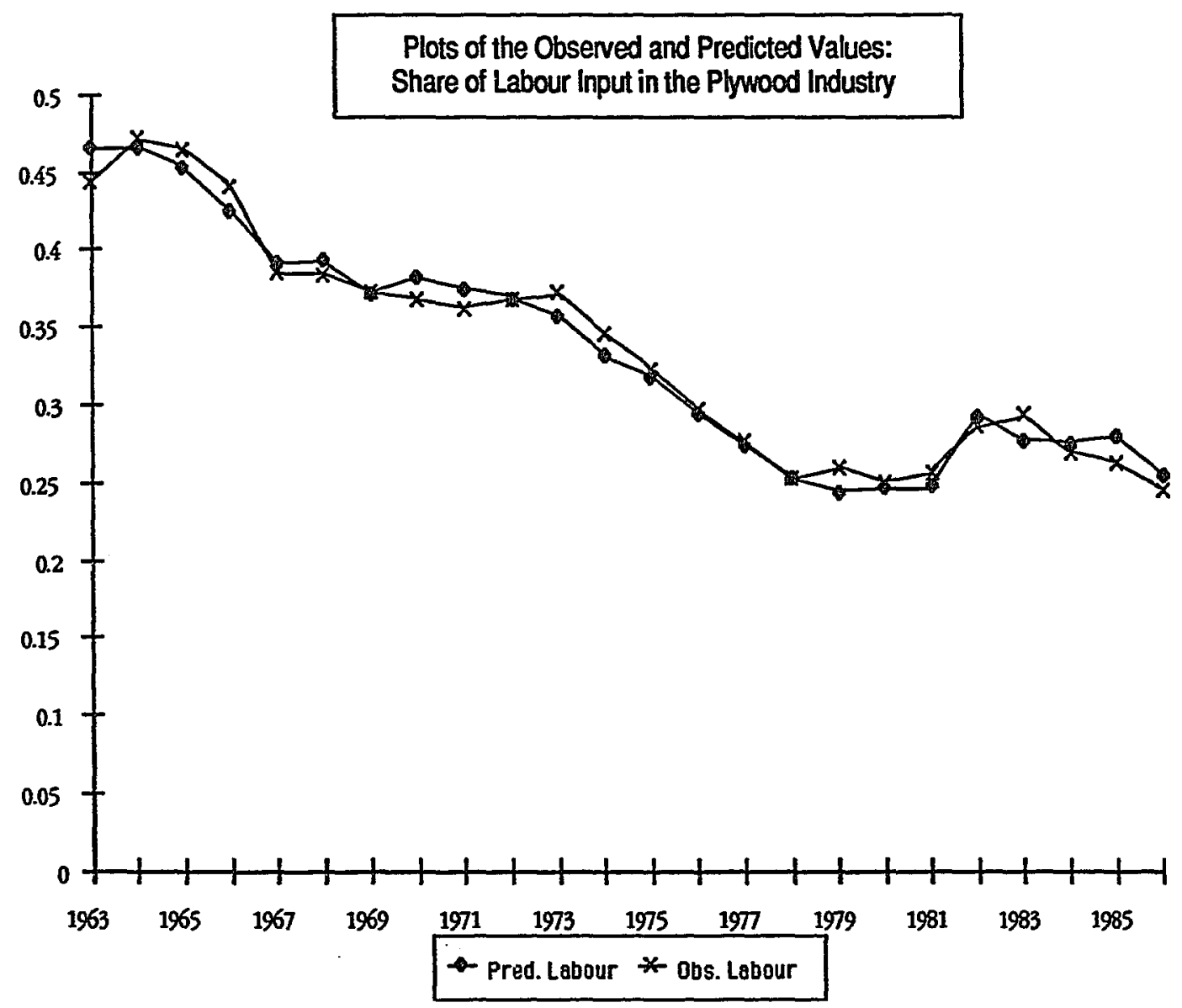




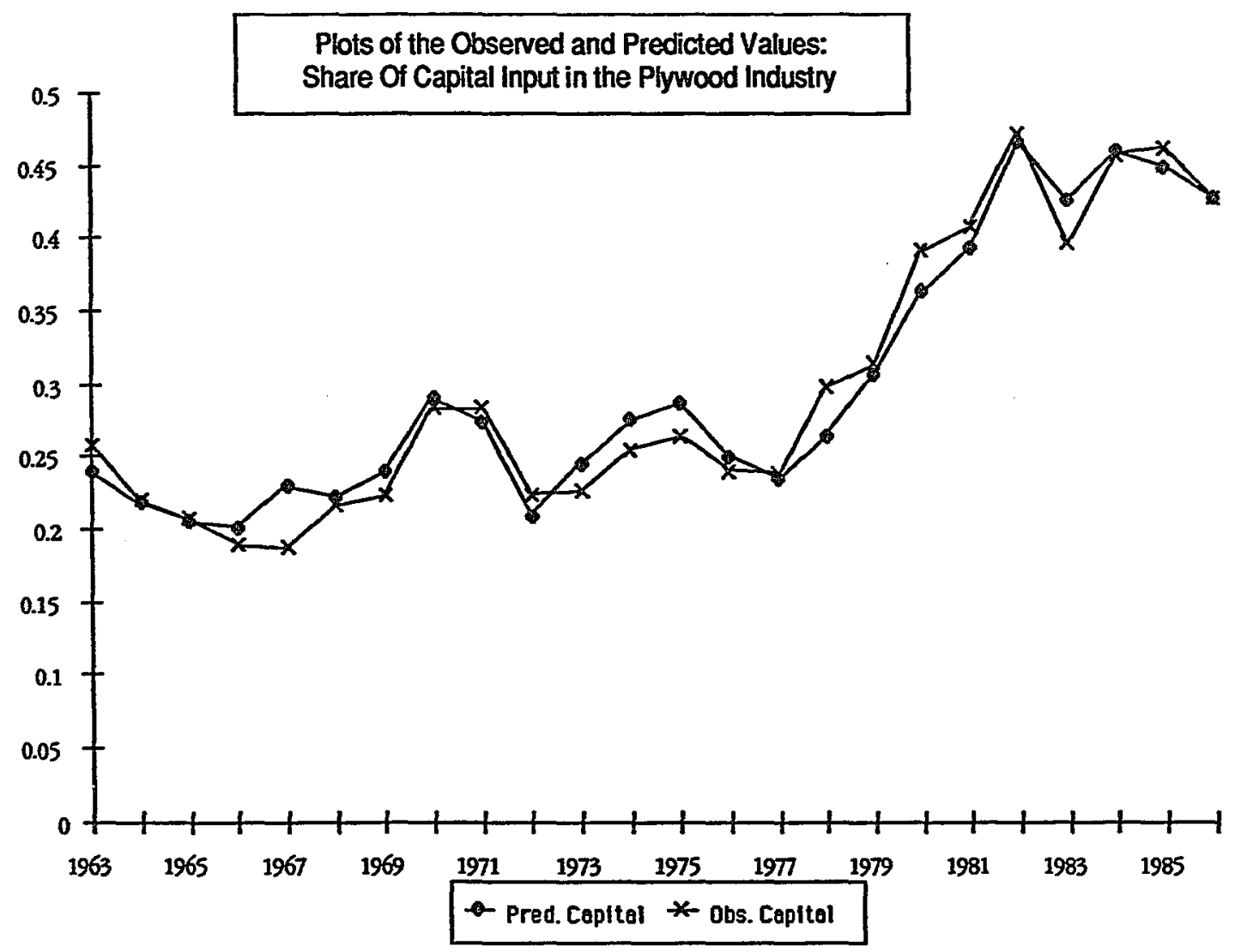


APPENDIX B

DATA 

195210338000.6 bos06 04238.0 1765\%5.0 1561000.1 016.79078 .95025 .5059 .958 .3000 .151058 .51 $195309723000.05678904331 .5174096 .4 \quad 1468000.2014 .34073 .06 \quad 025.9063 .858 .80 \quad 0.151 \quad 060.92$ $195409253000.34990304451 .5195548 .0 \quad 1397000.2013 .76072 .21 \quad 026.3 \quad 059.5 \quad 55.50 \quad 0.151 \quad 056.63$ 195509635000.05391804726 .5219642 .8 1445in).3 016.16 $080.93027 .2065 .453 .50 \quad 0.150 \quad 055.48$ $195608716000.8 .46867 \quad 04841.5 \quad 260106.5 \quad 1311700.9 .5023 .73081 .17028 .1068 .5 \quad 54.30 \quad 0.150060 .61$ $195707927000.1^{\circ} 3081204771.0 \quad 206429.0 \quad 1184100.1021 .93071 .83029 .1068 .655 .00 \quad 0.150 \quad 065.56$ 1959 ca3teco0.7 3546604859.5202116 .2 13586n0.3 $020.24069 .43029 .7063 .455 .60 \quad 0.150066 .44$ $195909074000.0 \quad 37510 \quad 05262.5 \quad 214283.3 \quad 1.361000 .1 \quad 020.19078 .94030 .4 \quad 069.0 \quad 54.60 \quad 0.150 \quad 066.52$ $1960 \quad 08290000.834759$ 05208.5 $202564.3 \quad 1235000.3022 .64075 .01030 .9070 .055 .10 \quad 0.149068 .15$

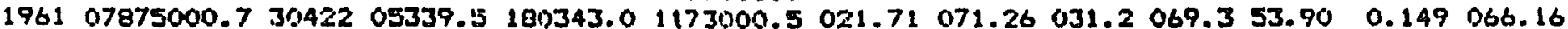
$196208203000.0 \quad 3063605541.3 \quad 1850102.7 \quad 1222 \% 00.2019 .99073 .33031 .9 \quad 073.7 \quad 43.30 \quad 0.149 \quad 054.59$ $1963018517000.92960205796 .0 \quad 136137.21269000 .2019 .75074 .60 \quad 032.4076 .644 .00 \quad 0.149055 .89$

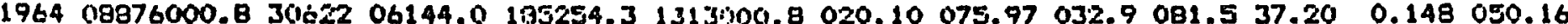
$196509890000.62991206364 .0 \quad 221239.9 \quad 1315000.8 \quad 022.68076 .09033 .8 \quad 089.0 \quad 35.70 \quad 0.148 \quad 049.92$ $196608439000.029753 \quad 06645.5203349 .8$ 1 $249000.0 \quad 028.75080 .78035 .0 \quad 096.6 \quad 36.50 \quad 0.148 \quad 052.44$ $1967018040000.42763406842 .0 \quad 196479.8 \quad 1170000.0 \quad 038.72091 .30035 .9 \quad 100.045 .50 \quad 0.148063 .12$ $196308758001.128173 \quad 0751 \% .5 \quad 228589.7 \quad 1276000.2036 .58097 .22037 .7 \quad 106.0 \quad 43.50 \quad 0.148 \quad 063.54$ $196907418000.82794307360 .0203513 .4 \quad 1092000.0 \quad 044.75108 .36039 .8 \quad 111.445 .80 \quad 0.147069 .93$ $197007364000.0 \quad 2383208488.0 \quad 223605.9 \quad 1082000.5038 .49089 .57042 .0 \quad 109.249 .70 \quad 0.147 \quad 079.32$ $197108273000.92765609154 .5241515 .1 \quad 1158000.3041 .31 \quad 110.67048 .4 \quad 109.749 .10 \quad 0.140 \quad 083.30$ $197208726000.0 \quad 2945409713.5 \quad 264990.9 \quad 1221000.6 \quad 049.94 \quad 129.24046 .5 \quad 118.4 \quad 32.90 \quad 0.140 \quad 066.17$ $197308750000.93147210479 .0 \quad 390048.91244000 .2051 .50173 .12049 .5128 .231 .80 \quad 0.139067 .45$ 1974 CBSA5000.7 31565 11214.0 $453768.2 \quad 11931000.4065 .45163 .19054 .0 \quad 126.433 .90 \quad 0.139076 .40$ $197507313000.728921 \quad 11903.0403989 .8 \quad 1016000.6071 .04 \quad 150.48059 .3116 .237 .00 \quad 0.139091 .90$ $197608322000.0 \quad 31151 \quad 13865.0 \quad 443024.9 \quad 1138600.9095 .01 \quad 187.50 \quad 063.1 \quad 124.8 \quad 35.10 \quad 0.139095 .38$ $197708796000.0 \quad 32159 \quad 15068.5546899 .91204000 .4116 .40216 .78067 .3 \quad 133.632 .00 \quad 0.139097 .21$ $1978.08845000 .032211 \quad 16801.0$ 684804.9 $1206000.5133 .91246 .03072 .7144 .033 .20 \quad 0.139107 .04$ 197908427000.03155518561 .0 609681.8 $1146000.4142 .47283 .78078 .6150 .230 .10 \quad 0.139111 .30$ $198006815000.02869719465 .0591927 .2 \quad 0918000.1 \quad 142.44263 .45085 .7 \quad 144.8 \quad 31.90 \quad 0.138 \quad 124.96$ $\begin{array}{lllllllllllllllll}1981 & 06270000.0 & 27101 & 20324.5 & 539238.4 & 0843000.4 & 135.29 & 232.49 & 094.0 & 146.0 & 17.70 & 0.138 & 113.49\end{array}$ $198205473000.02409220761 .5495166 .30771000 .0087 .07198 .43100 .0 \quad 136.324 .60 \quad 0.138132 .63$ 198307934000.02586822271 .5515829 .9 10701000.1 095.43 2\%0.11 $103.9139 .925 .60 \% 0.138132 .80$ 198408329000.026853 22425.5 528959.3 1117000.8087 .03213 .09107 .9154 .5265040 .138134 .29 $178508062000.02483623470 .0 \quad 471562.6 \quad 1060000.9$ (187.37 $212.58 \quad 111.5 \quad 160.3 \quad 27.30 \% \quad 0.138 \quad 136.59$ $198609142000.02507123537 .5474270 .61281000 .6099 .15213 .15114 .5164 .728 .00 * 0.138140 .00$ 


\begin{tabular}{|c|c|c|c|c|c|c|c|c|c|c|c|c|}
\hline $\begin{array}{l}\text { Year } \\
1951 \\
1952 \\
1953 \\
1954 \\
1955 \\
1956 \\
1957 \\
1958 \\
1959 \\
1760 \\
1961 \\
1962 \\
1963 \\
1964 \\
1965 \\
1766 \\
1967 \\
1969 \\
1969 \\
1970 \\
1971 \\
1972 \\
1973 \\
1974 \\
1975 \\
1976 \\
1977 \\
1978 \\
1979 \\
1980 \\
1981 \\
1982 \\
1983 \\
1984 \\
1985 \\
1986\end{array}$ & $\begin{array}{l}08344000.1 \\
09416000.3 \\
09612000.9 \\
09343000.2 \\
08659000.2 \\
09625000.9 \\
018319000.6 \\
08521000.7 \\
09328000.9 \\
098950010.4 \\
09729000.8 \\
018018000.0 \\
07849000.5 \\
08701000.5 \\
09164000.7 \\
09328000.5 \\
018644000.9 \\
016655000.9 \\
06247000.6 \\
05667000.9 \\
073750010.7 \\
075620010.1 \\
07657000.5 \\
08706000.0\end{array}$ & $\begin{array}{l}32509 \\
35854 \\
36770 \\
36615 \\
33515 \\
33786 \\
32727 \\
30574 \\
32013 \\
33306 \\
32868 \\
30148 \\
26879 \\
28698 \\
29559 \\
30318 \\
29225 \\
24533 \\
22998 \\
20285 \\
21338 \\
20620 \\
19298 \\
19593\end{array}$ & $\begin{array}{l}126741.8 \\
132415.6 \\
134530.2 \\
119772.2 \\
106633.2 \\
130332.7 \\
116342.8 \\
133517.5 \\
165038.0 \\
183229.7 \\
163125.8 \\
149379.9 \\
151209.9 \\
189127.5 \\
221190.3 \\
279551.2 \\
248884.4 \\
227030.1 \\
219228.0 \\
202453.5 \\
221556.4 \\
253481.2 \\
279397.3 \\
295877.7\end{array}$ & $\begin{array}{l}642000 \\
716000 \\
731000 \\
710000 \\
658000 \\
722000 \\
624000 \\
639000 \\
690000 \\
732000 \\
720000 \\
593000 \\
573000 \\
650000 \\
669000 \\
672000 \\
622000 \\
479000 \\
450000 \\
418000 \\
524000 \\
537000 \\
544000 \\
618000\end{array}$ & $\begin{array}{l}06 \% .63 \\
060.30 \\
060.85 \\
061.50 \\
057.79 \\
073.78 \\
080.10 \\
066.88 \\
069.71 \\
091.17 \\
168.76 \\
104.89 \\
112.54 \\
137.93 \\
164.26 \\
180.72 \\
183.83 \\
178.28 \\
173.34 \\
159.89 \\
167.87 \\
170.75 \\
165.21 \\
157.00\end{array}$ & $\begin{array}{l}0.0770 \\
0.0760 \\
0.0760 \\
0.0760 \\
0.0760 \\
0.0750 \\
0.0750 \\
0.0750 \\
0.0740 \\
0.0740 \\
0.0740 \\
0.0740 \\
0.0730 \\
0.0730 \\
0.0730 \\
0.0720 \\
0.0720 \\
0.0720 \\
0.0720 \\
0.0720 \\
0.0710 \\
0.0710 \\
0.0706 \\
0.0706\end{array}$ & $\begin{array}{l}022960.13 \\
025434.03 \\
027513.70 \\
033100.00 \\
041248.66 \\
033000.00 \\
037000.00 \\
052900.00 \\
042800.00 \\
048700.00 \\
058200.00 \\
052900.00 \\
060100.00 \\
062400.00 \\
095900.00 \\
077940.60 \\
071991.27 \\
057952.56 \\
056200.00 \\
045100.00 \\
056534.65 \% \\
048173.92 \\
126477.30\end{array}$ & $\begin{array}{c}T \\
053026.33 \\
045722.41 \\
039030.44 \\
036158.00 \\
051717.24 \\
056949.03 \\
045364.43 \\
036778.00 \\
039781.00 \\
050603.00 \\
041364.00 \\
035977.00 \\
037567.00 \\
045016.00 \\
056308.00 \\
045102.00 \\
039000.00 \\
058696.95 \\
061400.00 \\
050600.00 \\
048600.00 \\
088196.26 \\
153673.90 \\
129861.20 \\
100102.10 \\
133976.30 \\
175000.00 \\
197900.00 \\
247505.20 \\
211524.40 \\
166949.10 \\
103400.00 \\
091000.00 \\
083706.13 * \\
074414.26 \\
147719.70\end{array}$ & $\begin{array}{c}U \\
005629.43 \\
010390.59 \\
011968.11 \\
066302.00 \\
095784.00 \\
095154.00 \\
064540.00 \\
080937.00 \\
099439.00 \\
109293.00 \\
081054.00 \\
095552.00 \\
107269.00 \\
122883.00 \\
150505.00 \\
140378.00 \\
115400.00 \\
159000.00 \\
168900.00 \\
146200.00 \\
167700.00 \\
221300.00 \\
236300.00 \\
344600.00 \\
453500.00 \\
326906.00 \\
425200.00 \\
480600.00 \\
481956.20 \\
490000.00 * \\
579657.00 * \\
257500.00 \\
233600.00 \\
178565.00 * \\
169527.90 \\
237133.00\end{array}$ & $\begin{array}{l}v \\
01.75 \\
01.75 \\
01.99 \\
01.80 \\
01.89 \\
02.77 \\
03.12 \\
02.15 \\
03.36 \\
03.53 \\
03.00 \\
03.00 \\
03.23 \\
03.55 \\
04.04 \\
04.50 \\
04.19 \\
05.16 \\
05.97 \\
05.95 \\
04.89 \\
04.50 \\
06.44 \\
07.93 \\
06.25 \\
05.50 \\
05.46 \\
07.46 \\
10.28 \\
11.77 \\
13.42 \\
11.02 \\
08.50 \\
08.80 \\
07.69 \\
06.33\end{array}$ & $\begin{array}{c}w \\
02.56 \\
03.00 \\
03.17 \\
03.05 \\
03.16 \\
03.77 \\
04.20 \\
03.83 \\
04.48 \\
014.82 \\
04.50 \\
04.50 \\
04.50 \\
04.50 \\
04.54 \\
05.63 \\
05.61 \\
06.30 \\
07.96 \\
07.91 \\
05.72 \\
05.25 \\
09.03 \\
10.81 \\
07.86 \\
06.84 \\
06.83 \\
09.06 \\
12.67 \\
15.27 \\
18.87 \\
14.86 \\
10.79 \\
12.04 \\
09.93 \\
08.33\end{array}$ & $\begin{array}{c}x \\
024.2 \\
024.4 \\
025.1 \\
025.2 \\
025.8 \\
027.7 \\
029.5 \\
029.5 \\
030.2 \\
030.6 \\
030.5 \\
030.9 \\
031.3 \\
031.5 \\
032.1 \\
033.3 \\
034.4 \\
035.9 \\
037.9 \\
039.9 \\
042.4 \\
044.4 \\
046.0 \\
050.5 \\
057.9 \\
061.9 \\
066.1 \\
071.5 \\
077.8 \\
085.1 \\
093.4 \\
100.0 \\
098.8 \\
098.7 \\
099.3 \\
100.8\end{array}$ \\
\hline
\end{tabular}

* Llenotes data was estimated for the individual year 
$A=$ softrood l vedber production

Thousand board feet luber tally

- Average annwas employwent in the lumber industery (SIC 2421)

C = Average annwal wages for the Jumber and wood products industery in Oragon and Washingtion (U.S. dollars)

0 - Capital stock levels in the lumber industiry

(Thousands of dollaris)

E - Log inputs used in the production of softwood lumber

(Thousand clbic feet)

F = Price of logs (Value of timber harvested in Mational forest Reglons in the U.S.).

(Doll ars per thousand board feet, scribner log scale)

6 - Softwood lumber prleas

(Per thousand board feet l luber tallys

$H$ a Implicit price deflator for gross national product

(1982a100)

I - Composite index of bour roughly colnetdent indicators (1967:10s)

J = Marginal corporate bay rate

(percent per annual

$K$ - Lumber recovery conversion factor

(Cuole feet/mbf. I unber tally)

$L$ - Rental cost of capital

$M$ - Softwood plywood product ton

(Square feet. 3/8 inch basis)

4 - Average annual eaploywent in the plywdod industry(sic 24328 2435 and 2436)

- - Caplital stoch levels in the plymood industry

(rhousands of dollars)

P - Log input used in the production of softwood plywood

(Thousand cuble (eet)

Q - Softwood plyouod prices

(per thousend equare test. 3/B inch)

R - Plyood recovery conversion factor

ICubic feet / mst. J/8 inch)

8 - Capital expenditure in the plymood industry (sic 243) in the states of Oregon and washingtion (1phwa)

- Capital expenditure in the lumber industry (SIC 242) in the states of oregon and viashington (Pinus)

(Thousands of dollars)

$U=$ (Thousands of dollars)

Crhousands of dollarsi

V - Discount rate, Federal Reserve Bank of New York

(percent per amiun)

H = Prime rate charged by banks

- (percent per annuma)

price deflator for nonresidential fixed investment

$(1982=100)$

All date is for the pouglas-tir region unless otherwise stated 